\title{
AMANDA BURG RECH
}

Campos pequenos de radiação e materiais alternativos em dosimetria com espectroscopia de ressonância magnética eletrônica

(Small radiation field and alternative materials in dosimetry with electron magnetic resonance spectroscopy)

\section{Versão corrigida}

Tese apresentada à Faculdade de Filosofia, Ciências e Letras de Ribeirão Preto da Universidade de São Paulo para obtenção do título de Doutor em Ciências.

Área de concentração: Física aplicada à Medicina e Biologia

Orientador: Prof. Dr. Oswaldo Baffa Filho 
Autorizo a reprodução e divulgação total ou parcial deste trabalho, por qualquer meio convencional ou eletrônico, para fins de estudo e pesquisa, desde que citada a fonte.

Catalogação da Publicação

Serviço de Documentação da Universidade de São Paulo

Faculdade de Filosofia, Ciências e Letras de Ribeirão Preto

Rech, Amanda Burg.

Campos pequenos de radiação e materiais alternativos em dosimetria com espectroscopia de ressonância magnética eletrônica/ Amanda Burg Rech ; orientador: Oswaldo Baffa Filho - Ribeirão Preto, 2017.

118 f.:il.

Tese (Doutorado) - Universidade de São Paulo, 2017.

1. Ressonância magnética eletrônica. 2. Dosimetria. 3. Minidosímetro. 4. Alanina. 
RECH, A. B. Campos pequenos de radiação e materiais alternativos em dosimetria com espectroscopia de ressonância magnética eletrônica. Tese apresentada à Faculdade de Filosofia Ciências e Letras de Ribeirão Preto da Universidade de São Paulo para obtenção do título de Doutor em Ciências.

Aprovado em:

Banca examinadora

Prof. Dr. Oswaldo Baffa Filho

Julgamento: Aprovada

Profa. Dra. Juliana Fernandes Pavoni

Julgamento: Aprovada

Profa. Dr. Patricia Nicolucci

Julgamento: Aprovada

Prof. Dr. Felipe Chen Abrego

Julgamento: Aprovada

Profa. Dra. Diana Rodrigues de Pina

Julgamento: Aprovada
Instituição: FFCLRP-USP

Instituição: FFCLRP-USP

Instituição: FFCLRP-USP

Instituição: Universidade Federal do $\mathrm{ABC}$

Instituição: UNESP 
À minha família, que são meu exemplo, força, orgulho e amor.

Meu melhor modelo para encarar a vida. 


\section{ACKNOWLEDGEMENTS}

Many people participated in this phase of my life, and I am grateful to everyone, even if not listed below, after all, sometimes we unintentionally forget someone.

First of all, I am extremely grateful to my family, for all the education and support I have had. We were apart for years; years in which they always gave me freedom and believed in my choices.

To my advisor Oswaldo Baffa, for all the years of partnership, learning, and personal growth, I hope our scientific collaboration continues!

To Carlos Brunello, my greatest laboratory companion on this journey. Also, to Lourenço Rocha, for all the help given, whether with tablets, phantom heads or anything necessary.

To François Trompier, for the guidance abroad, for all practical knowledge and to show me what it is to not let the machine stop. Thank you for so much learning in such little time.

To the professors / researchers: Paulo Donate, for the collaboration in the researches with alternative materials; Juliana Pavoni for clarification and help in clinical research; and to Marie-Noelle for the opportunity to collaborate with CEA and learning.

Samples irradiation and clinical research would not be possible without the collaboration of several centers, thanks to the Groupe Hospitalier Pitié-Salpêtrière; to the Hospital das Clínicas de Ribeirão Preto, especially to Leandro; to the IRMEV, particularly to Francisco; and to the Centro de Radioterapia de São Carlos, especially Fernanda, Karina and Sarah.

To the institutions FFCLRP-USP and IRSN, for the facilities, collaborations, personal and technological support, which supplied the necessary conditions for the development of my project. Especially to FAMB (FFCLRP-USP) post-graduation program, with the employees: André, Aziani, Carlos, Elcio, Julio, Lourenço, Nilza and Renato; also, the LDRI (IRSN) department, under the leading of Isabelle Clairand and Jean-François BottollierDepois. 
To my laboratory friends, especially to: Eder Guidelli, Angela Kinoshita, Jorge Gómez, Renan Matsuda, Matheus Silveira, Leonardo França, Luiz Carlos de Oliveira and Iara Lima. To my close friends: Ana Carolina Godoy, Bianca Machado, Camila Olska, Érika Ribeiro, Fernanda Toniolli, Felipe Haddad, Gabriela Almeida, Gabriela Paschoini, Gabriela Saber, Jenifer Martins, José Augusto Gual, Lis Silva, Marija Jovanović, Marina Pelorca, Ricardo Cardoso, Sarah Borin, Tiago Arruda and Tina Mash; it was more than parties and fun, there were talks, comfort, different kinds of help (such as rides, figure edition and translations) and a family far from home.

To CAPES, for the scholarship in the first year of this thesis.

To FAPESP, for the opportunity to have two different scholarships (2013/03258-9 and 2014/02494-3) that made several experiences possible, both academic and personal, thank you so much for making all of this possible! 
"Nothing either good or bad, but thinking makes it so"

\section{Shakespeare}




\section{RESUMO}

Rech AB. Campos pequenos de radiação e materiais alternativos em dosimetria com espectroscopia de ressonância magnética eletrônica [tese]. Ribeirão Preto: Universidade de São Paulo, Faculdade de Filosofia, Ciências e Letras de Ribeirão Preto; 2017.

Para acompanhar os avanços em radioterapia, os sistemas dosimétricos necessitam de aperfeiçoamento para garantir a acurácia do tratamento; e, paralelamente, a exposição radioativa vai além do uso clínico, sendo de interesse também a detecção em cenários radiológicos imprevistos. A espectroscopia de ressonância magnética eletrônica (RME) é capaz de detectar centros paramagnéticos criados em materiais expostos à radiação, relacionando resposta espectral com dose absorvida, executando assim a dosimetria de maneira não destrutiva, ao preservar a informação após a leitura. Após a padronização da alanina como detector de altas doses e a também aplicabilidade em estudos clínicos, dificuldades apresentadas propiciaram a investigação de outros materiais para dosimetria com RME; em contrapartida, classificar compostos presentes no cotidiano e com possibilidade de tecido equivalência é outro argumento para a expansão da análise de materiais alternativos. $\mathrm{O}$ desenvolvimento desta tese é entre dois tópicos distintos, porém interligados; primeiramente são apresentados minidosímetros para uso em campos pequenos, com abordagem clínica, e então a investigação de materiais alternativos, ambos para uso em dosimetria com RME. Em relação aos minidosímetros, o formato de pastilha é estudado, e são apresentados um novo conceito de detector, denominado EPResize ${ }^{\circledR}$, e auditoria de ponta-a-ponta de um tratamento de radiocirurgia estereotáxica; sobre a investigação de materiais, foram estudados mais de 20 compostos, estes baseados em amônio, lítio, potássio e sódio. Os resultados mostraram que as dificuldades na determinação de dose com campos pequenos para um intervalo de dose clínico é uma questão que ainda necessita de muita atenção e adequação dos sistemas dosimétricos, de modo a extrair a maior sensibilidade possível, necessitando empregar parâmetros e métodos de análise além do rotineiramente utilizados; variados materiais se apresentaram adequados para a dosimetria com RME, tais como sulfato de amônio, formiato de sódio, ditionito de sódio, citrato de sódio e diferentes sulfitos, mesmo quando não satisfazendo aspectos clínicos, são alternativas para controle e determinação de doses em cenários não usuais. A capacidade de realizar a dosimetria com RME para campos pequenos e a padronização deste sistema possibilitam a verificação de tratamentos mais confiáveis em 
radioterapia não convencional; e a disponibilização de maior variedade de materiais para dosimetria com RME facilita a necessidade de mapeamento de dose em casos não previstos.

Palavras chave: Ressonância magnética eletrônica. Dosimetria. Minidosímetro. Alanina. 


\begin{abstract}
Rech AB. Small radiation field and alternative materials in dosimetry with electron magnetic resonance spectroscopy [thesis]. Ribeirão Preto: Universidade de São Paulo, Faculdade de Filosofia, Ciências e Letras de Ribeirão Preto; 2017.

To keep up with advances in radiotherapy, dosimetric systems need improvement to meet the standards established for treatment accuracy; simultaneously, radioactive exposure goes beyond clinical use, and the detection in unforeseen scenarios is of interest too. Electron magnetic resonance spectroscopy (EMR) can detect paramagnetic centers created in materials exposed to radiation, relating spectral response with absorbed dose, thus performing nondestructively dosimetry, by keeping the information after the readout. After standardization of alanine as a high dose detector and the applicability in clinical studies, difficulties allowed the investigation of other EMR dosimetry materials; on the other hand, classifying compounds that are present daily and with the possibility of tissue equivalence is another stimulus for the expansion of alternative materials analysis. The development of this thesis is between two distinct but interconnected topics; first minidosimeters are presented for small field dosimetry, with a clinical approach, and the investigation of alternative materials, both topics applied in EMR dosimetry. Concerning the minidosimeters, some pellets' aspects are studied, a new concept of detector, called EPResize ${ }^{\circledR}$; and a stereotactic radiosurgery end-to-end audit are presented; about alternative materials research, more than 20 compounds were studied, based on ammonium, lithium, potassium and sodium. The results showed that the difficulties in determining the dose with small fields in a clinical dose range is an issue that still needs much attention and adequacy of the dosimetric systems, in order to extract the greatest possible sensitivity, with the need to employ parameters and methods of analysis besides the daily used; several materials were adequate for EMR dosimetry, such as ammonium sulfate, sodium formate, sodium dithionate, sodium citrate and different sulfites, which, even when not satisfying clinical aspects, are alternatives for control and determination of doses in other scenarios. The ability to perform clinical dosimetry with RME and the standardization of this system allow the improvement of treatments accuracy, and the availability of a greater variety of EMR dosimetry materials facilitates the need for dose mapping unforeseen cases.
\end{abstract}

Keywords: Electron Magnetic Resonance. Dosimetry. Minidosimeter. Alanine. 


\section{LIST OF ILLUSTRATIONS}

Figure 1 - Diagram showing the absorption of energy from radiation until it results in biological damage. (A) describes the moment when a photon collides with an electron, starting the interaction process; $(B)$ represents the moment that the electron, now in high speed motion, could ionize, excite and break bonds along its way; it can also transfer heat; all these actions can produce chemical changes (not the heat part) showed in $(C)$; then, chemical damage is observed (D) (Johns and Cunningham, 1983).

Figure 2 - Graphical abstract showing the behavior of absorbed dose (continuous line) and kerma (dotted line) for two different irradiation scenarios. The squares illustrate the quantity of electrons presented in each square of the range, helping to explain the different resulting lines. In a) there is no attenuation of the beam, presenting a region of electronic equilibrium; in $b)$ the beam is attenuated and, instead of a region, an equilibrium point is observed......... 28 Figure 3 - Graphical abstract showing (A) free electrons presenting random orientation when not exposed to a magnetic field; $(B)$ such that when applied a magnetic field different from zero, electrons align with the field direction according to spin orientation, which can be spin up or down, with different energy values, known as Zeeman splitting. In the presence of a microwave, the vibration of the lattice happens, causing electron motion in the lattice, and the phenomena of resonance and relaxation are observed. 30

Figure 4 - Allowed energy levels of an electron spin in function of magnetic field $H$. The resonance condition by microwave absorption occurs when $H 0=h v g \beta$.

Figure 5 - Theoretical splitting of the protons hyperfine structure. The contribution of protons with $I=12$ results in lines with different ratio intensity, in accordance with coefficients of a binomial expansion, as presented in table 1 also until $n=6$................................................. 32 Figure 6 - Diagram with the main components of an EMR spectrometer. Unlike the UV-Vis absorption spectrometer, which gives the absorption curve as the signal result (A), this signal is presented as the first derivative of the absorption spectrum (B). 33

Figure 7 - Microwave power study curves for ammonium tartrate and lithium formate in which the EMR response is proportional to the square root of the microwave power. Saturation is observed at $0.2 \mathrm{~mW}$ for ammonium tartrate, presenting a faster saturation, and for lithium formate at $3 \mathrm{~mW}$ (slower saturation, in comparison with ammonium tartrate)..... 34 
Figure 8 - Monosodium glutamate EMR signal with different values of modulation amplitude. As the line width varies from 0.6 to $1.0 \mathrm{mT}$, in c) and d), signal distortion and improvement of the second harmonic signal are observed.

Figure 9 - Relation between EMR response and positioning of a DPPH sample inside a resonant cavity mode $T E_{011}$. The response tends to decrease as the sample gets away from the central region, suffering variation from 0.6 to $99.5 \%$.

Figure 10 - Relation between EMR signal and the quantity of alanine sample in the capillary tube; a) is related to the quantity of mass and b) to the column height. Even if the response is proportional to mass, it is observed that for heights higher than $8 \mathrm{~mm}$ the repeatability variation goes from 1.8 to $23.0 \%$, as between 4 to $8 \mathrm{~mm}$ is up to $0.4 \%$.

Figure 11 - Representation of electric and magnetic fields in a resonant cavity, mode TE 011 , showing also the sensitive position inside the cavity.

Figure 12 - Absorption and the first derivatives of Gaussian and Lorentzian line shapes. The parameters used to differentiate are also highlighted, as the half-width $\Delta H_{1 / 2}$, the maximum slope width $\Delta H_{m s l p}$ and the average of the second moment $<\Delta H^{2}>_{a v}^{1 / 2}{ }^{2}$

Figure 13 - Zeeman energy for two electron spins with different $g$ factor, as $g_{1}$ and $g_{2}(a)$. The EMR spectrum position is different for each $\mathrm{g}$ factor, so $\mathrm{g}_{1}$ will be placed in $\mathrm{H}_{01}$ and $\mathrm{g}_{2}$ in $\mathrm{H}_{02}$, respectively $(b)$.

Figure 14 - Alanine signal and the components that constitute the EMR experimental spectrum; the resulting signal is the combination of the "pure" signal, baseline and noise. .41 Figure 15 - Alanine stereoisomers: D-alanine, on the left, and L-alanine, on the right. 42 Figure 16 - Different radicals induced in alanine by ionizing radiation, called $R 1, R 2$ and $R 3$. The dots indicate the position of the unpaired electron.

Figure 17 - Comparison between the energy mass atenuation and absorption coefficients of soft tissue and alanine, pointing the tissue-equivalent-behavior.

Figure 18 - Characteristic alanine five line spectrum and single line lithium formate spectrum. 44

Figure 19 - Highlight of each alanine peak, determining which one is considered the main line peak (peak-to-peak amplitude), which is known as the EMR response and related to absorbed dose.

Figure 20 - The black line represents the five line alanine spectrum, the blue one represents the first integration curve and the red one represents the double integrated curve. The area 
under the double integrated curve is related to the number of paramagnetic centers created and related to the amount of radiation absorbed.

Figure 21 - Normalized dose-response curve of different materials irradiated with a Co 60 gamma source with doses from 1 to $30 \mathrm{~Gy}$......

Figure 22 - Dose-response curve of L-alanine (95\%) and PVA (5\%) pellets with 1 and $2 \mathrm{~mm}$ diameter. The error bars correspond to the measured repeatability. 50

Figure 23 - Dose-response curve of lithium formate pellets irradiated with a 6 MV linear accelerator with doses from 0 to $3.5 \mathrm{~Gy}$. Also in the graphic box, the correlation coefficient, the intercept and the slope of the linear fit proposed for the dose-response curve are presented.

Figure 24 - Preliminary dosimetric system designed to facilitate the saving of material mass when handling. It was made of a PVC holder on the outside, and EMR sensitive material and binder on the inside; for the test, L-alanine (95\%) and PVA (5\%) were used. 52 Figure 25 - On the left, EMR signals of: PVC holder filled; PVC holder filled empty; and pure L-alanine with an absorbed dose of $10 \mathrm{~Gy}$. On the right, the dose-response curve obtained for the PVC holder with and without alanine, not considering standard deviation. Figure 26 - EPResize ${ }^{\circledR}$ design. Two types of cap are possible, intending readouts with X(green) or Q-band (red) EMR spectrometers. Unlike the cap, the holders are the same inside.

Figure 27 - EPResize ${ }^{\circledR}$ holders with a scale perspective. The one in a transparent different material was produced for tests and comparison. Only the model with extended cap is presented here.

Figure 28 - Quartz tube used to EMR spectrometry readout, with a capillary tube filled with L-alanine as sample.

Figure 29 - Dose-response curve for the experimental EPResize ${ }^{\circledR}$ simulation with EMR Xband. The continuous line represents the linear fit of peak-to-peak amplitude response and the dashed line is of the sum of peaks response.

Figure 30 - Dose-response curve obtained with Q-band EMR spectrometer for a measurement like the EPResize $e^{\circledR}$ experimental simulation performed with $X$-band.

Figure 31 - Setup for the irradiation of dose-response study for EPResize ${ }^{\circledR}$ samples; a) Primus linear accelerator from Siemens, in which the samples were positioned close to the focus, b) above the block tray in a field size of $40 \mathrm{~cm} \times 40 \mathrm{~cm} ; \mathrm{c})$ gelatin capsules filled with powder samples were also irradiated. 
Figure 32 - Dose-response curve and linear fit obtained with the irradiation of EPResize ${ }^{\circledR}$ and crystal powder of L-alanine and lithium formate.

Figure 33 - Dose rate study for L-alanine and lithium formate irradiated with 5 Gy. The dotted line for L-alanine corresponds to a $\pm 10 \%$ interval of the mean value and the dotted line for lithium formate to a $\pm 5 \%$ interval, showing that lithium formate has less dependence with dose rate variation. The reference for $100 \%$ consideration was the value for 200 MU/min, as it presented less standard deviation related to repeatability 61

Figure 34 - EBT2 film irradiated previously showing the field delimitation and the location of the EPResize ${ }^{\circledR}$, ensuring centralization for the irradiation performed with a $6 \times 6 \mathrm{~mm}^{2}$ field for output factor determination.

Figure 35 - EMR dose-response curve of EPResize ${ }^{\circledR}$ filled with L-alanine and lithium formate irradiated with a $220 \mathrm{kV} X$-ray irradiator. 64

Figure 36 - Dose profiles for different field sizes $\left(1 \times 1 \mathrm{~cm}^{2}, 2 \times 2 \mathrm{~cm}^{2}\right.$ and $\left.3 \times 3 \mathrm{~cm}^{2}\right)$ with the EPResize ${ }^{\circledR}$ detector filled with L-alanine, compared to the treatment planning data. 67 Figure 37 - Dose profiles for different field sizes $\left(1 \times 1 \mathrm{~cm}^{2}, 2 \times 2 \mathrm{~cm}^{2}\right.$ and $\left.3 \times 3 \mathrm{~cm}^{2}\right)$ with the EPResize ${ }^{\circledR}$ detector filled with lithium formate, compared to the treatment planning data..... 68 Figure 38 - Planned dose profile for each field size and a representation of the EPResize ${ }^{\circledR}$ detector volume position in relation to the center of fields.

Figure 39 - Anthropomorphic head phantom used to experimentally simulate a stereotactic treatment. On the left: frontal vision; on the right: lateral vision, where the different slices from 1 to 9 can be seen.

Figure 40 - Anthropomorphic head slices showing the location of the lesions (detectors), characteristic of a multiple lesions SRS treatment. The white points are nylon caps confining the radio-sensitive material L-alanine.

Figure 41 - Dose-response curve of L-alanine powder used as reference for the anthropomorphic head irradiation. The red line represents the linear fit, presenting also the correlation coefficient and the equation that relates absorbed dose and EMR signal intensity.

Figure 42 - Graphical comparison between experimental and planned dose of the anthropomorphic head phantom study. The error bars correspond to the standard deviations of each technique. 
Figure 43 - Ammonium tartrate microwave power saturation study relating EMR response to microwave power with different modulation amplitudes (a) and with different absorbed doses (b).

Figure 44 - Ammonium tartrate spectra acquired with different EMR spectrometer frequencies, such as $X$-band (9.5 GHz), $K$-band $(24 \mathrm{GHz})$ and $Q$-band (35 GHz). 80 Figure 45 - Dose-response curve and linear fit of ammonium tartrate with X-band EMR spectroscopy normalized by mass irradiated with ${ }^{60} \mathrm{Co} \gamma$-rays for doses from 0 to $25 \mathrm{~Gy}$......80 Figure 46 - Ammonium tartrate dose-response curve and linear fit with Q-band EMR spectrometer. The graphic presents two different methods of analysis: normalization by mass (black) and by $Q$-factor (blue).

Figure 47 - Ammonium carbonate and ammonium sulfate EMR single line spectrum irradiated with 100 Gy by a $50 \mathrm{kV} X$-ray. 82 Figure 48 - Dose-response relation for ammonium sulfate and carbonate irradiated with a 50 $k V X$-ray. The graphic has two different Y-axes: the black one is for ammonium carbonate (not dose-related); the blue one is for ammonium sulfate. The EMR responses are normalized by mass and readout gain for proper comparison.

Figure 49 - Ammonium sulfate dose-response curve in comparison with the lithium formate curve. Lithium formate presents higher EMR response, but a correction multiplying by a factor of 20 would measure the real difference between the two irradiated compounds. 83 Figure 50 - X-band EMR spectra of the different compounds irradiated with $100 \mathrm{~Gy}$, all recorded with low modulation amplitude aiming signal resolution. 88 Figure 51 - Lithium carbonate dose-response curve and the EMR spectrum recorded at each irradiation dose, highlighting the peak-to-peak amplitude. The curve linear fitting and parameters are also presented, considering the dose range from 0 to $20 \mathrm{~Gy}$. 89 Figure 52 - Lithium formate dose-response curve and its linear fit coefficients, for the dose interval until 20 Gy. The EMR spectrum recorded at each dose is presented, highlighting the single line dosimetric peak.

Figure 53 - Sodium acetate dose-response curve. The spectrum presents three peaks and the dosimetric response is considered as the sum of peaks, with linear fitting in the range of 0 to 20 Gy and the respective parameters. The EMR spectra up to 100 Gy are also presented..... 90 Figure 54 - Sodium carbonate single peak dose-response curve and fitting parameters for the range of 0 to $20 \mathrm{~Gy}$. Also, the EMR spectrum for each dose is presented, showing the peak increase up to $100 \mathrm{~Gy}$..... 
Figure 55 - Sodium citrate dose-response curve with a linear behavior in the range up to 20 Gy, with its parameters informed below. The dosimetric signal is considered as the first peak of the spectrum, determined as peak 1. The EMR signal growth is present for doses until 100 Gy.

Figure 56 - Sodium dithionite presents a linear behavior for doses up to $20 \mathrm{~Gy}$, and the fitting parameters are shown below. The dosimetric peak is considered as the amplitude of the most intense peak (peak 3), since for low doses, peak 1 and 2 have poor resolution. The EMR spectra from 0 until 100 Gy are discriminated. 92 Figure 57 - Sodium formate dose-response curve with a linear fit up to $20 \mathrm{~Gy}$, and its parameters. The compound presents a three peak spectrum, where the dosimetric peak is considered as the amplitude from the maximum to the minimum peak. EMR spectra up to 100 Gy are also presented.

Figure 58 - Mass attenuation coefficient curve of the compounds that presented suitable doseresponse curve. The energy range agreed with the clinical range on going from diagnostic $X$ rays to megavoltage (0.02 - $25 \mathrm{MeV})$, also including lower values, such as $0.008-0.02 \mathrm{MeV}$, in accordance with the beam used. It is possible to see a zoom in of the zone in which the previous irradiation was performed.

Figure 59 - EMR signal of different sulfites and their chemical structure, all of them characterized by one single line EMR spectrum. 99

Figure 60 - Dose-response curve by EMR peak-to-peak amplitude and double integration method for each sulfite. 102

Figure 61 - Sulfites spectra obtained for doses from 0 to $20 \mathrm{~Gy}$. 103 Figure 62 - Comparison between the experimental EMR spectrum of sodium sulfite and the simulated $\mathrm{SO}_{3}{ }^{-}$EMR spectrum. 105

Figure 63 - Sulfites and L-alanine dose-response curves. The parameters were normalized for comparison. 106 


\section{LIST OF TABLES}

Table 1 - Coefficients of the binomial expansion up to $n=6$, where $n$ corresponds to the number of microstates acting on the hyperfine interactions and the coefficients correspond to the relative intensity and the number of RME lines. 32

Table 2 - Parameters and values of each EMR spectrum line shape, the illustration of halfwidth $\Delta H_{1 / 2}$, the maximum slope width $\Delta H_{m s l p}$ and the average of the second moment $<\Delta H^{2}>^{1 / 2}$ av are in figure $12 .^{2}$

Table 3 - Different frequency and magnetic field bands that characterize EMR spectrometers, for $g=2$.

Table 4 - Main EMR parameters used to obtain various dose-response curves for different materials irradiated with $\mathrm{Co}^{60}$

Table 5 - EMR readout parameters for L-alanine (95\%) and PVA (5\%) pellets with different diameters.

Table 6 - Dose-response curve equation and correlation coefficients $\left(R^{2}\right)$ for different materials irradiated with a $\mathrm{Co}^{60}$ gamma source.

Table 7 - Equation and correlation coefficient of the dose-response curve of L-alanine (95\%) and PVA (5\%) pellets with different diameters.

Table 8 - Parameters used to the readout of the experimental simulation of EPResize ${ }^{\circledR}$ with an $X$-band and $Q$-band EMR spectrometer.

Table 9 - Dose-response curves and correlation coefficients of the different analyses used to evaluate the EPResize ${ }^{\circledR}$ experimental simulation with X-band EMR spectrometer. 56

Table 10 - EMR parameters used for the analysis of EPResize ${ }^{\circledR}$ dose-response and dose-rate study.

Table 11 - Coefficients from the linear fit of the dose-response curve obtained for EPResize ${ }^{\circledR}$ filled with L-alanine and lithium formate.

Table 12 - EMR parameters readout used for output factor studies. 62

Table 13 - Output factors maeasured with different detectors in a $6 \times 6 \mathrm{~mm}^{2}$ field size, irradiated with a Novalis with jaws size of $8 \times 8 \mathrm{~mm}^{2}$ and equipped with microMLC.

Table 14 - EMR dose-response curve equation and correlation coefficient for an EPResize ${ }^{\circledR}$ filled with L-alanine and lithium formate when irradiated with a $220 \mathrm{kV} X$-ray irradiator and output factor values for different field sizes. An open field was considered the reference field (value equal to 1), or as the standard field. 65 
Table 15 - Parameters used for the EMR readout of EPResize ${ }^{\circledR}$ samples used in the field profile study.

Table 16 - SRS arcs information obtained from the treatment planning. 72

Table 17 - EMR parameters readout for the studies surrounding the stereotactic experimental simulation. 72

Table 18 - Doses calculated by the treatment planning and experimentally verified for the anthropomorphic head irradiation study. For planned doses, the deviation is related to the standard deviation between minimum and maximum dose presented in the position delimited.

Table 19 - Microwave power and modulation amplitude values used for X-and Q-band doseresponse study of ammonium tartrate.

Table 20 - Main EMR parameters used to perform readout with the alternative ammonium compounds with Bruker and JEOL X-band spectrometers. 78

Table 21 - Ammonium tartrate fitting parameters obtained when considering a linear behavior of dose-response curve acquired with $X$ - and $Q$-band.

Table 22 - Comparison between dose-response curve parameters of ammonium sulfate and lithium formate. The data was not normalized by EMR readout gain, so, for correction, lithium formate results should be multiplied by a factor of 20 .

Table 23 - List of the lithium, potassium and sodium compounds studied and information where they could be found in daily life. 84

Table 24 - Brand of all the compounds studied. 85

Table 25 - Common parameters used for EMR analyses of the different compounds. 86 Table 26 - Different EMR parameters used for each studied compound after proper optimization of the signal.

Table 27 - List of compounds and their respective parameters used to plot the dose-response curves. The angular coefficient is compared to lithium formate as reference. The standard deviation represents the interval obtained for each dose point in the dose-response curve. Here, the coefficients were normalized by the readout gain.

Table 28 - Different properties of the compounds studied. The EMR signal peaks are considered for the radical induced by radiation for a maximum absorbed dose of 100 Gy... 95 Table 29 - g factors reported in the literature of some radicals that constitute the spectra of the lithium, potassium and sodium compounds studied. 
Table 30 - Summary showing which compound presented the best behavior in terms of each

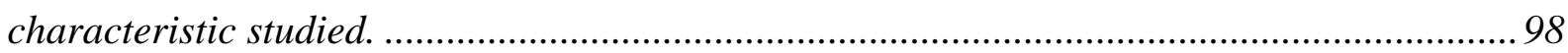

Table 31 - Some chemical and physical properties of the sulfites studied ............................. 99

Table 32 - EMR spectrometer parameters for the sulfites study........................................ 100

Table 33 - Equations and correlation coefficients for each sulfite for the corresponding

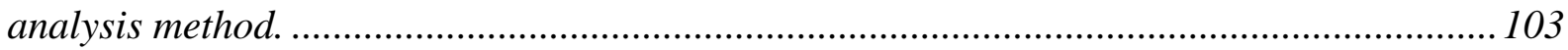

Table 34 - Uncertainties budget concerning the sulfites EMR readout and analyses. .......... 104

Table 35 - Slopes of L-alanine and sulfites dose-response curve. ...................................... 106 


\section{LIST OF ACRONYMS}

AAPM The American Association of Physicist in Medicine

CEA Commissariat à l'Énergie Atomique et aux Énergies Alternatives

CT Computed tomography

DPPH Diphenyl-picryl-hydrazyl

EMR Electron magnetic resonance

EPR Electron paramagnetic resonance

ESR Electron spin resonance

HVL Half-value layer

IAEA International Atomic Energy Agency

IMRT Intensity-modulated radiotherapy

IRMEV Instituto de Radioterapia e Megavoltagem de Ribeirão Preto

IRSN Institut de Radioprotection et de Sûreté Nucléaire

MLC Multileaf collimator

MU Monitor unit

OF Output factor

OSLD Optically stimulated dosimetry

PCL Polycaprolacton

PVA Polyvinyl alcohol

PVC Polyvinyl chloride

Q-factor Quality-factor

SRS Stereotactic radiosurgery

SSD Source-surface distance

TE Transverse electric

TLD Thermoluminescent dosimetry

TMRS Tissue maximum ratios

TPS Treatment planning system

WHO World Health Organization 


\section{LIST OF SYMBOLS}

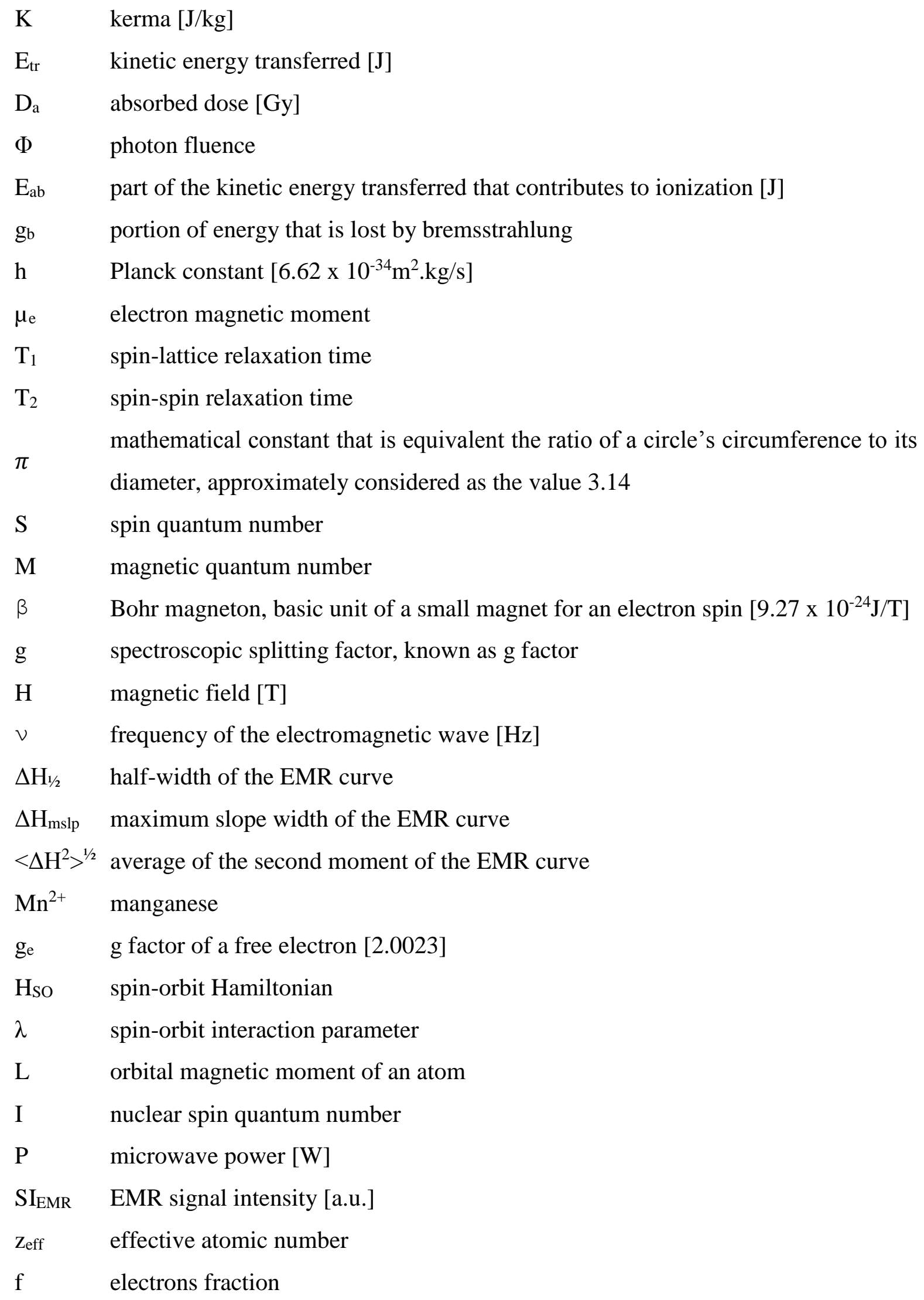


ZEMPeff empirical effective atomic number

$\mathrm{z}$ atomic number

SIEMRdi double integration EMR signal intensity [a.u.] 
1. INTRODUCTION

2. THEORY AND GENERAL CONCEPTS

2.1. IONIZING RADIATION AND MATTER 25

2.2. RADIATION DOSIMETRY 26

2.3. ELECTRON MAGNETIC RESONANCE 29

2.3.1. THE ELECTRON SPIN AND EMR PRINCIPLES 29

2.3.2. THE EMR SPECTROMETER, PARAMETERS AND SIGNAL 33

2.4. EMR DOSIMETRY 40

3. MINIDOSIMETERS FOR SMALL FIELD DOSIMETRY

3.1. MINIDOSIMETERS - PELLETS STUDY 47

3.1.1. MATERIALS AND METHODS 47

3.1.2. RESULTS AND DISCUSSION

3.2. EPRESIZE $^{\circledR} \quad 52$

3.2.1. X-AND Q-BAND EXPERIMENTAL SIMULATION

3.2.1.1. MATERIALS AND METHODS 54

3.2.1.2. RESULTS AND DISCUSSION

3.2.2. DOSE-RESPONSE CURVE

3.2.2.2. RESULTS AND DISCUSSION

3.2.3. OUTPUT FACTOR 61

3.2.3.1. MATERIALS AND METHODS 61

3.2.3.2. RESULTS AND DISCUSSION

3.2.4. FIELD PROFILE

3.2.4.1. MATERIALS AND METHODS

3.2.4.2. RESULTS AND DISCUSSION 66

3.3. EXPERIMENTAL SIMULATION OF A STEREOTACTIC TREATMENT 69

3.3.1. MATERIALS AND METHODS

3.3.2. RESULTS AND DISCUSSION

4. ALTERNATIVE MATERIALS FOR EMR DOSIMETRY

4.1. AMMONIUM COMPOUNDS

4.1.1. MATERIALS AND METHODS

4.1.2. RESULTS AND DISCUSSION 78

4.2. LITHIUM, POTASSIUM AND SODIUM COMPOUNDS 84 
4.2.1. MATERIALS AND METHODS

4.2.2. RESULTS AND DISCUSSION

4.3. SULFITES

4.3.1. MATERIALS AND METHODS

4.3.2. RESULTS AND DISCUSSION

101

5. CONCLUSION 107

REFERENCES 


\section{INTRODUCTION}

Dosimetry determines the quantity of absorbed dose originated from the interaction between ionizing radiation and matter, covering also measurements such as dose rate, equivalent dose, energy imparted, fluence, and others (Attix, 1986); it is an essential procedure when working with radioactive or radiation emitter equipment. Present also in cases of radiation accidents as an indicator of the contamination; in clinical facilities using radiation producing machines (e.g. linear accelerator, X-rays) or radioactive sources; workplaces and individuals constantly in contact with radiation professionally (e.g. power plants); industrial procedures (e.g. food decontamination); or even in cosmic or commercial flights, showing that radiation evaluation is common and routinely necessary.

A dosimeter is a device able to give the readout of absorbed dose, when exposed to ionizing radiation. This device may be composed by a detector, in which radiation is delivered in its volume, and a reading technique (when needed). One of these techniques concerns electron magnetic resonance (EMR), in which the absorbed radiation induces a detector to produce paramagnetic centers, which are dose related by a characteristic EMR spectrum.

The progress in radiotherapy brought a new generation of machines, reflecting also in cases of radiobiological studies, allowing beams of less than $5 \mathrm{~mm}$ for patient treatment and 1 $\mathrm{mm}$ for radiobiology. For these small beams, standard dosimetry reference protocols cannot be applied, so the challenge lies in the development of suitable minidosimeters.

The goal was to analyze different minidosimeters and materials, characterize them with EMR spectroscopy. Thereby, a new minidosimeter model is presented, initially aiming clinical applications, and compounds of different elements are investigated and verified for applied EMR dosimetry.

This thesis is divided in two main topics, all concerning EMR spectroscopy dosimetry. The first presents small size detectors (minidosimeters), investigated for non-conventional treatment fields; and as second, the investigation of different materials, being more suitable in cases of accident. Therefore, the text will be developed according to this division, in which the topics are independent, but first the theory and general concepts are presented. 


\section{THEORY AND GENERAL CONCEPTS}

This chapter discusses the theory and general concepts regarding the main topics studied during the thesis development. These topics concern interaction between radiation and matter, principles of EMR spectroscopy and dosimetry. Concepts that are specific for each area will be discussed in the chapters ahead.

\subsection{IONIZING RADIATION AND MATTER}

Radiation is the propagation of energy in a medium, having a dual wave-particle behavior, as described by quantum physics. When set as ionizing radiation, it has energy enough to be able to ionize atoms and molecules. In the electromagnetic spectrum, it starts after the visible light, embracing part of ultraviolet and all the $\mathrm{X}$ and $\gamma$-rays, including also cosmic rays (Eisberg and Resnick, 1985).

When an X-ray, or photon beam, penetrates an absorbing medium, part of its energy is transferred and absorbed, which may result in biological damage, in cases of biological systems. In a body, the energy absorbed by mass is called absorbed dose, which is determinative to occur biological damage. Figure 1 diagram briefly illustrates the process that happens when ionizing radiation enters a biological system and could result in biological damage. First, a photon collides with an electron of the body, resulting in radiation scattering and in the movement of a high-speed electron (presented by A in figure 1). The high-speed electron provokes ionization along its way, exciting atoms and breaking bonds (showed in B in figure 1), resulting in biological damage and in heat (no biological effect); all these processes results in energy losses by the electron. This phenomenon is defined as stopping power. Another possibility for an electron in motion is to collide with a nucleus and suffer bremsstrahlung. As for the scattered radiation, the bremsstrahlung can also produce interactions like the original photon. Photons could interact with matter mainly by photoelectric effect, Compton scattering and pair production. The processes happen simultaneously, being able to exchange, emit or absorb energy. In soft tissue, the Compton scattering is more meaningful than the two other processes for photons in the range of 100 $\mathrm{keV}$ to $10 \mathrm{MeV}$ (Johns and Cunningham, 1983). 
Figure 1 - Diagram showing the absorption of energy from radiation until it results in biological damage. (A) describes the moment when a photon collides with an electron, starting the interaction process; (B) represents the moment that the electron, now in high speed motion, could ionize, excite and break bonds along its way; it can also transfer heat; all these actions can produce chemical changes (not the heat part) showed in (C); then, chemical damage is observed (D) (Johns and Cunningham, 1983).

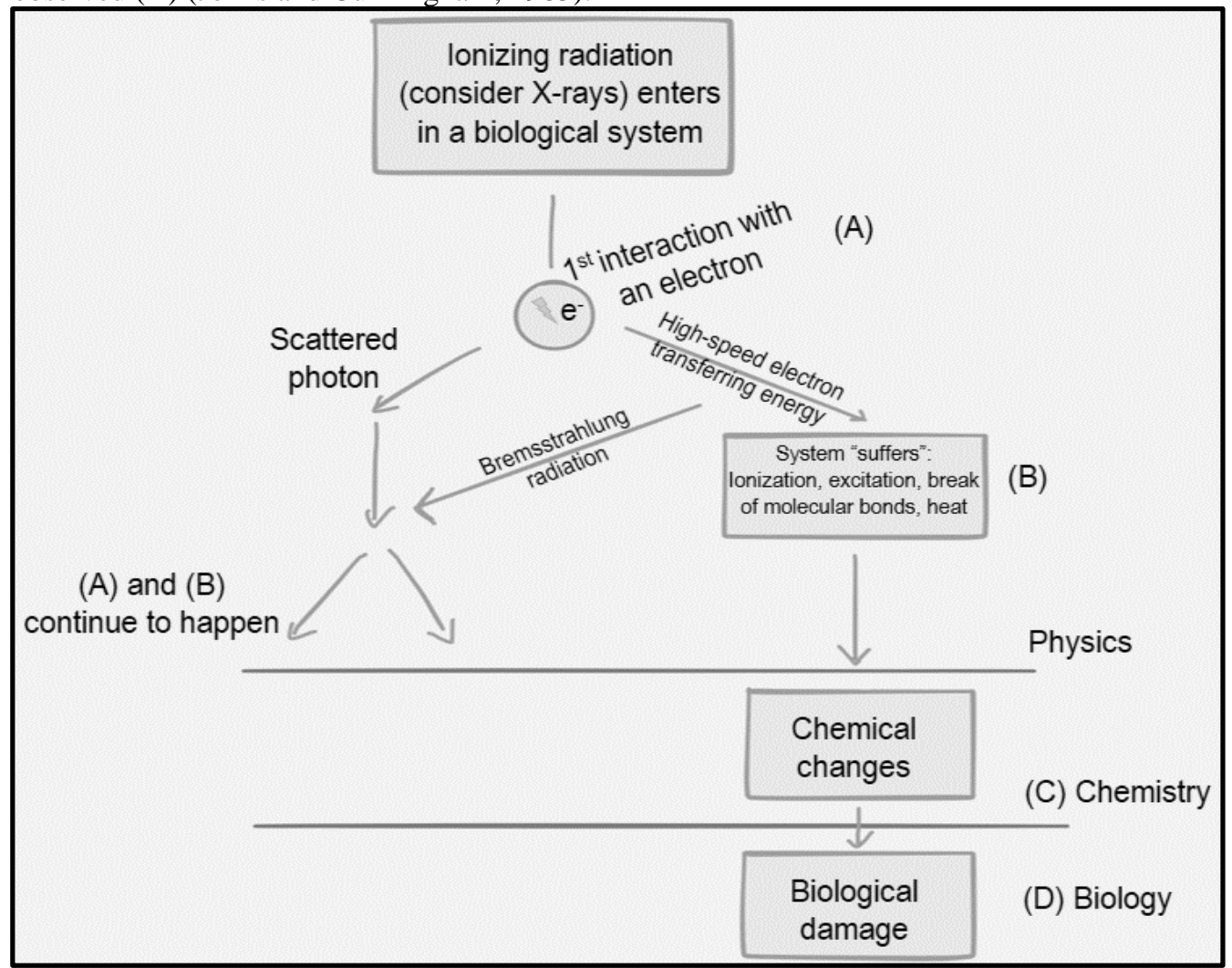

\subsection{RADIATION DOSIMETRY}

Dosimetry has two main lines that could be considered: the description of a radiation beam or the quantity of energy that a radiation beam delivers in a medium. Considering the purpose of this study, the second case will be discussed and explored.

As mentioned in the section before, the energy transferred from a photon to a medium happens in two stages, described by (A) and (B) in figure 1. The quantity to describe the first interaction (figure 1A) is called kerma $(\mathrm{K})$, which means Kinetic Energy Released in the Medium, representing the kinetic energy transferred $\left(\mathrm{E}_{\mathrm{tr}}\right)$ from photons to electrons of a region with a certain quantity of mass. In the second stage (figure 1B), the energy that is retained in the medium with a certain mass is called absorbed dose $\left(D_{a b}\right)$, being of importance to radiotherapy and radiobiology.

Due to the track of the electron, kerma and absorbed dose happen in different regions. Kerma can be related to photon fluence $(\Phi)$, as stated by the equation: 


$$
K=\Phi\left(\frac{\mu}{\rho}\right) \bar{E}_{t r}
$$

but absorbed dose can only be calculated if there is equilibrium between the two dosimetric quantities. Two different scenarios are possible:

i. no attenuation of the photon beam;

ii. attenuation of the photon beam.

So, figure 2 shows the two situations, a) for i. and b) for ii., the range $R$ indicates the trajectory of high speed electrons, where each letter corresponds to a trajectory square and the number indicated is the quantity of electrons able to get each square, starting with a total of 100 electrons from the first interaction with the photon (Johns and Cunningham, 1983).

First, when i. happens, as there is no attenuation of the photon beam, all the electrons can go through $\mathrm{A}$ to $\mathrm{G}$, reaching a maximum value in $\mathrm{D}$. The absorbed dose will be proportional to the ionization happening in each square. The extension between $\mathrm{A}$ (the surface) and D (a certain depth with maximum ionization) is called build-up region, and beyond it is the electronic equilibrium region, where electrons can be stopped or set in motion. Kerma is constant with depth, as shown by the dotted lines, assuming no bremsstrahlung occurs, the absorbed dose and kerma will be the same after the build-up region, as shown in figure 2a) (Johns and Cunningham, 1983).

Considering the presence of an attenuator, the ionization produced by the electron in motion will reduce (for the example given, $5 \%$ in each square), such as the kerma. Thus, D presents the maximum ionization, but it is not the same as produced in A, being a reduced value, so the kerma will decrease and the absorbed dose will have the maximum value, and then decrease, as before. In an equivalent thickness, kerma and absorbed dose will be in equilibrium. Afterwards, they will exponentially fall with absorbed dose above if bremsstrahlung is not considered. In that case, as presented in figure $2 b$ ), there is no region of equilibrium, but a point of equilibrium (Johns and Cunningham, 1983). 
Figure 2 - Graphical abstract showing the behavior of absorbed dose (continuous line) and kerma (dotted line) for two different irradiation scenarios. The squares illustrate the quantity of electrons presented in each square of the range, helping to explain the different resulting lines. In a) there is no attenuation of the beam, presenting a region of electronic equilibrium; in b) the beam is attenuated and, instead of a region, an equilibrium point is observed. ${ }^{1}$

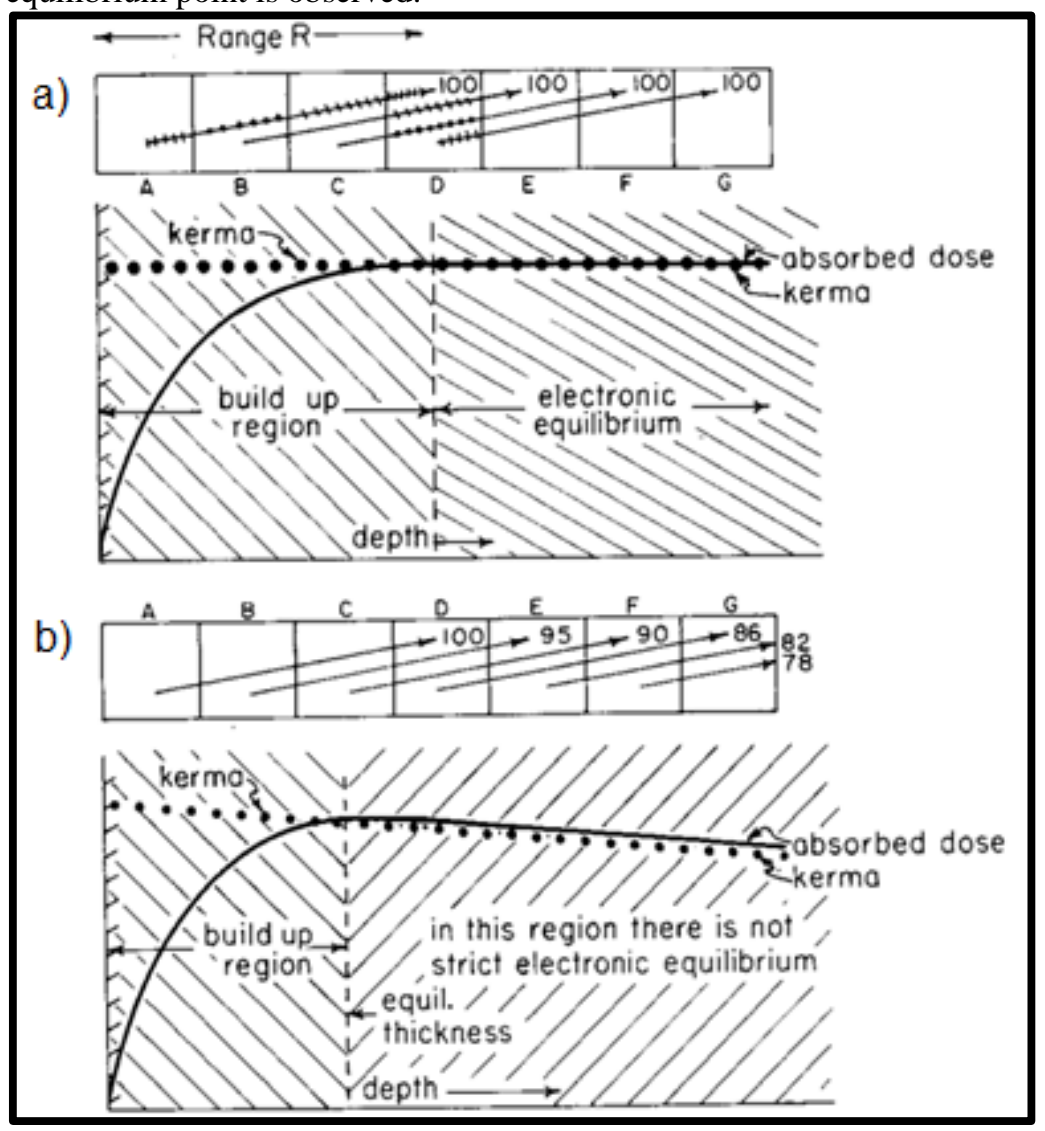

In an equilibrium condition, the absorbed dose can be calculated by the equation:

$$
D_{a b}=\Phi\left(\frac{\mu}{\rho}\right) \bar{E}_{a b}=K\left(1-g_{b}\right)
$$

in which $\mathrm{E}_{\mathrm{ab}}$ is the part of kinetic energy transferred to electron that contributes to ionization, $\mathrm{g}_{\mathrm{b}}$ is the fraction of energy lost by bremsstrahlung.

As mentioned previously, a dosimeter can detect and furnish a reading of absorbed dose measured in a medium. It can be liquid, solid or gaseous and its sensitive volume is called cavity. Dosimeters can be characterized by some general aspects, such as whether it informs the dose with or without previous calibration; about its accuracy and precision, its operation range, its dependence on energy, rate or any other factor, presenting a stable

\footnotetext{
${ }^{1}$ JOHNS, H. E.; CUNNINGHAM, J. R. The physics of radiology: fourth edition. Toronto: Charles C. Thomas, 1983
} 
behavior before and after irradiation (Attix, 1986). It can be described as active, when providing a direct readout, or passive, for the contrary.

\subsection{ELECTRON MAGNETIC RESONANCE}

Electron magnetic resonance (EMR) is a general term for electron spin resonance (ESR) or electron paramagnetic resonance (EPR). It is like nuclear magnetic resonance (NMR) and ion cyclotron resonance (ICR), but EMR deals with electrons, instead of NMR with nucleus and ICR with ions; and it can be applied to any sample with unpaired electrons.

EMR is a physical technique that, in the presence of a magnetic field, observes resonance of an unpaired electron spin caused by microwave absorption (Ikeya, 1993).

Despite being less popular than NMR, EMR was discovered first and is employed in several areas of knowledge, as radiation chemistry, biochemistry, solid state physics and medicine (some references as example of applications: Swartz et al., 1972; Swartz et al., 2004 and Berliner, 2010).

Usually the EMR spectrum is characterized by the Hamiltonian spin parameters, related to quantum physics, as described below in the following subsections.

\subsubsection{The electron spin and EMR principles}

Electron presents negative charge, its rotation produces an opposite current compared to the direction of its movement. This current produces a magnetic field in the electron vicinity. Consequently, the electron spin (self-rotating) can be considered a small magnet (Ikeya, 1993). Small electron magnetic spins form magnetic neutral pairs in atoms and molecules, so most of the materials presents null magnetic moment.

Natural or produced radiation is capable of breaking bonds (unpairing electrons). The capture of an unpaired electron by other atoms or imperfections in the lattice (also known as: traps) creates an atom with excess or lack of electrons (both with unpaired electrons), generating trapped-electron or trapped-hole centers, respectively. The unpaired electrons produce a net magnetic moment $\left(\mu_{\mathrm{e}}\right)$ (Ikeya, 1993).

Unpaired electrons tend to align parallel to the magnetic field direction and get magnetized, therefore when spinning electrons (figure 3A) are put in an external static magnetic field, the rotation direction of the electrons goes from random to the same or 
opposite direction of the field, according to its spin orientation as in figure 3B. Electron spins with different direction are energetically opposite situations, named as spin up and spin down. When excited by a microwave and absorbing it, electron spins from the lower level fall to the level above with the lattice vibration, and the time interval that it happens is called spin-lattice relaxation time $\left(\mathrm{T}_{1}\right)$, sketched in figure $3 \mathrm{C}$. The spin dislocation also happens because of the spins interactions, which are called spin-spin relaxation time $\left(\mathrm{T}_{2}\right)$. When the microwave power is too high, the relaxation time is too long for the recovery of the level population, so a decrease is observed in the response obtained with EMR, a phenomenon called saturation (Ikeya, 1993).

Figure 3 - Graphical abstract showing (A) free electrons presenting random orientation when not exposed to a magnetic field; (B) such that when applied a magnetic field different from zero, electrons align with the field direction according to spin orientation, which can be spin up or down, with different energy values, known as Zeeman splitting. In the presence of a microwave, the vibration of the lattice happens, causing electron motion in the lattice, and the phenomena of resonance and relaxation are observed.

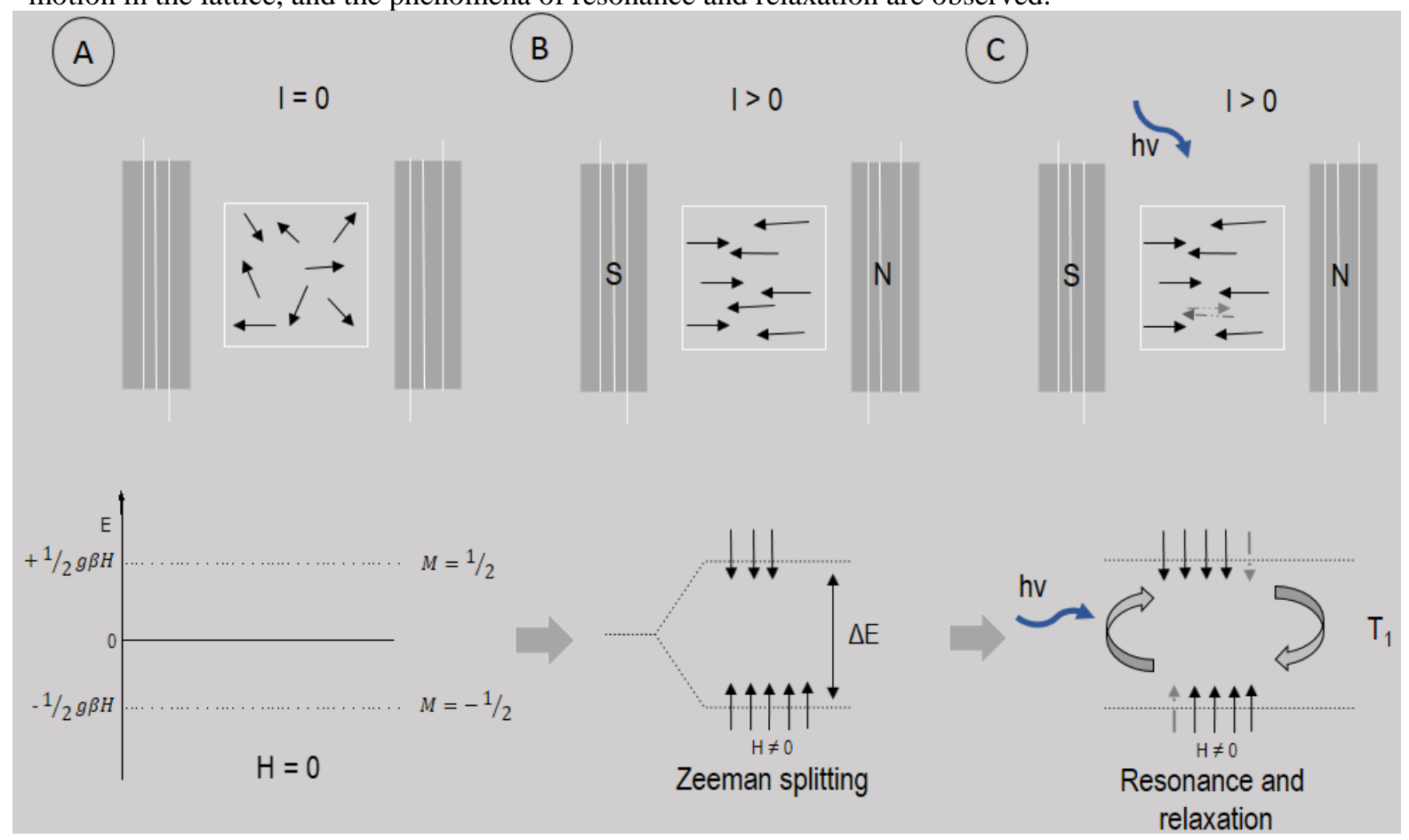

The magnetic properties of the unpaired electron are expressed by the spin angular momentum $S(h / 2 \pi)$, the spin quantum number $(S=1 / 2)$, the magnetic quantum number $(M=+1 / 2$ and $M=-1 / 2)$, the Bohr magneton $\beta$, the magnetic moment $\left(\mu_{e}=-g \beta M\right)$ and the spectroscopic splitting factor $(\mathrm{g}=2.0023)$. 
The energy that produces different spin states in a magnetic field $H$ is known as Zeeman Effect, which depends on the applied magnetic field $H$ and electron magnetic moment $(g \beta M)$. Thus, the Zeeman energy is given by:

$$
E_{z}=-\mu_{e} H \therefore E_{z}=g \beta H M
$$

The allowed level states for an electron of $\operatorname{spin} S=1 / 2$ are $M=+1 / 2$ and $M=-1 / 2$, presented in function of $H$ as in figure 4. Spin direction changes according to the microwave absorption, when the energy difference $\left(\Delta E_{z}=g \beta H\right)$ is the same as the energy of an electromagnetic wave $(h v) . \Delta E_{z}$ is equivalent to the difference between two energy levels, also shown in figure 4. The absorption of this microwave by unpaired electrons is designated electron magnetic resonance EMR. The resonance condition is

$$
g \beta H_{0}=h v,
$$

in which the frequency $v$ is kept constant while the magnetic field $H$ is swept (Ikeya, 1993).

Figure 4 - Allowed energy levels of an electron spin in function of magnetic field $H$. The resonance condition by microwave absorption occurs when $\boldsymbol{H}_{\mathbf{0}}=\boldsymbol{h} \boldsymbol{v} / \boldsymbol{g} \boldsymbol{\beta}$.

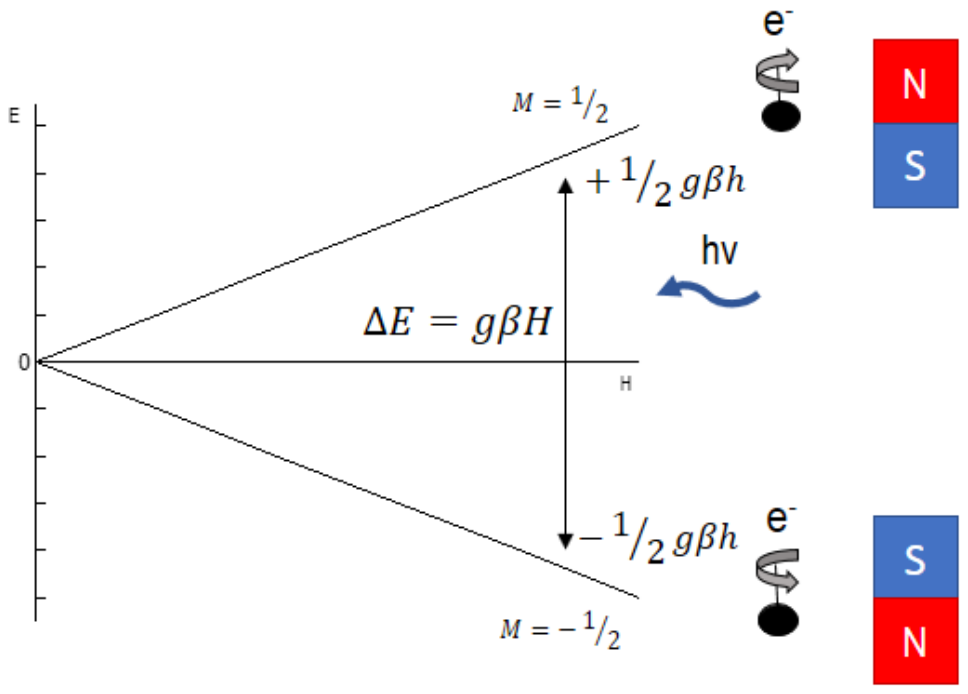

As for an electron spin, the self-rotation of a positive charged nucleus, nuclear spin, also creates a circular current, producing a magnetic field in the vicinity. The nuclear spin is equally considered a small magnet, magnetically interacting with electron spins. The EMR signal is affected by nuclear spin in the surroundings, such that the magnetic field induced by the nuclear spin also contributes to the Zeeman energy of the electron spin, and this is called hyperfine interaction or hyperfine structure. 
An EMR signal splits in two lines of same intensity (doublet) by the hyperfine interaction with the nuclear spin of a proton $(I=1 / 2)$, normally with $50.8 \mathrm{mT}$ line separation (Ikeya, 1993). Each line opens in two additional lines, if another proton is present. Figure 5 illustrates the theoretical splitting of the protons hyperfine structure and table 1 exemplifies a binomial expansion, relating the number of microstates interacting with the hyperfine structure and the quantity and intensity of lines in an EMR spectrum. In practice, the interaction with unpaired electrons could be different, resulting in stronger and weaker interactions (Swartz, Bolton and Borg, 1972).

Figure 5 - Theoretical splitting of the protons hyperfine structure. The contribution of protons with $I=1 / 2$ results in lines with different ratio intensity ${ }^{2}$, in accordance with coefficients of a binomial expansion, as presented in table 1 also until $\mathrm{n}=6$.

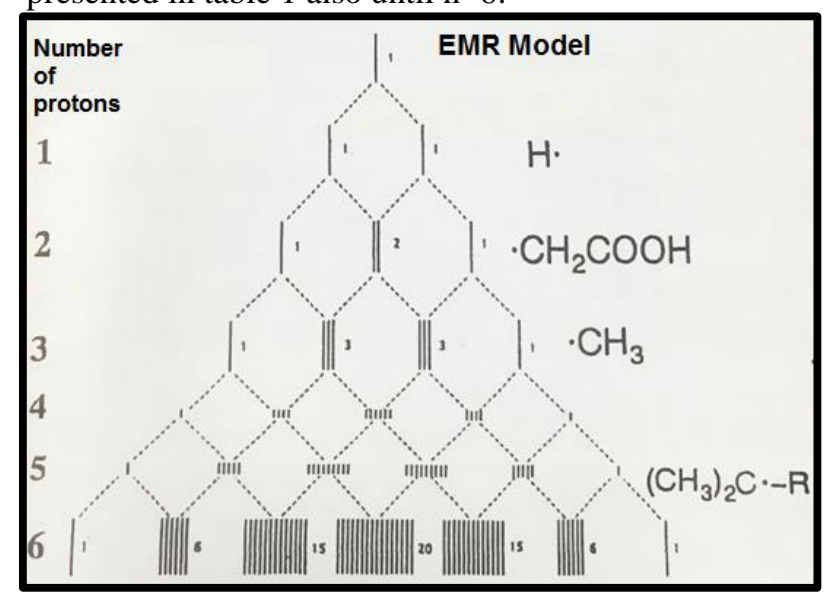

Table 1 - Coefficients of the binomial expansion up to $\mathrm{n}=6^{3}$, where $\mathrm{n}$ corresponds to the number of microstates acting on the hyperfine interactions and the coefficients correspond to the relative intensity and the number of RME lines.

\begin{tabular}{|c|c|c|}
\hline $\mathbf{N}$ & $\begin{array}{l}\text { RME } \\
\text { lines }\end{array}$ & $\begin{array}{c}\text { Relative intensity } \\
\text { of RME lines }\end{array}$ \\
\hline 1 & 2 & 11 \\
\hline 2 & 3 & 121 \\
\hline 3 & 4 & 1331 \\
\hline 4 & 5 & 14641 \\
\hline 5 & 6 & $\begin{array}{llllll}1 & 5 & 10 & 10 & 5 & 1\end{array}$ \\
\hline 6 & 7 & $\begin{array}{lllllll}1 & 6 & 15 & 20 & 15 & 6 & 1\end{array}$ \\
\hline
\end{tabular}

2 IKEYA, M. New applications of electron spin resonance: dating, dosimetry and microscopy. World Scientific, 1993.

${ }^{3}$ Modified from:

SWARTZ, H. M; BOLTON, J. R.; BORG, D. C. Biological applications of electron spin resonance. John Wiley \& Sons, 1972. 


\subsubsection{The EMR spectrometer, parameters and signal}

The figure 6 diagram presents the main components of an EMR spectrometer. Among these, it is important to highlight the microwave controller (source), the resonator (resonant cavity), the magnets and the current source (detector). The microwave source, known as klystron or Gunn-diode, works as a microwave oscillator; the microwaves are led by a waveguide to the resonant cavity, in the static magnetic field produced by the magnet. Usually, the microwave absorption is modulated by a frequency of $100 \mathrm{kHz}$ and amplified with a lock-in system. The sample is put into the resonant cavity, then the current in the electromagnetic coil changes and sweeps the strength of the magnetic field to obtain a spectrum. The magnetic field used to align the spins must be stable, otherwise it could result in energy levels variation, thus the intensity of the field must be controlled by a detector called Hall probe. The linear variation of the magnetic field makes the spectrum observable, the information is given by the data acquisition software, that provides the first derivative of the signal ( $d P / d H$ ), because of the use of the lock-in technique (Ikeya, 1993).

Figure 6 - Diagram with the main components of an EMR spectrometer. Unlike the UV-Vis absorption spectrometer, which gives the absorption curve as the signal result (A), this signal is presented as the first derivative of the absorption spectrum (B).

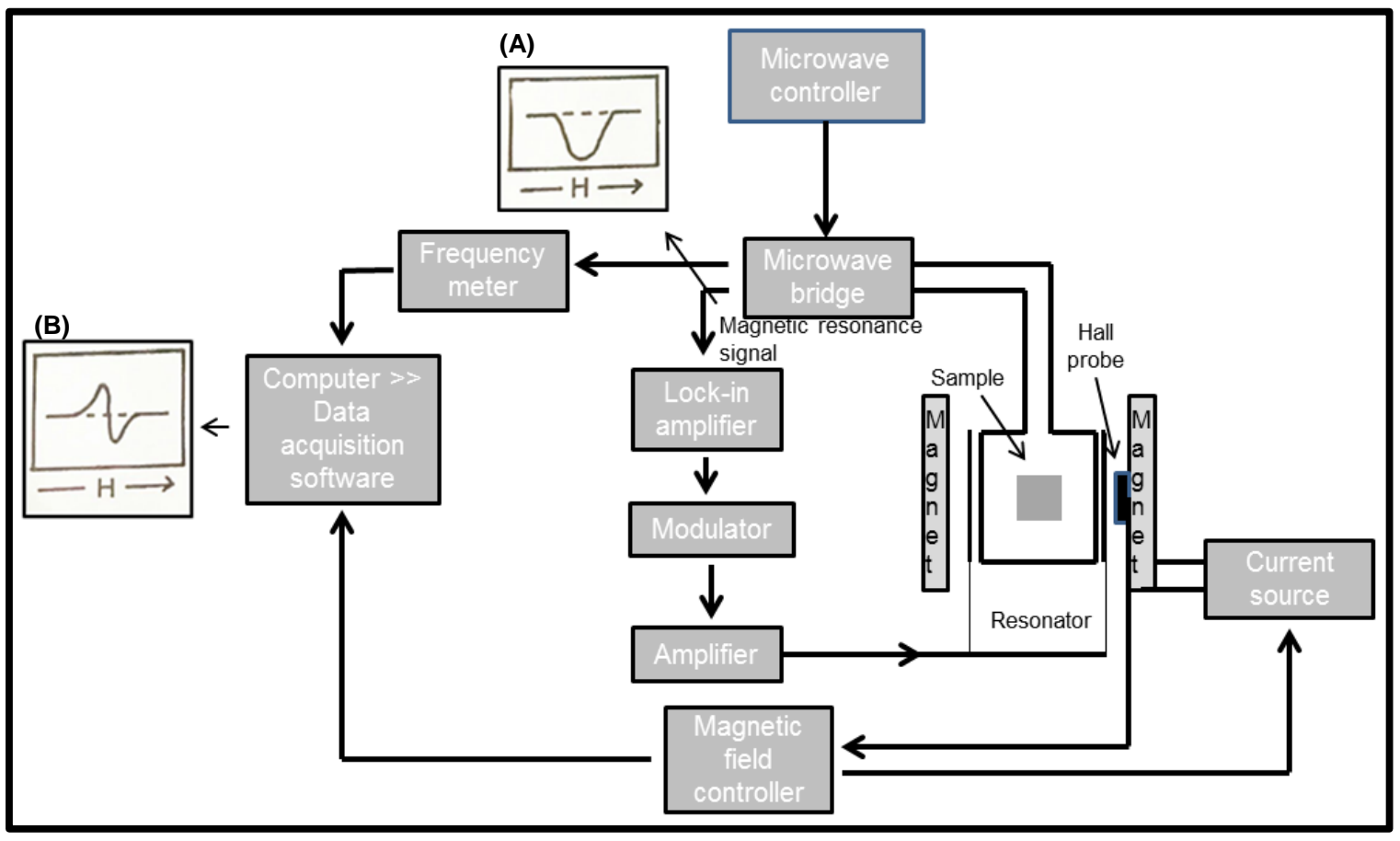


As mentioned in the previous subsection, electron spins fall from higher levels to lower levels, by photons emission or energy transference to the lattice, and the time of this action was determined as $T_{l}$. If the microwave power $(P)$ is higher enough to pump the electrons from the lowest to the highest level, the population from the higher level $\left(P_{2}\right)$ is reduced considering the power balance, such as:

$$
\frac{d N_{2}}{d t}=c P-\frac{N_{2}}{T_{1}}, \text { where } c \text { is a constant. }
$$

To avoid a signal overlap, it is necessary to analyze the microwave power value. Some signals saturate even with low microwave power, as others have intensity improvement, in accordance with the proportionality between EMR signal intensity ( $\left.\mathrm{SI}_{\mathrm{EMR}}\right)$ and the square root of the power:

$$
S I_{E M R} \propto \sqrt{P},
$$

as described in the literature (Feher, 1957; Marrale et al., 2006) and illustrated in figure 7 with the examples of ammonium tartrate (fast saturation, maximum response at $0.2 \mathrm{~mW}$ ) and lithium formate (slow saturation, maximum response at $3 \mathrm{~mW}$ ).

Figure 7 - Microwave power study curves for ammonium tartrate and lithium formate in which the EMR response is proportional to the square root of the microwave power. Saturation is observed at $0.2 \mathrm{~mW}$ for ammonium tartrate, presenting a faster saturation, and for lithium formate at $3 \mathrm{~mW}$ (slower saturation, in comparison with ammonium tartrate).

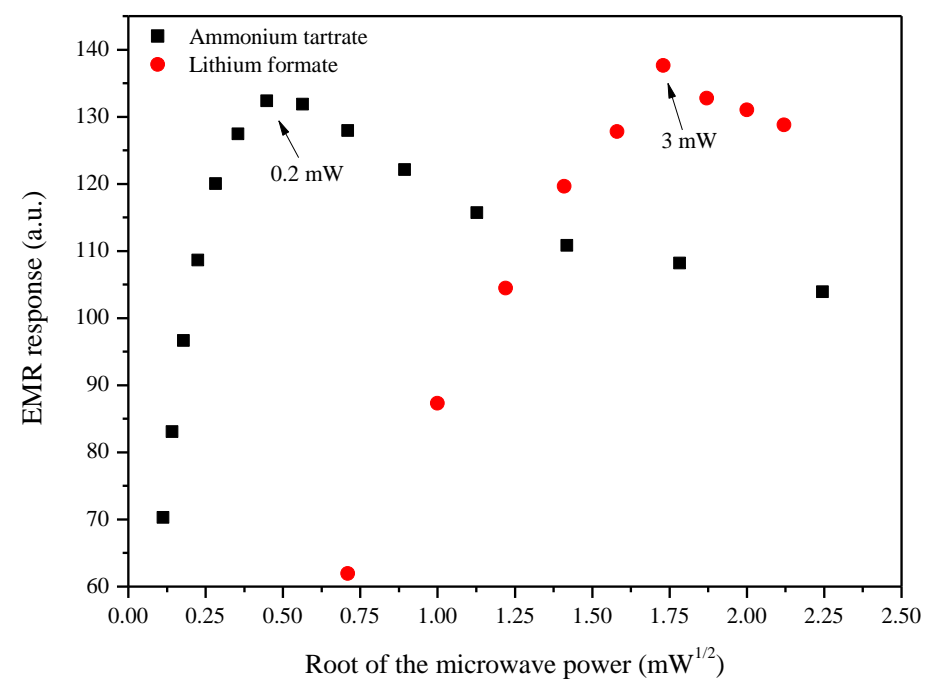

With the microwave power, modulation amplitude is one of the most important EMR measurement parameters. As exemplified in figure 8, when the modulation width of the magnetic field (modulation amplitude) is larger than the line width of the signal, spectral 
resolution is committed and signal distortion and overlapping are observed; but for dosimetry purposes it is acceptable to prioritize the intensity and not the resolution of the signal (Weil, Bolton and Wertz, 1994), then high modulation amplitude values are accepted in EMR dosimetry. Figure 8 also presents the second derivative of the signal (the less intense signal recorded, popularly called second harmonic). It separates line overlapping, as its intensity improves with the increase of modulation amplitude, also differentiating and determining each overlapped peak.

Figure 8 - Monosodium glutamate EMR signal with different values of modulation amplitude. As the line width varies from 0.6 to $1.0 \mathrm{mT}$, in c) and d), signal distortion and improvement of the second harmonic signal are observed.

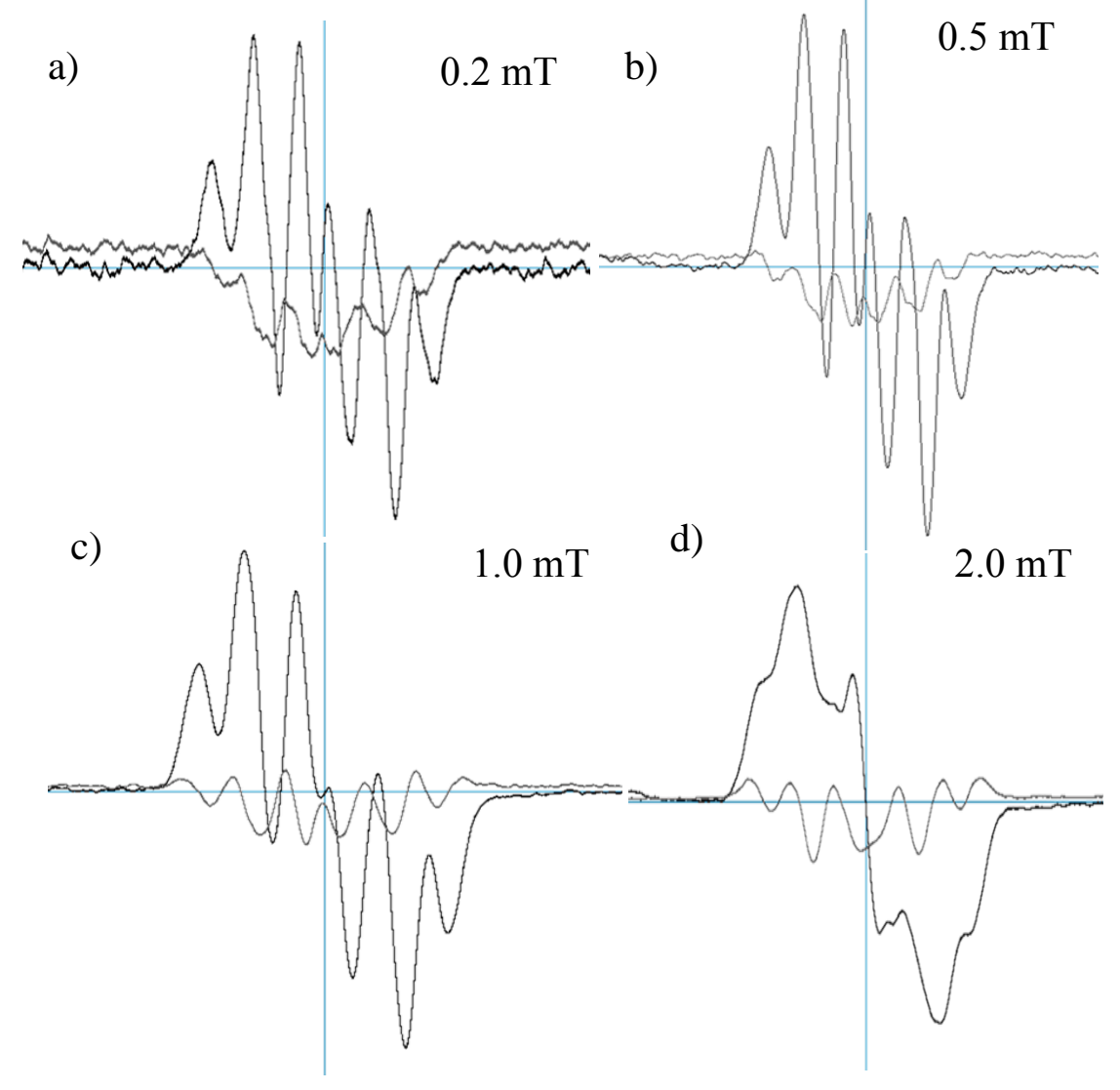

Other factors that can interfere in the quality of the signal are the positioning and the amount of the sample inside the resonant cavity. Figure 9 shows an experiment performed with a DPPH sample in a cylindrical $\mathrm{TE}_{011}$ resonant cavity, in which as the positioning gets away from the central region, the signal decreases up to $99 \%$. In figure 10 the quantity of mass and column height of alanine were varied inside the resonant cavity, showing that even if EMR response is proportional to the quantity of mass in the capillary, if the height is bigger than the sensitive area of the cavity (in this example, from $0.4 \mathrm{~mm}$ to $0.8 \mathrm{~mm}$ ), the signal will 
not increase and will present higher repeatability deviation (up to 23.0\%). The TE 011 cavity mode is characterized by concentrating electromagnetic lines in a central region, as represented in (figure 11).

Figure 9 - Relation between EMR response and positioning of a DPPH sample inside a resonant cavity mode $\mathrm{TE}_{011}$. The response tends to decrease as the sample gets away from the central region, suffering variation from 0.6 to $99.5 \%$.

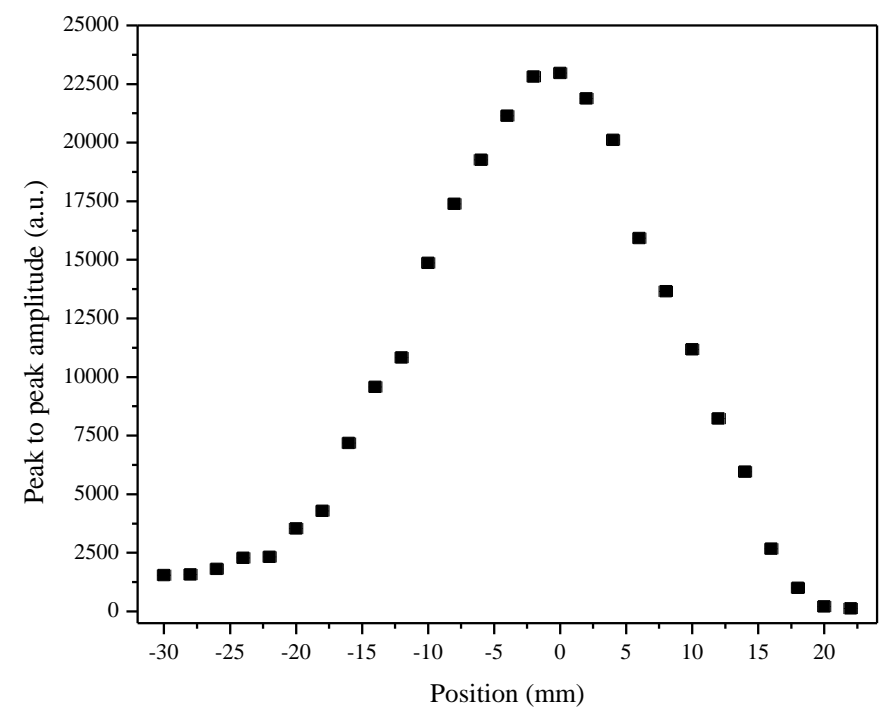

Figure 10 - Relation between EMR signal and the quantity of alanine sample in the capillary tube; a) is related to the quantity of mass and $b$ ) to the column height. Even if the response is proportional to mass, it is observed that for heights higher than $8 \mathrm{~mm}$ the repeatability variation goes from 1.8 to $23.0 \%$, as between 4 to $8 \mathrm{~mm}$ is up to $0.4 \%$.
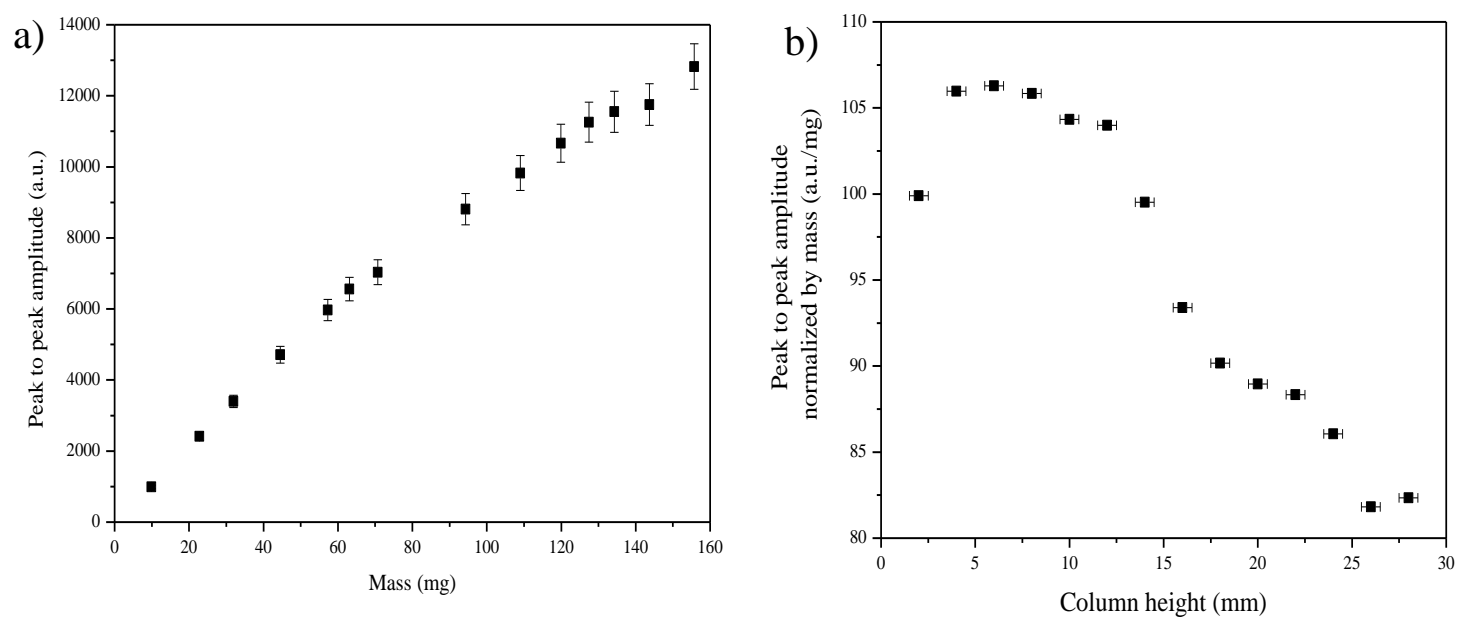
Figure 11 - Representation of electric and magnetic fields in a resonant cavity, mode $\mathrm{TE}_{011}$, showing also the sensitive position inside the cavity.

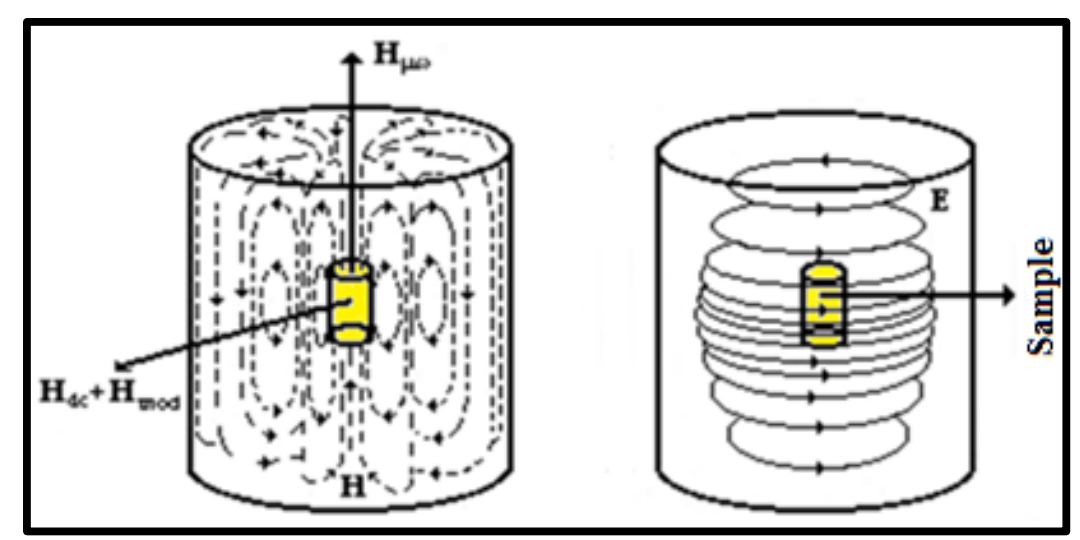

EMR signals can present curves in the Gaussian and Lorentzian form, distinguishable by the shape of the derived line. There is a relation between the spin relaxation time $T_{2}$ and the line shape, like for the half-width $\left(\Delta \mathrm{H}_{1 / 2}\right)$, the maximum slope width $\left(\Delta \mathrm{H}_{\mathrm{mslp}}\right)$ and the average of the second moment $\left(<\Delta \mathrm{H}^{2}>^{1 / 2}\right.$ av $)$, as illustrated in figure 12, each curve shape and the different parameters, as stated in table 2.

Figure 12 - Absorption and the first derivatives of Gaussian and Lorentzian line shapes. The parameters used to differentiate are also highlighted, as the half-width $\Delta H_{1 / 2}$, the maximum slope width $\Delta H_{m s l p}$ and the average of the second moment $\left\langle\Delta H^{2}\right\rangle^{1 / 2}{ }_{v v}{ }^{2}$

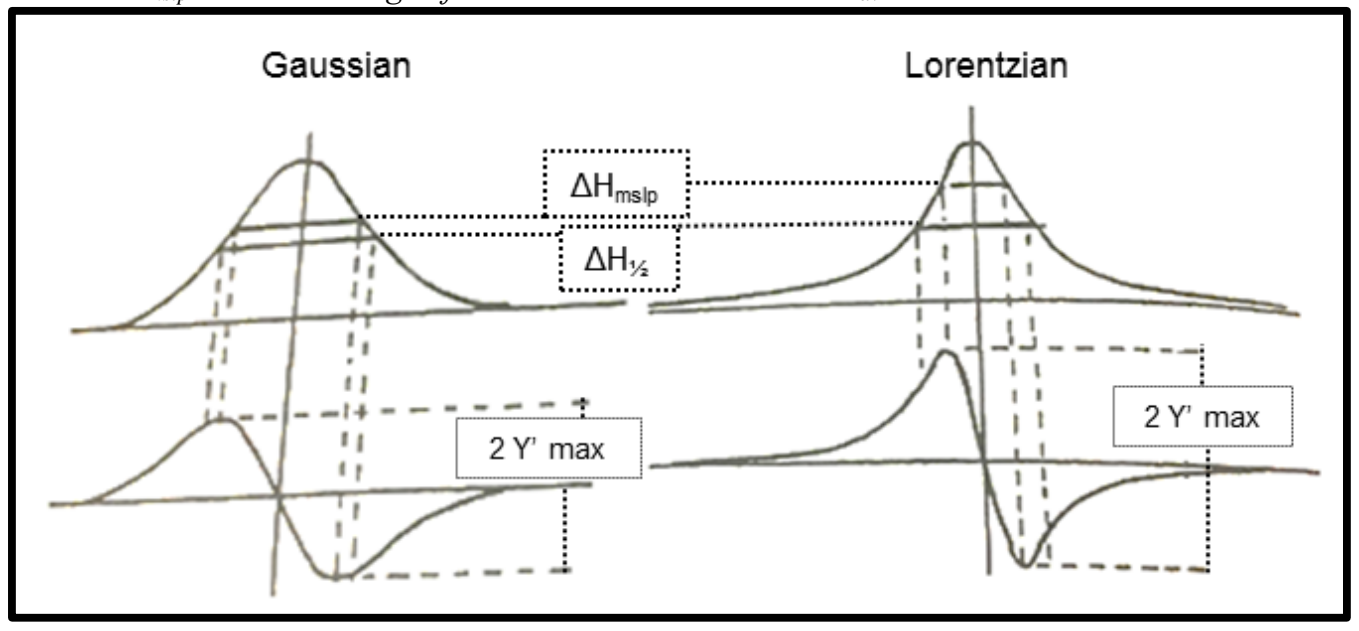


Table 2 - Parameters and values of each EMR spectrum line shape, the illustration of half-width $\Delta H_{1 / 2}$, the maximum slope width $\Delta H_{m s l p}$ and the average of the second moment $\left.<\Delta H^{2}\right\rangle^{1 / 2} a_{v}$ are in figure $12 .^{2}$

\begin{tabular}{cccccc}
\hline Lineshape & $\Delta \mathbf{H}_{1 / 2}$ & $\Delta \mathbf{H}_{\mathrm{mslp}}$ & $\left\langle\Delta \mathbf{H}^{2}\right\rangle^{1 / 2}{ }_{\text {av }}$ & $\frac{\Delta \mathbf{H}_{1 / 2}}{\Delta \mathbf{H}_{\mathrm{mslp}}}$ & $\frac{\Delta \mathbf{H}_{1 / 2}}{\left\langle\Delta \mathbf{H}^{2}\right\rangle_{a}^{1 / 2}}$ \\
\hline Gaussian & $\left(\frac{\ln 2}{\pi}\right)^{1 / 2} \frac{1}{T_{2}}$ & $\frac{1}{\sqrt{2 \pi} T_{2}}$ & $\frac{1}{\sqrt{8 \pi} T_{2}}$ & 1.177 & 2.355 \\
Lorentzian & $\frac{1}{\pi T_{2}}$ & $\frac{1}{\sqrt{3} \pi T_{2}}$ & $\infty$ & 1.732 & 0 \\
\hline
\end{tabular}

The spectroscopic splitting factor is known as $g$ factor, being the responsible for signals in different centers and regions of the magnetic field. Unpaired electrons present small differences for $\mathrm{g}$ factor in different environments. Classical physics attributes this difference to the change of the effective negative charge by the spread of the electron wave function. Indirectly, this change happens through the magnetic interaction between the spin magnetic moment and the orbital magnetic moment (spin-orbit interaction) (Ikeya, 1993).

Consider two electron spins, in different environments, having different $\mathrm{g}$ factors $\left(g_{l}\right.$ and $\left.g_{2}\right)$. As presented in figure 13, different $g$ factors imply different magnetic moment and Zeeman energy, for each spin. As the microwave frequency is the same for both electron spins, the signal of each $\mathrm{g}$ factor will occur in different regions of the magnetic field $\left(\mathrm{H}_{01}\right.$ and $\left.H_{02}\right)$.

Figure 13 - Zeeman energy for two electron spins with different $\mathrm{g}$ factor, as $g_{l}$ and $g_{2}$ (a). The EMR spectrum position is different for each $\mathrm{g}$ factor, so $g_{1}$ will be placed in $H_{01}$ and $g_{2}$ in $H_{02}$, respectively (b).

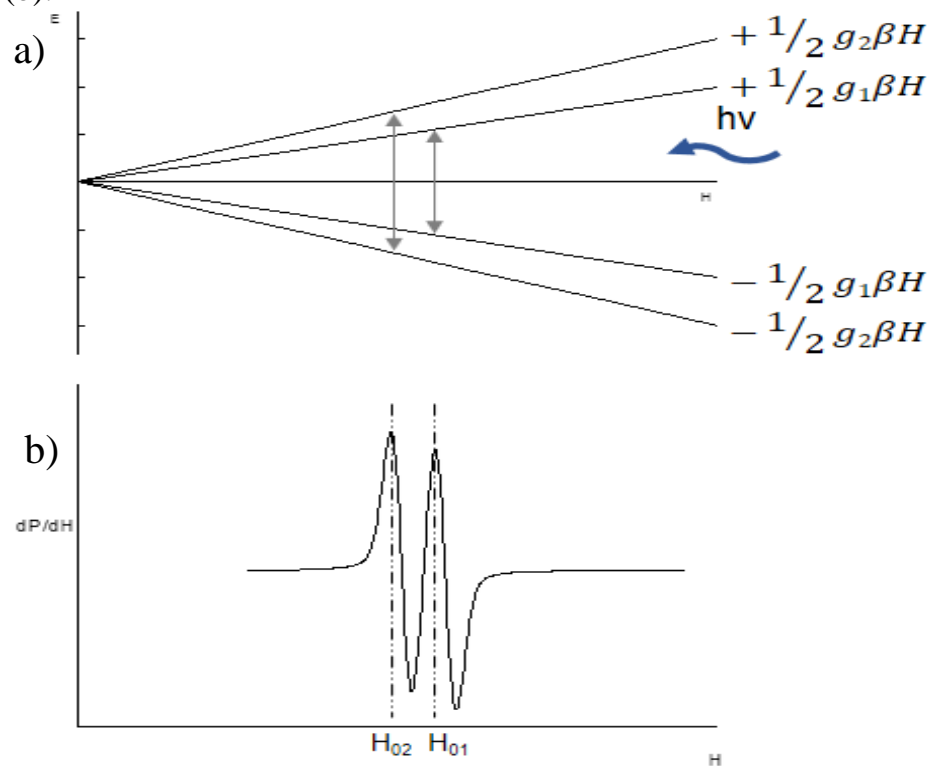


The $\mathrm{g}$ factor is determined by:

$$
g=\left(\frac{h}{\beta}\right)\left(\frac{v}{H}\right)=71.455 \times\left(\frac{v}{H}\right),
$$

with the microwave frequency $v$ in $\mathrm{GHz}$ and $\mathrm{H}$ in $\mathrm{T}$. When studying unknown signals, the $\mathrm{g}$ factor could be determined using a standard signal (e.g. DPPH or $\mathrm{Mn}^{+2}$ ) with known $\mathrm{g}$ factor. If the resonance of the standard sample with $g_{1}$ and the other one with $g_{2}$ happens in $H_{01}$ and $H_{02}$, respectively, the resonance condition is given by:

$$
\begin{aligned}
& g_{1} H_{01}=g_{2} H_{02}=\frac{h v}{\beta} \\
& g_{2}=\frac{g_{1} H_{01}}{H_{02}}=\frac{g_{1} H_{01}}{\left(H_{01}-\Delta H\right)} \mid \Delta H=H_{01}-H_{02} \\
& g_{2}=\frac{g_{1}}{\left(1-\Delta H / H_{01}\right)}
\end{aligned}
$$

The $\mathrm{g}$ factor is approximately equal to 2 . Usually it is determined in the fourth decimal number, with a standard deviation around $0.0002 \sim 0.0005$ (Ikeya, 1993). For a free electron, considering modern physics correction, the $\mathrm{g}$ factor is $g_{e}=2.0023$, and not 2.0000, as stated by classical physics. Thus, a radical with electron excess presents $g$ factor smaller than $g_{e}$, as for a radical with lack of electrons the $\mathrm{g}$ factor is higher than $g_{e}$.

An EMR signal is identified by the $\mathrm{g}$ factor. The variation of values is due to the spinorbit interaction $\left(\widehat{H}_{S O}=\lambda \hat{L} \cdot \hat{S}\right)$. Depending on the physical form presented by the sample, the $g$ factor also varies. For crystalline materials, $g$ can change with the magnetic field direction, because of the crystal symmetry, depending on the angulation and $g$ tensors in each direction, creating a standard deviation when comparing the signal of a same sample read in different angles, being necessary a signal average. For instance, for a solution (liquid sample), because of the free and fast rotation of the radical molecule, the EMR signal is called isotropic; for solid samples, radicals are confined in lattices having their rotation restricted, resulting in an anisotropic signal.

EMR spectrometers are classified depending on the microwave frequency used, differentiated by bands. The bands are denominated by letters, corresponding to a frequency and magnetic field, as presented in table 3. Besides, for each kind of band, the wave guides are also different. 
Table 3 - Different frequency and magnetic field bands that characterize EMR spectrometers, for $\mathrm{g}=2 .{ }^{4}$

\begin{tabular}{cccc}
\hline Band & Bandwidth & $\begin{array}{c}\text { EMR } \\
\text { frequency }(\mathbf{G H z})\end{array}$ & $\begin{array}{c}\text { EMR } \\
\text { magnetic field (mT) }\end{array}$ \\
\hline L & $0.390-1.550$ & 1.5 & 54 \\
S & $1.550-3.900$ & 3.0 & 110 \\
C & $3.900-6.200$ & 6.0 & 220 \\
X & $6.200-10.900$ & 9.5 & 340 \\
K & $10.900-36.000$ & 23 & 820 \\
Q & $36.000-46.000$ & 36 & 1300 \\
V & $46.000-56.000$ & 50 & 1800 \\
W & $56.000-100.000$ & 95 & 3400 \\
\hline
\end{tabular}

\subsection{EMR DOSIMETRY}

Some materials, when exposed to ionizing radiation, present radical formation, consequently, unpaired electrons, which are detectable by EMR spectroscopy. Then, an EMR signal intensity (SIEMR) produced by radiation is proportional to the quantity of absorbed dose $\left(D_{a}\right)$, as described in the equation:

$$
S I_{E M R}=c D_{a}, \text { where } c \text { is a constant. }
$$

Due to noise, impurity or even a background or baseline signal, an experimental EMR signal is composed by different components, as presented in figure 14. Therefore, the relation between $\mathrm{SI}_{\mathrm{EMR}}$ and $\mathrm{D}_{\mathrm{a}}$ could also be described by:

$$
S I_{E M R}=c_{1} D_{a}+c_{2} \text {, where } c_{2} \text { is equivalent to no-dose EMR signal intensity. }
$$

Or even by a polynomial relation, depending on the relation between absorbed dose and EMR signal, being described as:

$$
S I_{E M R}=c_{1} D_{a}^{2}+c_{2} D_{a}+c_{3} \text {, where } c_{3} \text { is equivalent to no-dose EMR signal intensity. }
$$

\footnotetext{
${ }^{4}$ WEIL, J. A.; BOLTON, J. R.; WERTZ, J. E. Electron paramagnetic resonance: elementary theory and practical applications. New York: John Wiley \& sons, 1994.
} 
Figure 14 - Alanine signal and the components that constitute the EMR experimental spectrum; the resulting signal is the combination of the "pure" signal, baseline and noise. ${ }^{5}$

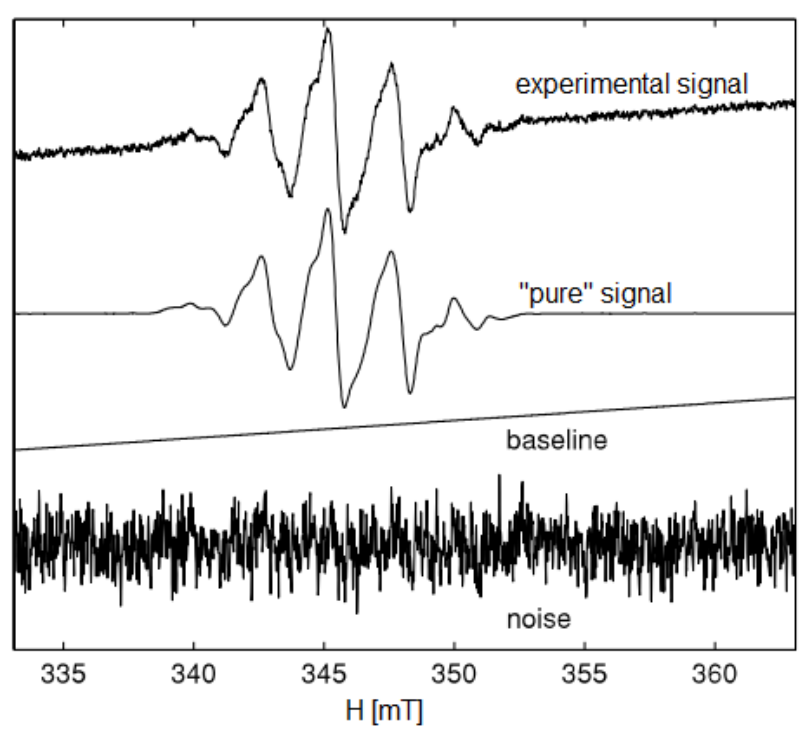

EMR spectroscopy dosimetry can be used for different applications (Regulla, 2000), with the advantage that the data from absorbed dose is not deleted when performed repeated readouts. It can be used for dating purposes (Ikeya, 1994; Jonas, 1997), in nuclear facilities (Romanyukha et al., 1994; Romanyukha et al., 1996), for atomic bomb survivors and environment (Ikeya, Miyajima and Okajima, 1984; Ikeya and Ishii, 1989), food irradiation to kill bacteria (Shukla, 2016; Miyagsusku et al., 2007), quality control of blood irradiation (Chen, Covas and Baffa, 2001), for any nature of radiation accident (Serezhenkov et al., 1992; Rossi et al., 2000; Clairand et al., 2006) and clinical dosimetry (Schauer et al., 2007).

The most known material for EMR dosimetry is alanine, introduced more than thirty years ago (Regulla and Deffner, 1982). Alanine is the popular name of the 2-aminopropanoic acid, an amino acid that composes the proteins of living beings. Its molecule is formed by a carboxylic $(\mathrm{COOH})$, an amino $\left(\mathrm{NH}_{2}\right)$ and a methyl $\left(\mathrm{CH}_{3}\right)$ group with a hydrogen $(\mathrm{H})$ atom, all bonded to a central carbon (C). Originally found in two possible configurations, D- or Lalanine (figure 15), their optical behavior is opposite when under the incidence of a polarized light, behaving differently in the presence of an electromagnetic field, due to the electronic difference of each other. Moreover, alanine can be found as a mixture of D- and L-alanine, in

\footnotetext{
${ }^{5}$ Modified from:

ANTON, M. Uncertainties in alanine/ESR dosimetry at the Physikalisch-Technische Bundesanstalt. Physics in Medicine and Biology, v. 51, p. 5419-5440, 2006.
} 
the form DL-alanine, that can be obtained by two different crystallization processes (Ma et al., 2006; Niederberger and Colfen, 2006; Schwahn et al., 2007).

Figure 15 - Alanine stereoisomers: D-alanine, on the left, and L-alanine, on the right.

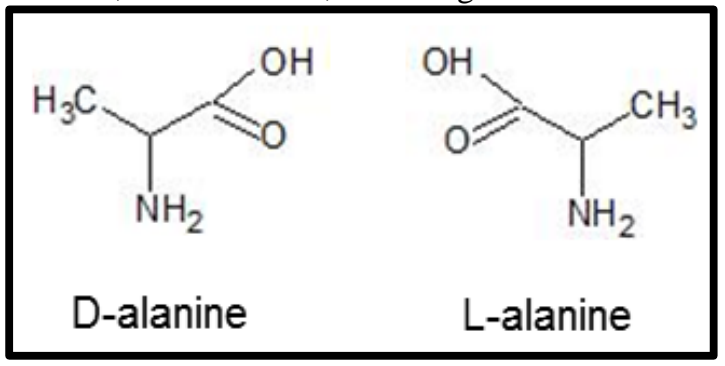

Radiation, as mentioned before, could induce free radicals in alanine. The three most cited ones in the literature (Malinen et al., 2003), called R1, R2 and R3, are presented in figure 16. The bound breaks around the central carbon, creating an unpaired electron. Unpaired electrons give paramagnetic properties to the material, being called paramagnetic radical, detectable by EMR spectroscopy. Alanine also presents equivalent tissue behavior, observed in figure 17, being an important characteristic when aiming clinical applications.

Figure 16 - Different radicals induced in alanine by ionizing radiation, called R1, $\mathrm{R} 2$ and R3. The dots indicate the position of the unpaired electron.

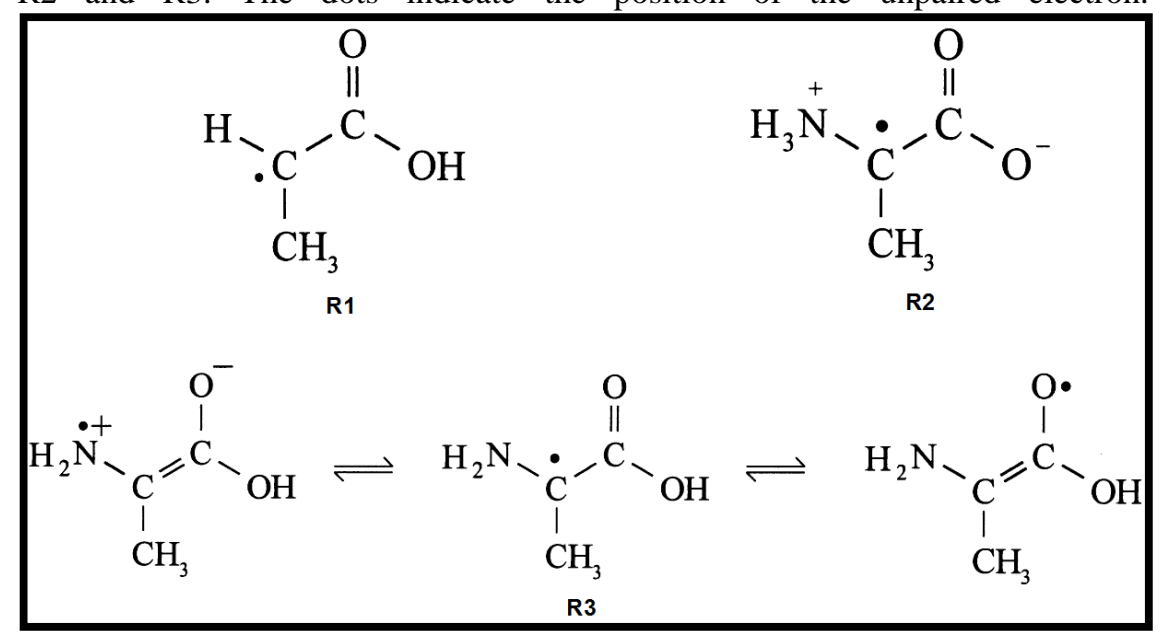


Figure 17 - Comparison between the energy mass atenuation and absorption coefficients of soft tissue and alanine, pointing the tissue-equivalent-behavior. ${ }^{6}$

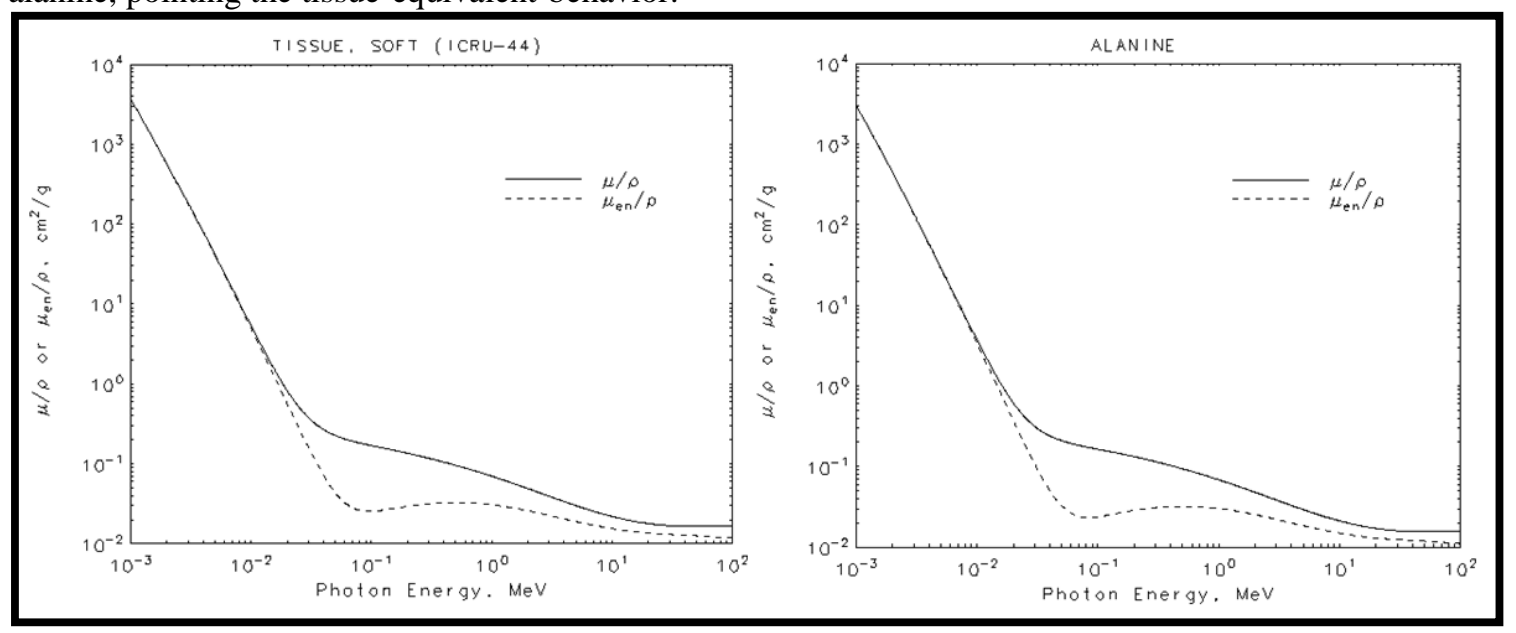

Several papers report the use of alanine in EMR dosimetry, already being proposed as a standard dosimeter for different kinds of beams (Panta, Strzelczak-Burlinska and Tomasinski, 1989; Nichiporov et al., 1995; Mehta and Girzikowsky, 1996). One of the main interests is clinical, so lots of work was already published in medical scenario with alanine (for a recent review see Baffa and Kinoshita, 2014), but to improve the method, new materials started being proposed, aiming higher sensitivity and lower detection limit (Lund et al., 2002; Vestad et al., 2003; Lund et al., 2005; Gancheva, Sagstuen and Yordanov, 2006; Borgonove et al., 2007; Alzimami, Maghraby and Bradley, 2014).

Among the materials investigated, lithium formate $\left(\mathrm{HCO}_{2} \mathrm{Li} \cdot \mathrm{H}_{2} \mathrm{O}\right)$, a salt derived from formic acid, was the one that presented greater potential. One of the advantages is that it presents effective atomic number ( $\mathrm{Z}_{\text {eff }}$ ) close to water (Vestad et al., 2004a), and a single line spectrum, which is less complex than alanine signal, as the models in figure 18. Thus, as alanine was investigated in clinical applications (Chu et al., 1989; Gall et al., 1996; Kuntz et al., 1996; De Angelis et al., 1999; De Angelis et al., 2000; Cieszielski et al., 2003; Schultka et al., 2006; Wagner et al., 2008; Schaeken et al., 2010; Garcia et al., 2011; Wagner, Anton and Vorwerk, 2011; Tanderup et al., 2013; Rech et al., 2014; Alves et al., 2015; BravoMiranda et al., 2015) so was lithium formate (Gustafsson, Lund and Olsson, 2008; Adolfsson et al., 2010; Waldeland et al., 2010a). In general, literature presents investigation with several organic compounds for EMR dosimetry (Hassan, Ikeya and Toyoda, 1998; Olsson et al., 1999; Hassan, Ulusoy and Ikeya, 2000; Gustafsson et al., 2004; Sharaf and Hassan, 2004;

\footnotetext{
${ }^{6}$ SELTZER, S. M.; HUBBELL, J. H. Tables of X-ray attenuation coefficients and mass energy-absorption coefficients from $1 \mathrm{keV}$ to $20 \mathrm{MeV}$ for elements $\mathrm{Z}=1$ to 92 and 48 additional substances of dosimetric interest. NIST Standard Reference Database 126, jul. 2004.
} 
Yurus, Ozbey and Korkmaz, 2004; Danilczuk et al., 2008; Davidson and Jordan, 2009; Popoca and Ureña-Núñez, 2009; Ureña-Núñez and Ballesteros, 2009; Gustafsson, Lund and Lund, 2011; Lelie et al., 2013; Negron-Mendoza et al., 2015; Rushdi et al., 2015; Nor et al., 2016), especially for high dose.

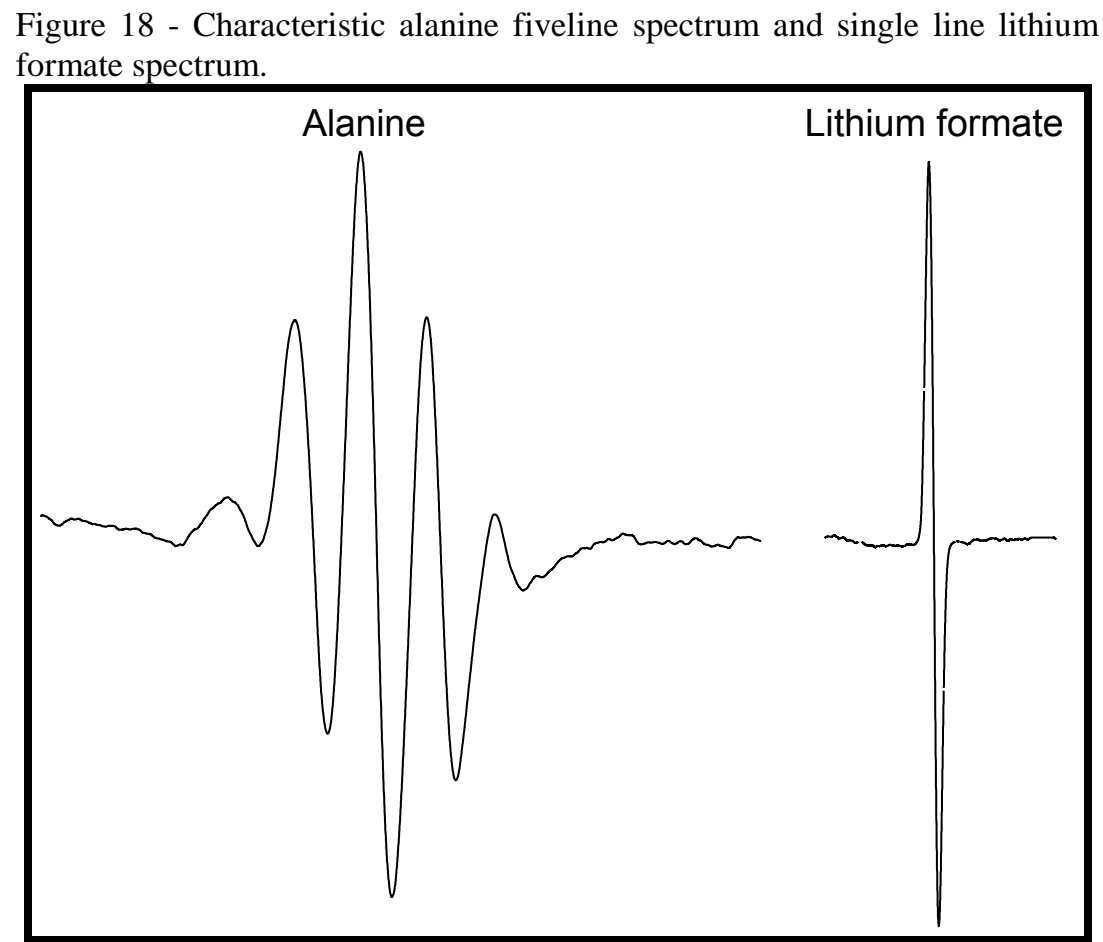

The EMR response is commonly considered the peak-to-peak amplitude of the main line, usually the one with higher amplitude. Figure 19 shows an example of alanine signal, where each peak is numbered and the intensity of the main line is highlighted and called peakto-peak amplitude. This quantity is also related to absorbed dose. Also, other methods can be used as EMR response, such as the sum of peaks or the non-consideration of the main line, but of a different one, in order to improve the sensitivity and find the best balance between standard deviation, signal and absorbed dose (Haskell, Hayes and Kenner, 1998); or the use of double-integrated EMR signal (figure 20), where the area under the resulting curve is related to the quantity of paramagnetic centers created, so it is related to the amount of absorbed dose (Wertz and Bolton, 1972; Ciesielski et al., 2004); or even the use of the second harmonic, presented in figure 8, could be used as a response parameter (Chen, Graeff and Baffa, 2002). 
Figure 19 - Highlight of each alanine peak, determining which one is considered the main line peak (peak-to-peak amplitude), which is known as the EMR response and related to absorbed dose.

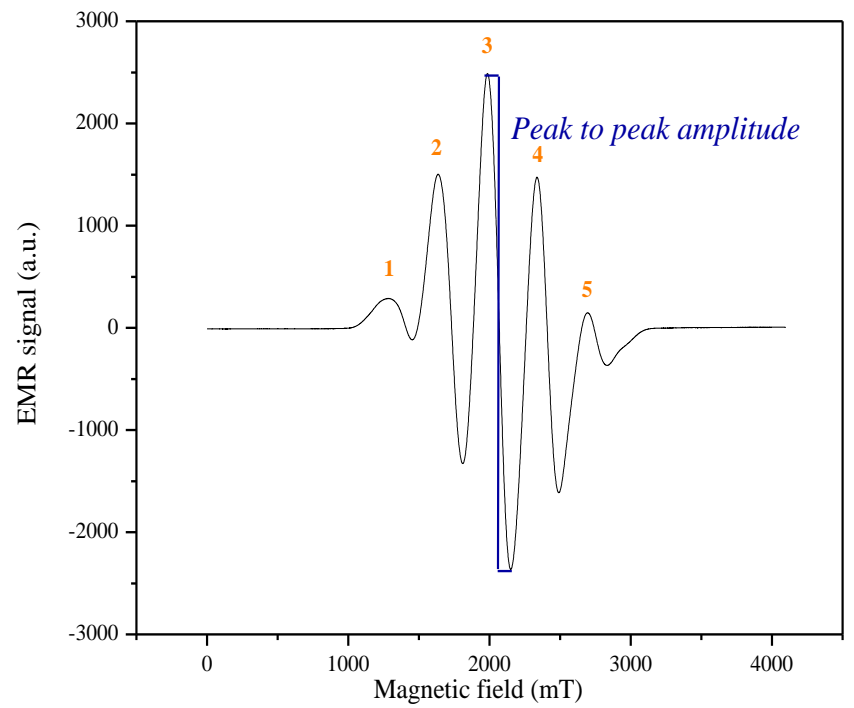

Figure 20 - The black line represents the five line alanine spectrum, the blue one represents the first integration curve and the red one represents the double integrated curve. The area under the double integrated curve is related to the number of paramagnetic centers created and related to the amount of radiation absorbed.

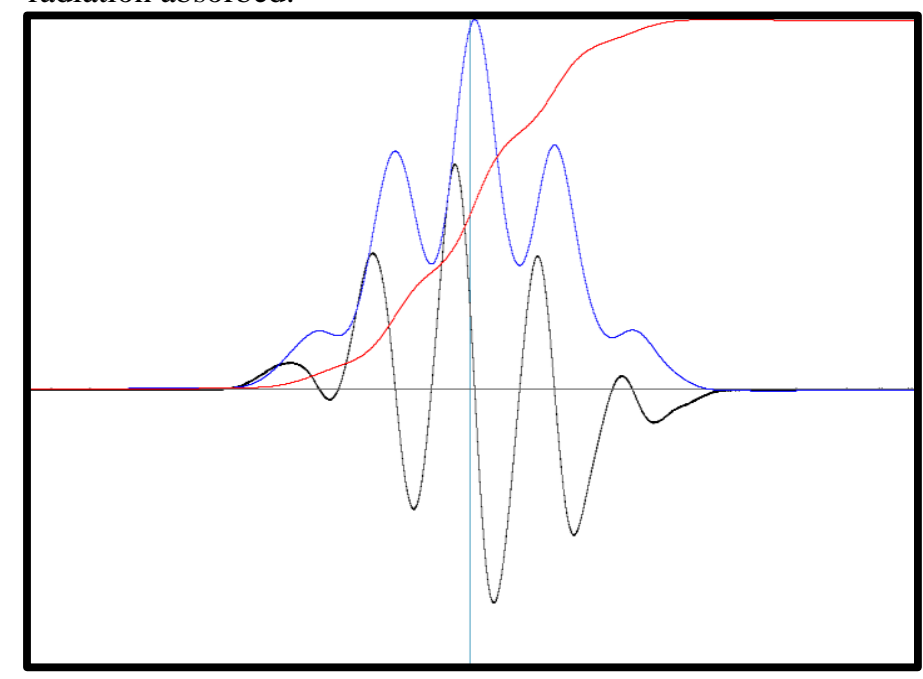




\section{MINIDOSIMETERS FOR SMALL FIELD DOSIMETRY}

Modern radiation therapy uses small field size to deliver dose. A field is considered unconventional when its dimensions are smaller than the lateral range of the secondary electrons and/or the collimator obstructs part of the beam source (Bassinet et al., 2013). In these cases, protocols used for standard radiotherapy fields cannot be used (Alfonso et al., 2008), then this kind of field is considered and called small or non-standard field. The accuracy of treatments based on small or non-standard fields are compromised, presenting challenges and difficulties, already published in the literature (Duggan and Coffey II, 1998; Alfonso et al., 2008; Das, Ding and Ahnesjö, 2008; Wuerfel, 2013; Abdul-Hadi et al., 2016; Bagheri et al., 2017). In that scenario, non-standard fields dosimetry became a topic of research recommendation by IAEA (Merwe et al., 2017).

Small fields are used in radiotherapy as small portions in intensity-modulated radiotherapy (IMRT) or as small independent field in stereotactic radiosurgery (SRS), with equipment as Cyberknife ${ }^{\circledR}$ and TomoTherapy ${ }^{\circledR}$ (Bagheri et al., 2017) or others forms of IMRT as RapidArc ${ }^{\circledR}$ technology (Teoh et al., 2011). Considering SRS, the greatest interest when performing dosimetry is about three quantities: central-axis depth distribution, cross-beam profiles, and output factors (Khan, 2003).

As mentioned in section 2.4, several materials started being studied for EMR dosimetry, and when mentioning clinical applications, the main interest is to find tissueequivalency and good EMR response (Olsson et al., 1999; Hassan, Ulusoy and Ikeya, 2000; Lund et al., 2002; Gustafsson et al., 2004; Sharaf and Hassan, 2004; Hassan and Sharaf, 2005; Lund et al., 2005; Borgonove et al., 2007; Lelie et al., 2013; Alzimami, Maghraby and Bradley, 2014). Also in literature, it is even possible to find studies about adipose tissue equivalent materials (Soliman and Abdel-Fattah, 2012). Among the materials studied, lithium formate and 2-methylalanine presented interesting characteristics, such as sensibility higher than alanine, lower spectral saturation and low energy dependence (Lund et al., 2002; Vestad et al., 2003; Rossi, Chen and Baffa, 2005; Chen, Graeff and Baffa, 2007; Waldeland et al., 2010b; Waldeland, Helt-Hansen and Malinen, 2011). Still, alanine remains as the safest option for clinical verification application, continuing present in recent research publications (Distefano et al., 2017; Wagner, Hermann and Hille, 2017; Wagner et al., 2017; Pavoni et al., 2017). 


\subsection{MINIDOSIMETERS - PELLETS STUDY}

Pellets present isotropic response and are easier to handle than powder samples, as the handling of powder could result in losses; with pellets the conservation of mass is guaranteed. Aiming to improve the EMR technique dosimetry, the interest relies in increasing the minimum detection range with different materials. Therefore, the goal was to manufacture lithium formate and 2-methylalanine pellets with the minimum size and amount of binder, or no binder at all.

\subsubsection{Materials and methods}

Before starting the production of pellets, 2-methylalanine (Sigma-Aldrich) and lithium formate (Alfa Aesar) were tested in comparison with L-alanine (Sigma-Aldrich), DL-alanine (Sigma-Aldrich) and polyvinyl alcohol (PVA) (Sigma-Aldrich), all in their crystalline form. Then, to be produced in the pellet form, alanine and other materials need a binder to aggregate. The initial choice was PVA, as it presented suitable use as a binder (Chen, Graeff and Baffa, 2007; Chen et al., 2010; Vega-Ramirez et al., 2011), and no dosimetric response for low doses (Desrosiers, Puhl and McLaughlin, 1993). Alternative blends were tried, such as stearic acids and even reduced quantities of the already known paraffin (Wieser et al., 1993), but none presented better behavior than PVA, so it was maintained. The pellet composition was 95\% dosimetric material and 5\% binder, which were mixed and then mechanically pressed. To verify the relation between pellet size and EMR signal, pellets with $5 \mathrm{~mm}$ height and variable diameter of 1 and $2 \mathrm{~mm}$ of L-alanine were produced.

The irradiations were performed with a clinical $\mathrm{Co}^{60}$ source with $\gamma$ beams and energy of $1.25 \mathrm{MeV}$, model Theratron 780C from Theratronics; the setup was $80 \mathrm{~cm}$ SSD and buildup region of $0.5 \mathrm{~cm}$ in a $10 \times 10 \mathrm{~cm}^{2}$ field, in accordance with the IAEA protocol (IAEA, 2001), and dose range from 1 to $30 \mathrm{~Gy}$ for the preliminary study and 0.5 to 35 Gy for pellets. The analyses were carried out with an X-band $(9.5 \mathrm{GHz})$ EMR spectrometer from JEOL, model JES-FA200 with a standard TE 011 cavity and modulation frequency of $100 \mathrm{kHz}$. The main EMR parameters are in table 4 for the irradiated materials and in table 5 for pellets, a previous study was conducted for determination of microwave power and modulation amplitude. 
Table 4 - Main EMR parameters used to obtain various doseresponse curves for different materials irradiated with $\mathrm{Co}^{60}$.

\begin{tabular}{cccc}
\cline { 2 - 4 } & $\begin{array}{c}\text { Microwave } \\
\text { power } \\
(\mathbf{m W})\end{array}$ & $\begin{array}{c}\text { Modulation } \\
\text { amplitude } \\
(\mathbf{m T})\end{array}$ & Gain \\
\hline 2-methylalanine & 3.0 & 0.8 & 5,000 \\
DL-alanine & 3.0 & 1.0 & 5,000 \\
L-alanine & 2.5 & 1.0 & 5,000 \\
Lithium formate & 2.5 & 1.0 & 500 \\
PVA & 3.0 & 1.0 & 5,000 \\
\hline
\end{tabular}

Table 5 - EMR readout parameters for L-alanine (95\%) and PVA (5\%) pellets with different diameters.

\begin{tabular}{|c|c|c|}
\hline \multirow[t]{2}{*}{ EMR Parameter } & \multicolumn{2}{|c|}{$\begin{array}{c}\text { L-alanine }(95 \%)+\text { PVA (5\%) } \\
\text { Pellets }\end{array}$} \\
\hline & $1 \mathrm{~mm}$ & $2 \mathrm{~mm}$ \\
\hline Center magnetic field & $335.234 \mathrm{mT}$ & $334.602 \mathrm{mT}$ \\
\hline Microwave power & \multicolumn{2}{|c|}{$2.5 \mathrm{~mW}$} \\
\hline Modulation amplitude & \multicolumn{2}{|c|}{$1.0 \mathrm{mT}$} \\
\hline Sweep width & \multicolumn{2}{|c|}{$15 \mathrm{mT}$} \\
\hline Time constant & \multicolumn{2}{|c|}{$0.3 \mathrm{~s}$} \\
\hline Gain & \multicolumn{2}{|c|}{5000} \\
\hline Sweep time & \multicolumn{2}{|c|}{$1 \mathrm{~min}$} \\
\hline Number of scans & \multicolumn{2}{|c|}{3} \\
\hline Inner diameter quartz tube & $2 \mathrm{~mm}$ & $3 \mathrm{~mm}$ \\
\hline
\end{tabular}

Aiming to increase the amount of sensitive material in the pellet mixture, homogenous blends of 2-methylalanine and PVA in the percentages of 0 to $5 \%$ were produced with $2 \mathrm{~mm}$ diameter and $5 \mathrm{~mm}$ height, testing their physical appearance and compression without defragmentation.

Lithium formate pellets were already reported in literature, standing out because of the non-necessity of binders (Vestad et al., 2004a). A test with pellets of dimensions $9.7 \mathrm{~mm}$ height and $4 \mathrm{~mm}$ diameter was carried out. Irradiation was performed with a $6 \mathrm{MV}$ linear accelerator UNIQUE from Varian, with irradiation setup of $10 \times 10 \mathrm{~cm}^{2}$ field size, $1.5 \mathrm{~cm}$ build-up and $15 \mathrm{~cm}$ of solid water slabs for proper backscattering, in accordance with the code of practice of IAEA (2001), with doses from 0 to 3.5 Gy. Analyses were made with the JEOL $\mathrm{X}$-band EMR spectrometer, proving the concise physical aspect and dosimetric sensitivity

\subsubsection{Results and discussion}

All five materials irradiated presented linear response with absorbed dose. The doseresponse curves are in figure 21 and the equation and correlation coefficient are presented in 
table 6. As expected for a binder (Kojima et al., 1985), PVA presents the lowest response, at least ten times less than DL-alanine, which presented the second lowest response. As expected, L-alanine presented higher sensitivity than DL-alanine, while lithium formate and 2-methylalanine presented the highest responses and sensitivities. Some preliminary studies performed with different energy beams showed that beyond the higher sensitivity, lithium formate also has less energetic dependence than 2-methylalanine, but none of them are considered standard for dosimetry as much as alanine, still considered a reference for EMR dosimetry.

Figure 21 - Normalized dose-response curve of different materials irradiated with a $\mathrm{Co}^{60}$ gamma source with doses from 1 to $30 \mathrm{~Gy}$.

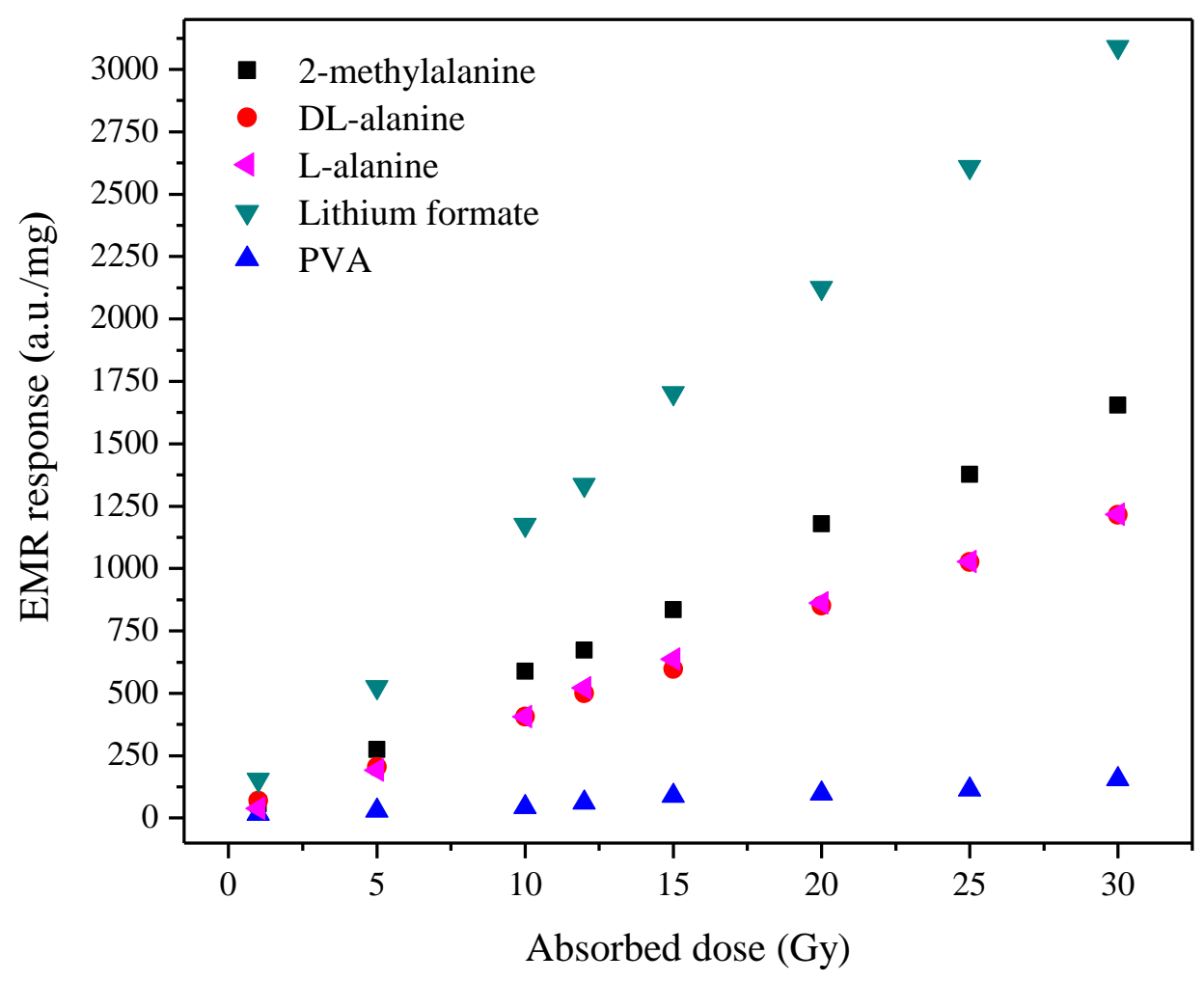

Table 6 - Dose-response curve equation and correlation coefficients $\left(\mathrm{R}^{2}\right)$ for different materials irradiated with a $\mathrm{Co}^{60}$ gamma source.

\begin{tabular}{ccc}
\hline & Equation & $\mathbf{R}^{\mathbf{2}}$ \\
\hline 2-methylalanine & $\mathrm{SI}_{\mathrm{EMR}}=12.23+55.41 \mathrm{D}_{\mathrm{a}}$ & 0.9971 \\
DL-alanine & $\mathrm{SI}_{\mathrm{EMR}}=13.73+40.34 \mathrm{D}_{\mathrm{a}}$ & 0.9978 \\
L-alanine & $\mathrm{SI}_{\mathrm{EMR}}=4.85+41.21 \mathrm{D}_{\mathrm{a}}$ & 0.9970 \\
Lithium formate & $\mathrm{SI}_{\mathrm{EMR}}=92.60+101.50 \mathrm{D}_{\mathrm{a}}$ & 0.9962 \\
PVA & $\mathrm{SI}_{\mathrm{EMR}}=6.91+4.71 \mathrm{D}_{\mathrm{a}}$ & 0.9677 \\
\hline
\end{tabular}


In figure 21 there are no error bars, as the experiment was not reproduced. The idea was to evaluate the response of each material, as a preliminary test. Therefore, the results presented in table 6 are estimated not considering standard deviation from repeatability or reproducibility. The high value of lithium formate linear coefficient agrees with the high noise observed for the no-dose spectrum.

For pellets produced with L-alanine (95\%) and PVA (5\%), the dose-response curves are in figure 22. Both presented linear response with dose, but each presented different dose threshold, which for $1 \mathrm{~mm}$ diameter is $5 \mathrm{~Gy}$ and for $2 \mathrm{~mm}$ is $1 \mathrm{~Gy}$. The error bars are related to the readout repeatability, considering the rotation of the pellet inside the resonant cavity, representing also the anisotropy. As expected, the smaller the pellet, the greater is the standard deviation when repeating the measurement in different angles. Table 7 presents the equation obtained from dose-response curve, adjusted considering the EMR response threshold, and the curve correlation coefficients. The fitting covered only the curve linear region, starting from the detection threshold, determined for each diameter, because of the poor resolution and distinction between signal and noise.

Figure 22 - Dose-response curve of L-alanine (95\%) and PVA (5\%) pellets with 1 and $2 \mathrm{~mm}$ diameter. The error bars correspond to the measured repeatability.

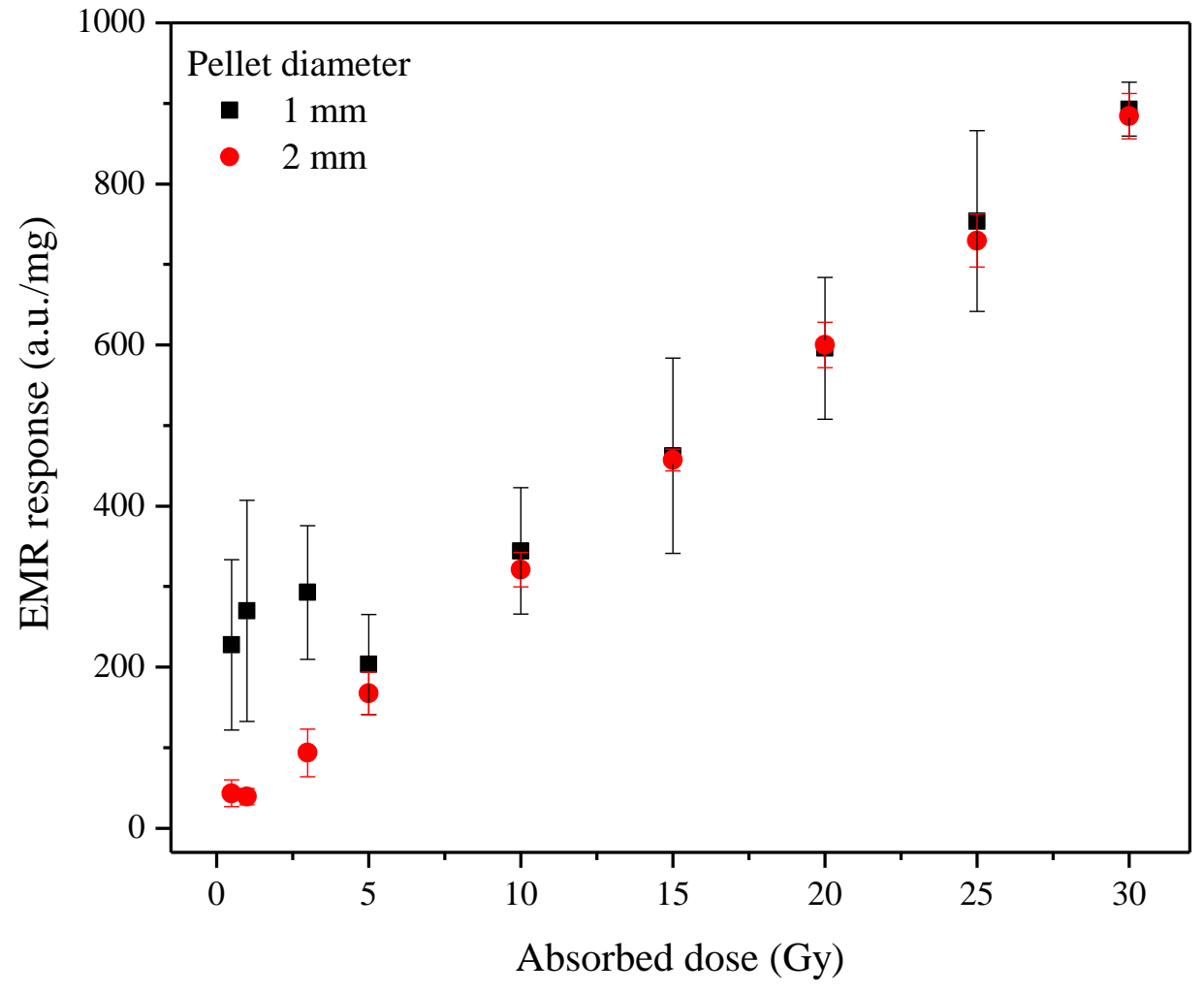


Table 7 - Equation and correlation coefficient of the dose-response curve of L-alanine (95\%) and PVA (5\%) pellets with different diameters.

\begin{tabular}{ccc}
\hline Pellet diameter $(\mathbf{m m})$ & Equation & $\mathbf{R}^{\mathbf{2}}$ \\
\hline $\mathbf{1}$ & $\mathrm{SI}_{\mathrm{EMR}}=61.16+27.70 \mathrm{D}_{\mathrm{a}}$ & 0.9994 \\
$\mathbf{2}$ & $\mathrm{SI}_{\mathrm{EMR}}=21.49+27.98 \mathrm{D}_{\mathrm{a}}$ & 0.9952 \\
\hline
\end{tabular}

Concerning the study to increase the amount of sensitive material in a mixture for the production of pellets with binders, it was observed that with less than $3 \%$ it is not possible to obtain pellet form by physical compression. So, it is viable to increase the mixture to $97 \%$ of sensitive material, but it is still complicated to handle because of material loss, causing the pellet disintegration.

In figure 23 the dose-response curve obtained with binder free lithium formate pellets is presented. The error bars are related to the pellets repeatability/anisotropy readout, as the pellets were analyzed three times with a sample rotation inside the resonant cavity of approximately 120 degrees. If the same gain and optimum parameters were used for EMR readout, the linearity for lithium formate pellets and alanine pellets presented in figure 22 would be equivalent, but the lithium formate dose threshold and sensitivity are remarkably superior, as already stated.

Figure 23 - Dose-response curve of lithium formate pellets irradiated with a 6 MV linear accelerator with doses from 0 to $3.5 \mathrm{~Gy}$. Also in the graphic box, the correlation coefficient, the intercept and the slope of the linear fit proposed for the dose-response curve are presented.

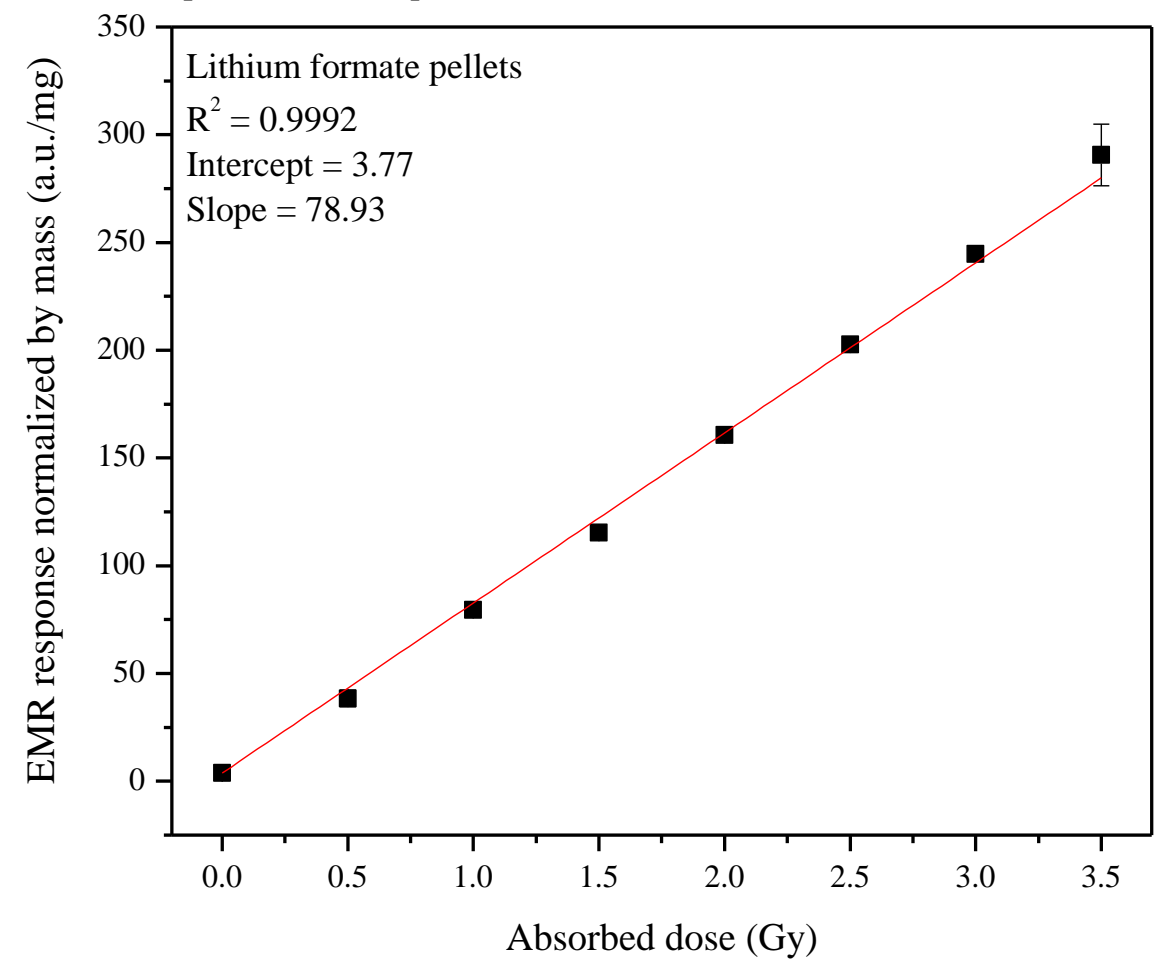


Dosimeters in the form of pellets ensure the uniformity of the sample, and would be the best option in handling. The difficulty relies on finding binders with no response and that can satisfactory aggregate with the highest concentration of sensitive material. Considering this, pure lithium formate pellets presented the best results. The investigation with pellets of smaller dimensions than already presented in the literature were relevant: $3 \mathrm{~mm}$ diameter $x 2$ mm height and doses 1 - 20 Gy (Waldeland et al., 2010a), $4.8 \mathrm{~mm}$ diameter $x 4.5 \mathrm{~mm}$ height and doses 7 - 20 Gy (Adolfsson et al., 2012), $5 \mathrm{~mm}$ diameter $x 2 \mathrm{~mm}$ height and doses 3 - 9 Gy (Malinen et al., 2007), $5 \mathrm{~mm}$ diameter $x 2.5 \mathrm{~mm}$ height and doses 3 - 6 Gy (Waldeland $e t$ al., 2010b), $5 \mathrm{~mm}$ diameter $x 3.5 \pm 0.2 \mathrm{~mm}$ height and doses 0.5 - $2.5 \mathrm{~Gy}$ (Vestad et al., 2004a), especially applied with low doses.

\subsection{EPRESIZE $^{\circledR}$}

To facilitate sample handling, a preliminary system with a surrounding material was previously produced (figure 24), but it presented no suitable result when irradiated with $\mathrm{Co}^{60}$ $\gamma$-rays with doses up to $10 \mathrm{~Gy}$, and analyzed with an X-band spectrometer (figure 25). It was constituted by a polyvinyl chloride (PVC) holder with dimensions of $4 \mathrm{~mm}$ external diameter and $3 \mathrm{~mm}$ inner diameter $x 2 \mathrm{~mm}$ height, filled with alanine (95\%) and PVA (5\%). The blend was necessary to keep the material inside the holder attached, but still losses when handling were perceived.

Figure 24 - Preliminary dosimetric system designed to facilitate the saving of material mass when handling. It was made of a PVC holder on the outside, and EMR sensitive material and binder on the inside; for the test, L-alanine (95\%) and PVA (5\%) were used

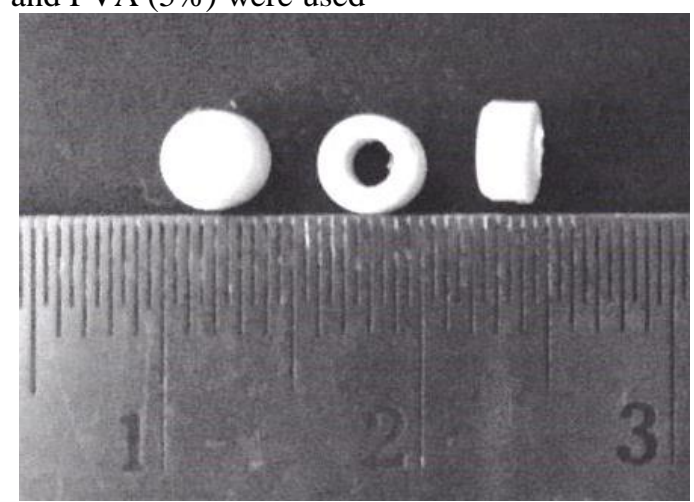


Figure 25 - On the left, EMR signals of: PVC holder filled; PVC holder filled empty; and pure L-alanine with an absorbed dose of $10 \mathrm{~Gy}$. On the right, the dose-response curve obtained for the PVC holder with and without alanine, not considering standard deviation.
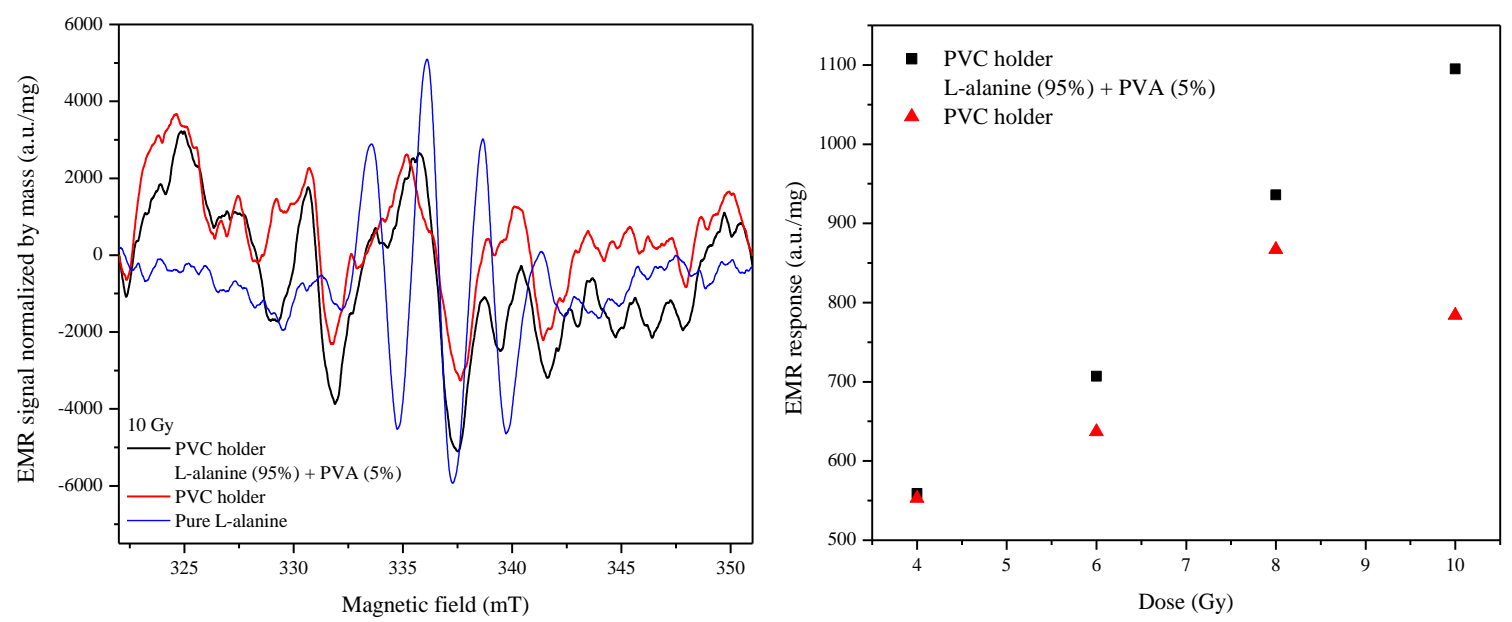

In a partnership with the French organizations CEA and IRSN (IRSN and CEA, 2015), a new concept of minidosimeter for EMR dosimetry is presented, called EPResize ${ }^{\circledR}$. Like the previous system, this prototype is constituted by a holder, produced by injection of polycaprolacton (PCL), and filled by a radio-sensitive EMR material. As presented in figure 26, two types of cap are possible, intending readouts with X- (green cap) and Q-band (red cap) EMR spectrometers. The cap was designed to make the holder waterproof, so it can be put directly in water phantoms.

Figure 26 - EPResize ${ }^{\circledR}$ design. Two types of cap are possible, intending readouts with X- (green) or Q-band (red) EMR spectrometers. Unlike the cap, the holders are the same inside.

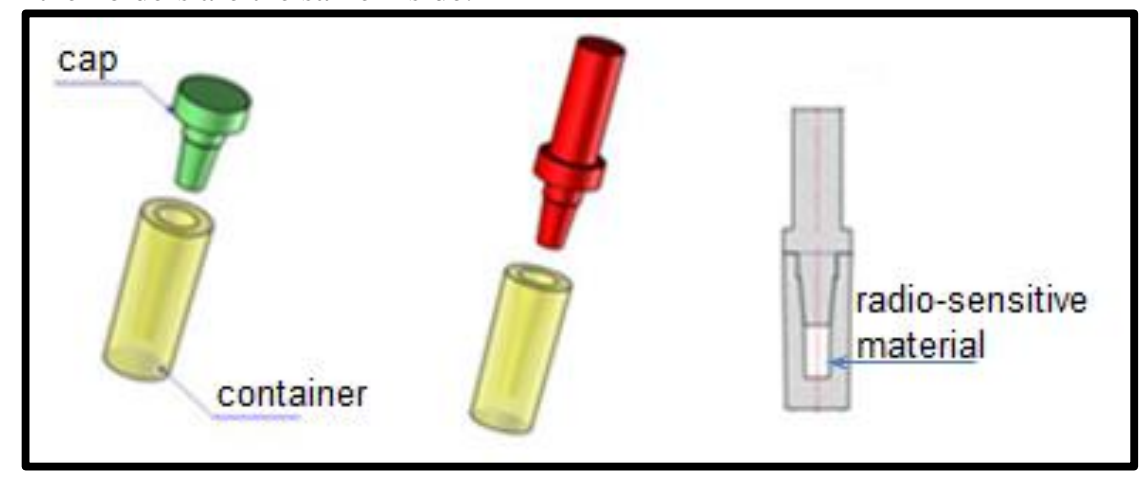

The original radio-sensitive material proposed is alanine, but any material can be used, with no binder needed. The dimensions inside the holder are: $1 \mathrm{~mm}$ diameter and $2 \mathrm{~mm}$ height, enabling approximately $2 \mathrm{mg}$ of radio-sensitive material; the outside has $2.5 \mathrm{~mm}$ 
diameter and $8 \mathrm{~mm}$ height (figure 27). PCL has density close to $1.00 \mathrm{~g} / \mathrm{cm}^{3}$ and does not have endogenous or stable radiation-induced signal overlapping the EMR signal.

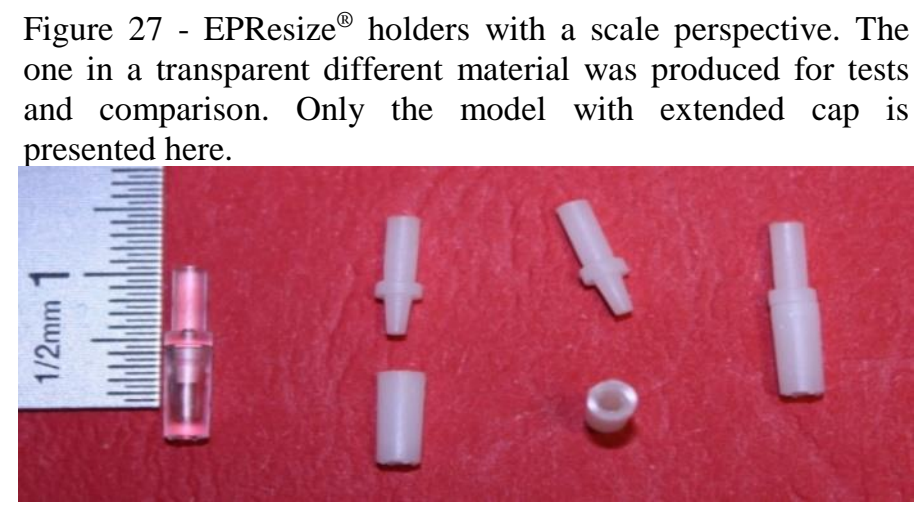

\subsection{1. $X$ - and $Q$-band experimental simulation}

Carrying out measurements with amount of mass around $2 \mathrm{mg}$ could present difficulties for readout with an X-band EMR spectrometer. Thus, previously to EPResize ${ }^{\circledR}$ filling and irradiation, the spectrometer's capacity to detect this amount of mass precisely was tested.

\subsubsection{Materials and methods}

Crystalline L-alanine (Sigma-Aldrich) was irradiated with a 6 MV Primus linear accelerator from Siemens, in a $10 \times 10 \mathrm{~cm}^{2}$ field size, $100 \mathrm{~cm} \mathrm{SSD,} 1.5 \mathrm{~cm}$ build-up and 15 $\mathrm{cm}$ for backscattering, in accordance to standard protocols (IAEA, 2001). The readout was performed with the EMR X-band JEOL spectrometer, and the parameters are presented in table 8 . For readout, the samples were put in a capillary tube with $1 \mathrm{~mm}$ inner diameter and 2 $\mathrm{mm}$ height as to simulate the inside of an EPResize ${ }^{\circledR}$ holder (figure 28). 
Table 8 - Parameters used to the readout of the experimental simulation of EPResize ${ }^{\circledR}$ with an X-band and Q-band EMR spectrometer.

\begin{tabular}{ccc}
\hline & \multicolumn{2}{c}{ L-alanine } \\
EMR Parameter & X-band & Q-band \\
\hline Center magnetic field & $335.403 \mathrm{mT}$ & $1213.6 \mathrm{mT}$ \\
Microwave power & $3 \mathrm{~mW}$ & $1 \mathrm{~mW}$ \\
Modulation amplitude & $1.0 \mathrm{mT}$ & $0.3 \mathrm{mT}$ \\
Sweep width & $10 \mathrm{mT}$ & $20 \mathrm{mT}$ \\
Time constant & $0.3 \mathrm{~s}$ & $10.24 \mathrm{~ms}$ \\
Sweep time & $60 \mathrm{~s}$ & $51 \mathrm{~s}$ \\
Number of scans & 5 & 5 \\
Inner diameter quartz tube & $2 \mathrm{~mm}$ & $2 \mathrm{~mm}$ \\
\hline
\end{tabular}

Figure 28 - Quartz tube used to EMR spectrometry readout, with a capillary tube filled with L-alanine as sample.

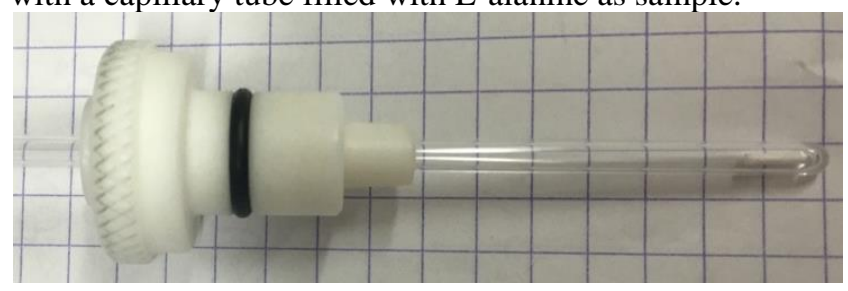

As for Q-band, crystalline L-alanine was irradiated with a $\mathrm{Co}^{60} \gamma$ source with doses up to $20 \mathrm{~Gy}$, considering dose in air. The analyses were carried out with a Bruker EMX plus, equipped with a premium Q-band bridge. A Suprasil ${ }^{\circledR}$ tube with $1 \mathrm{~mm}$ inner diameter was filled with $\pm 2 \mathrm{mg}$ of L-alanine, also with height similar to EPResize®. The readout parameters are also presented in table 8 .

\subsubsection{Results and discussion}

For X-band measurements, to reduce standard deviation from measurement repeatability, two kinds of peak analysis were performed with the EMR spectrum: the main line peak-to-peak amplitude and the sum of all peaks amplitudes. Figure 29 presents the doseresponse curve developed with the two analyses. Table 9 presents the coefficients of each fitting. The peak-to-peak amplitude method presents more linear behavior and less standard deviation associated to measurement repeatability when performing the measurement after relocating the sample inside the resonant cavity. 
Figure 29 - Dose-response curve for the experimental EPResize ${ }^{\circledR}$ simulation with EMR X-band. The continuous line represents the linear fit of peak-to-peak amplitude response and the dashed line is of the sum of peaks response.

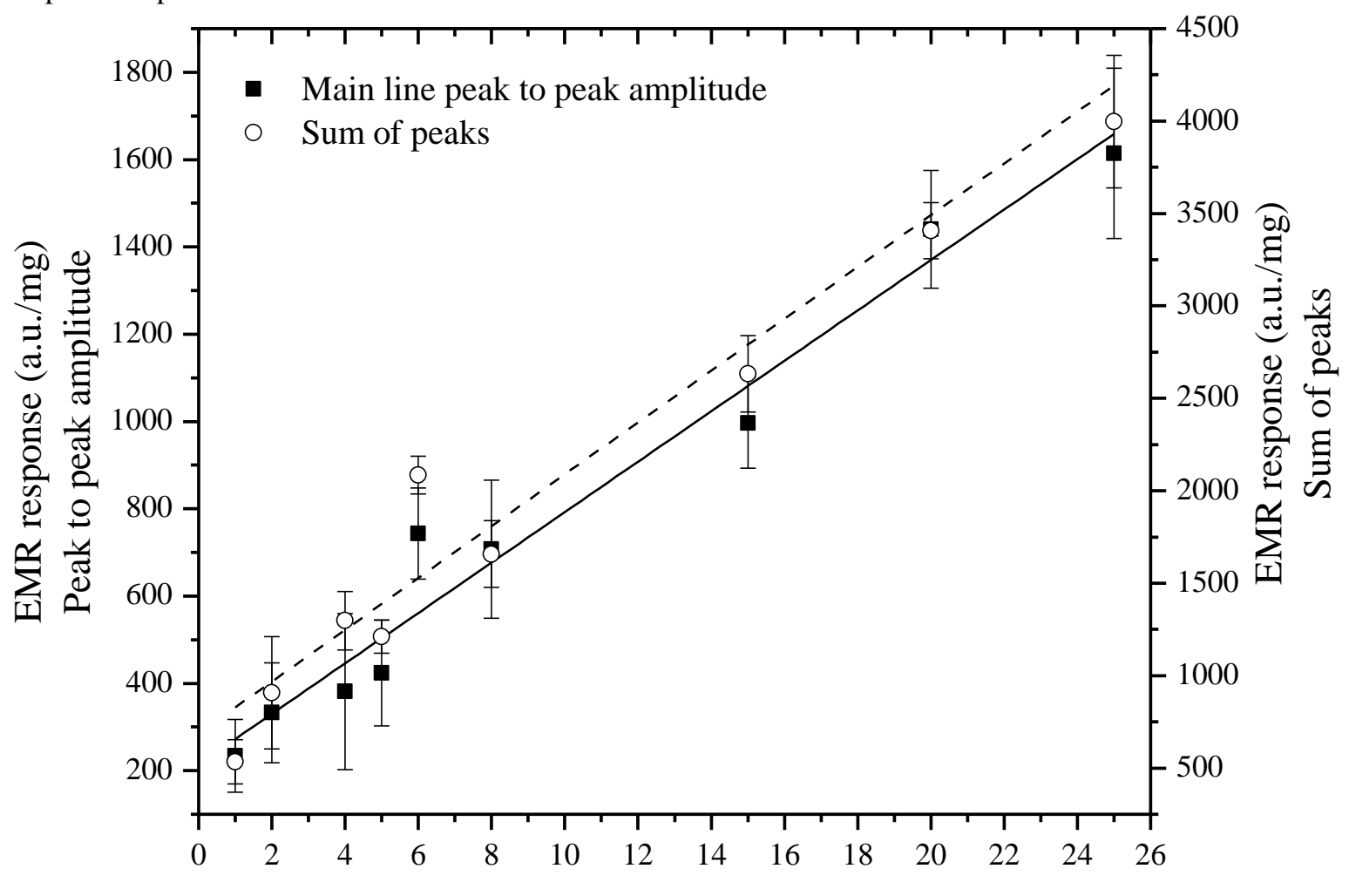

Absorbed dose (Gy)

Table 9 - Dose-response curves and correlation coefficients of the different analyses used to evaluate the EPResize ${ }^{\circledR}$ experimental simulation with X-band EMR spectrometer.

\begin{tabular}{ccc}
\hline EMR response method & Equation & $\mathbf{R}^{2}$ \\
\hline $\begin{array}{c}\text { Main line peak-to-peak } \\
\text { amplitude }\end{array}$ & $\mathrm{SI}_{\mathrm{EMR}}=214.54+57.77 \mathrm{D}_{\mathrm{a}}$ & 0.9493 \\
Sum of peaks amplitude & $\mathrm{SI}_{\mathrm{EMR}}=140.19+687.22 \mathrm{D}_{\mathrm{a}}$ & 0.8578 \\
\hline
\end{tabular}

For Q-band, the dose-response curve is in figure 30, where the equation and correlation coefficient of the linear fitted curve are presented. The response considered only the main line peak-to-peak amplitude, with no mass normalization, as the amount was kept constant. 
Figure 30 - Dose-response curve obtained with Q-band EMR spectrometer for a measurement like the EPResize ${ }^{\circledR}$ experimental simulation performed with X-band.

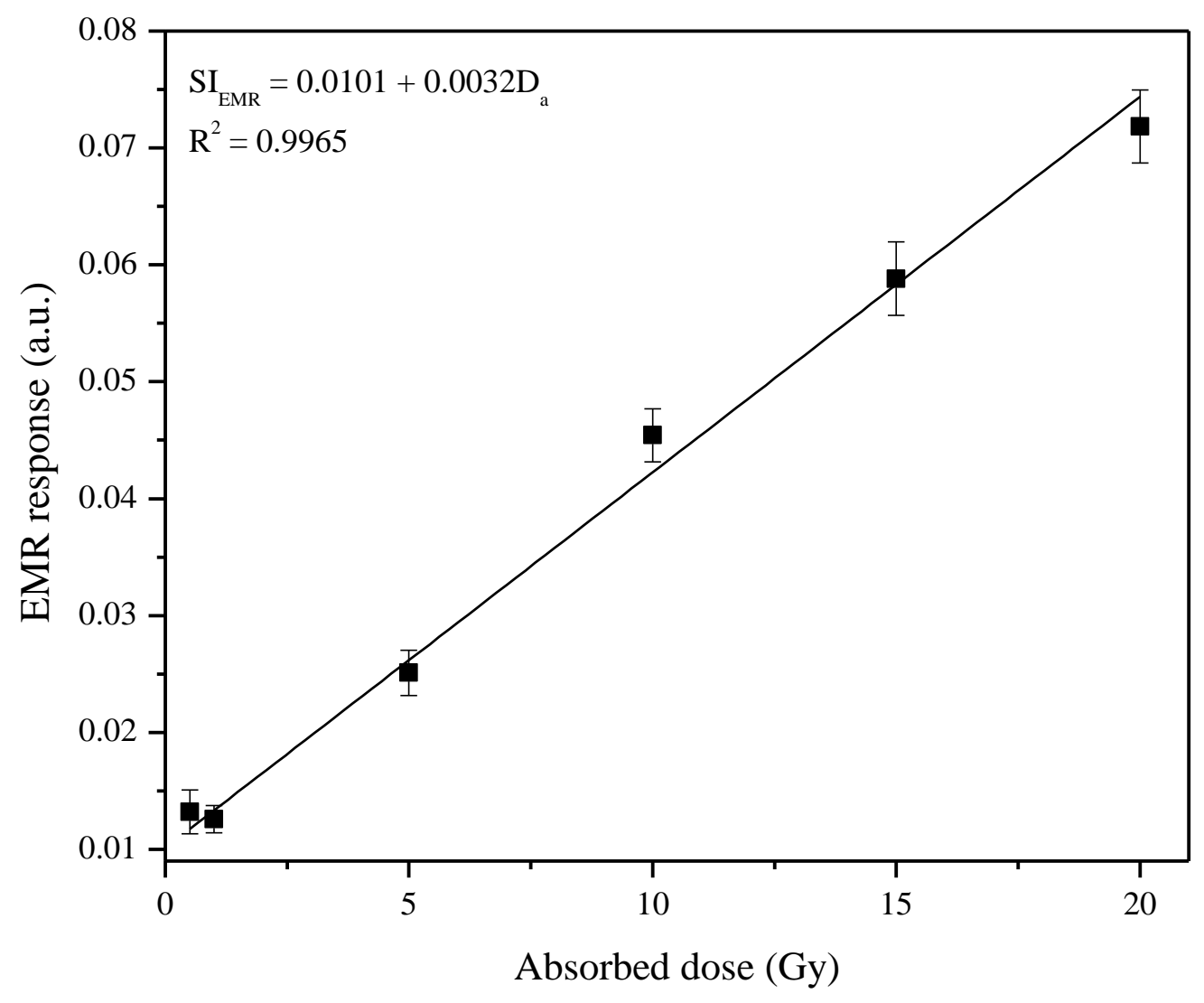

Q-band showed to be more linear than X-band. As the EMR response unit is arbitrary, it is not possible to compare both curve equations, but observing the curve behavior, error bars and literature, Q-band is more sensitive, as also seen for fingernail measurements (Romanyukha et al., 2011). So, with all the adjustments needed to perform the readout, Qband shows to be an interesting option for EPResize ${ }^{\circledR}$ dosimetry. Since the external diameters of the Q-band tube and EPResize ${ }^{\circledast}$ are equivalent, a system to bind the quartz tube and the EPResize $^{\circledR}$ together must be designed to prevent the holder from falling in the resonant cavity.

\subsubsection{Dose-response curve}

As X-band can detect the amount of mass intended, EPResize ${ }^{\circledR}$ holders were filled with L-alanine and lithium formate (separately) to construct a calibration curve, relating EMR response to absorbed dose. 


\subsubsection{Materials and methods}

EPResize $^{\circledR}$ devices filled with alanine and lithium formate were irradiated with a Primus 6 MV linear accelerator from Siemens (figure 31a). The samples were positioned 56.6 $\mathrm{cm}$ from the focus (figure 31b), above the block tray in a field size of $40 \mathrm{x} 40 \mathrm{~cm}^{2}$, with a 2 $\mathrm{cm}$ build-up region. With this setup, less irradiation time was required. Concomitantly, gelatin capsules (figure 31c) with alanine and lithium formate powder were irradiated, also for doseresponse study. Doses were from 5 up to $50 \mathrm{~Gy}$.

Figure 31 - Setup for the irradiation of dose-response study for EPResize ${ }^{\circledR}$ samples; a) Primus linear accelerator from Siemens, in which the samples were positioned close to the focus, b) above the block tray in a field size of $40 \mathrm{~cm} \mathrm{x} 40 \mathrm{~cm}$; c) gelatin capsules filled with powder samples were also irradiated.

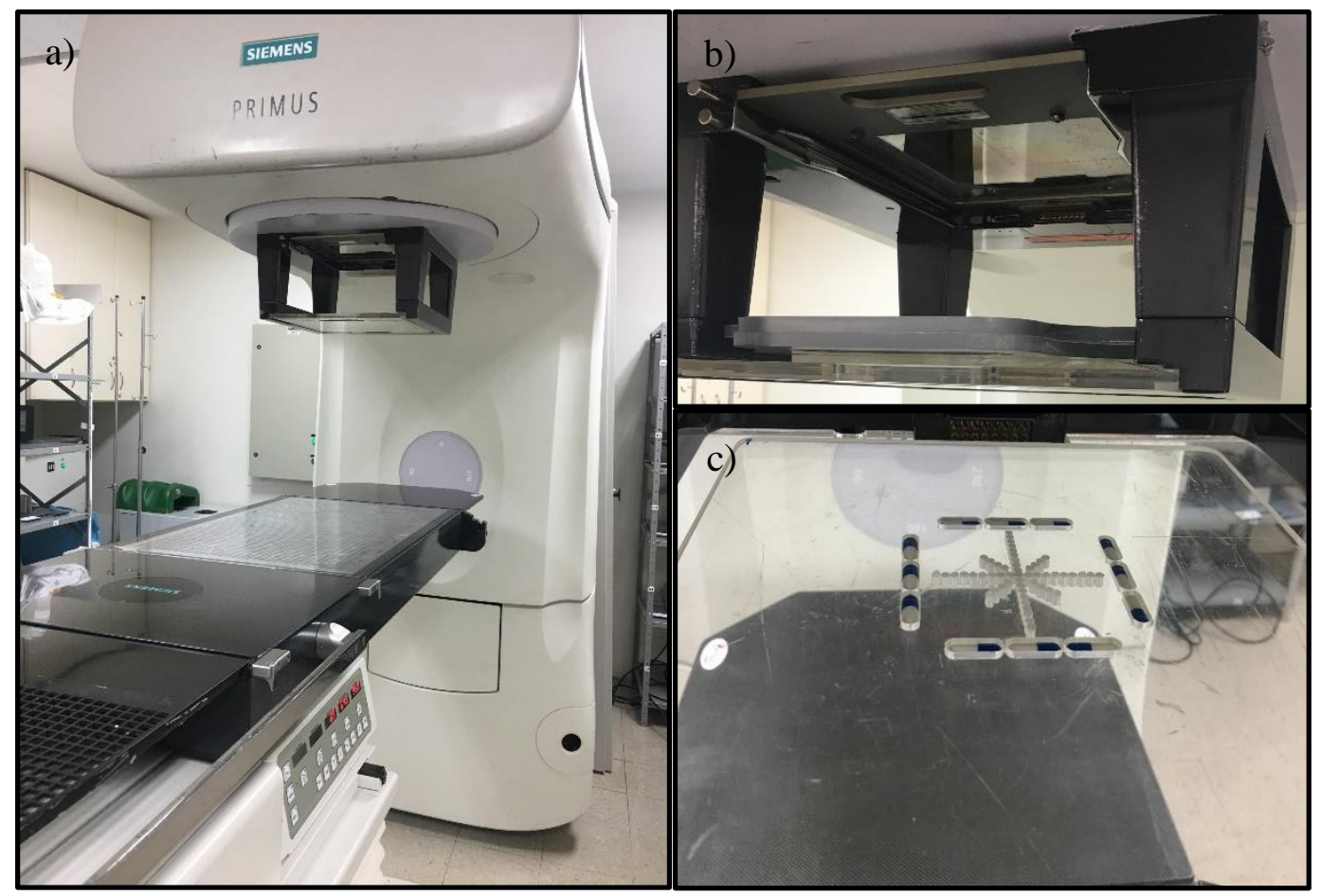

As an alternative setup was proposed for calibration, a dose-rate study for L-alanine and lithium formate powder was also performed. Both materials were irradiated with $5 \mathrm{~Gy}$ in a study varying the monitor reading from 100 to $600 \mathrm{MU} / \mathrm{min}$, with a UNIQUE $6 \mathrm{MV}$ linear accelerator from Varian. The setup was with $10 \times 10 \mathrm{~cm}^{2}$ field size, $1.5 \mathrm{~cm}$ build-up and proper backscattering of $15 \mathrm{~cm}$.

The analyses were carried out with the X-band EMR spectrometer from JEOL, and the parameters were the same for alanine and lithium formate (table 10), as in EPResize ${ }^{\circledR}$ or in the 
powder form irradiated in the gelatin capsule. The EMR response was considered the main line peak-to-peak amplitude.

Table 10 - EMR parameters used for the analysis of EPResize ${ }^{\circledR}$ dose-response and dose-rate study.

\begin{tabular}{|c|c|c|}
\hline EMR Parameter & $\begin{array}{c}\text { EPResize }^{\circledR} \text { and powder } \\
\text { dose-response }\end{array}$ & $\begin{array}{c}\text { Powder } \\
\text { dose-rate }\end{array}$ \\
\hline Center magnetic field & $344.716 \mathrm{mT}$ & $345,000 \mathrm{mT}$ \\
\hline Microwave power & $3 \mathrm{~mW}$ & \\
\hline Modulation amplitude & $1 \mathrm{mT}$ & \\
\hline Sweep width & $10 \mathrm{mT}$ & \\
\hline Time constant & $0.3 \mathrm{~s}$ & \\
\hline Gain & 10,000 & 5,000 \\
\hline Sweep time & $1 \mathrm{~min}$ & \\
\hline Number of scans & 4 & \\
\hline Repetition & 5 & 3 \\
\hline Inner diameter quartz tube & $2 \mathrm{~mm}$ & $3 \mathrm{~mm}$ \\
\hline
\end{tabular}

\subsubsection{Results and discussion}

The curves obtained for L-alanine and lithium formate in EPResize ${ }^{\circledast}$ or powder form are presented in figure 32, with their respective linear fits. Lithium formate presented higher response and resolution, when working with EPResize ${ }^{\circledR}$ system. The comparison between coefficient and linearity are in table 11.

Figure 32 - Dose-response curve and linear fit obtained with the irradiation of EPResize ${ }^{\circledR}$ and crystal powder of L-alanine and lithium formate.

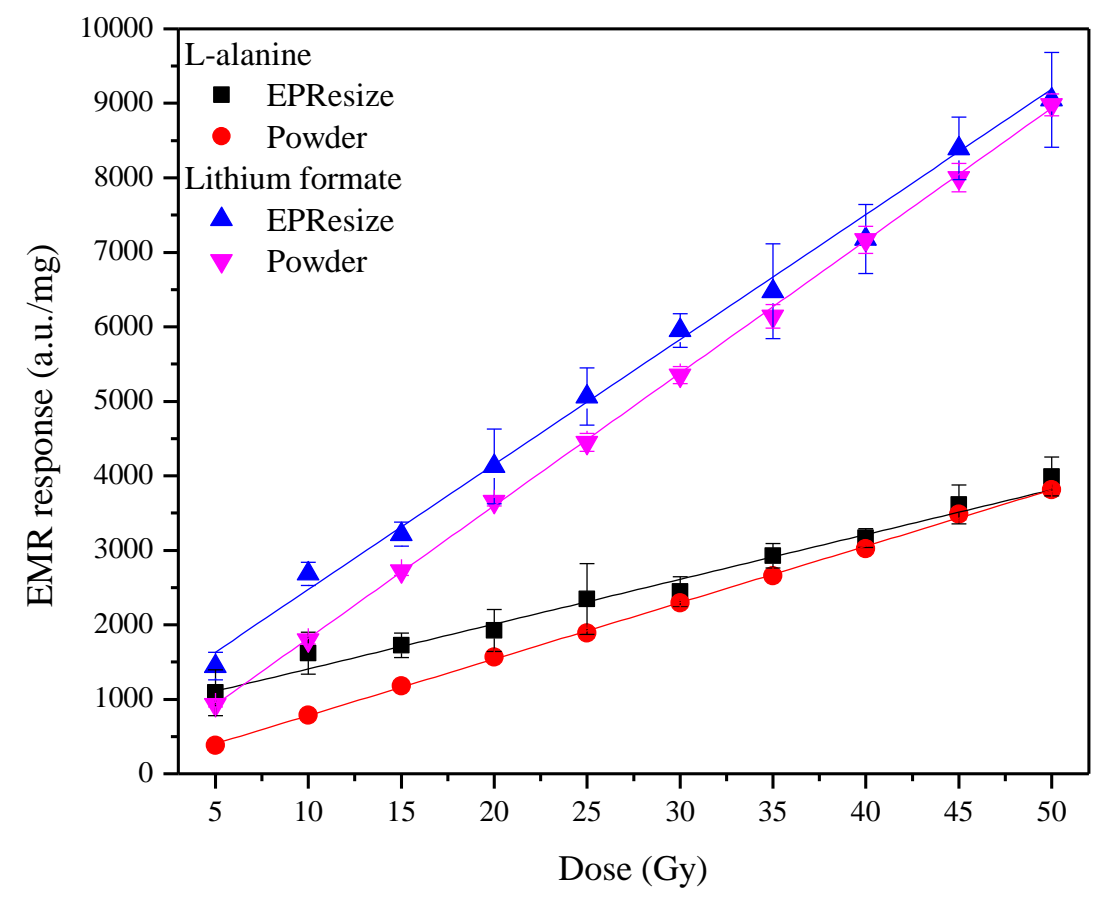


Table 11 - Coefficients from the linear fit of the dose-response curve obtained for EPResize ${ }^{\circledR}$ filled with L-alanine and lithium formate.

\begin{tabular}{ccccc}
\hline \multirow{2}{*}{ Coefficient } & \multicolumn{2}{c}{ L-alanine } & \multicolumn{2}{c}{ Lithium formate } \\
& EPResize $^{\circledR}$ & Powder & EPResize $^{\circledR}$ & Powder \\
\hline Correlation & 0.9827 & 0.9998 & 0.9919 & 0.9997 \\
Linear & 807.3 & 24.5 & 793.8 & 38.4 \\
Angular & 60.1 & 75.8 & 167.9 & 178.0 \\
\hline
\end{tabular}

For the initial doses, EPResize ${ }^{\circledR}$ presented higher EMR response than powder, and as the dose increases the curves tend to meet for each material. As the noise is higher for EPResize ${ }^{\circledR}$ samples, it results in higher response, but related to a high standard deviation (calculated by repeatability); as the dose increases, the noise decreases, resulting in a higher resolution EMR response, coinciding with the powder response. As table 11 presents, the pure powder is more linear and sensitive than the EPResize ${ }^{\circledR}$, which is mostly due to the quantity of mass employed.

Regarding the dose rate study, figure 33 shows the variation presented for L-alanine and lithium formate samples irradiated with the same dose (5 Gy). For lithium formate, the variation was smaller, presenting less than 5\% variation, approximately 3\%; regarding Lalanine, the variation was up to $10 \%$. For comparison, the value with less standard deviation was considered as reference, corresponding to the value obtained for the dose rate of 200 $\mathrm{MU} / \mathrm{min}$. 
Figure 33 - Dose rate study for L-alanine and lithium formate irradiated with $5 \mathrm{~Gy}$. The dotted line for L-alanine corresponds to a $\pm 10 \%$ interval of the mean value and the dotted line for lithium formate to a $\pm 5 \%$ interval, showing that lithium formate has less dependence with dose rate variation. The reference for $100 \%$ consideration was the value for $200 \mathrm{MU} / \mathrm{min}$, as it presented less standard deviation related to repeatability.

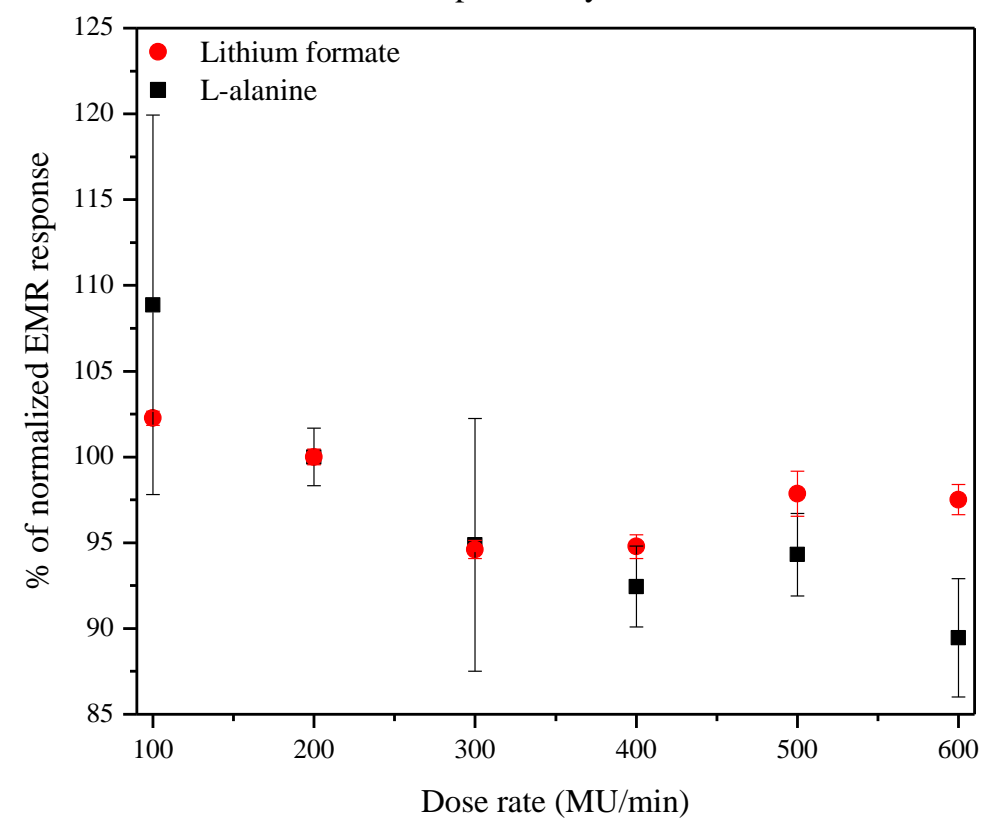

As the calibration was performed in a non-standard setup, the dose-rate study is important to analyze if could be uncertainties caused by the dose deliver rate. As presented above in figure 33, lithium formate present less dependency with dose-rate, but it can influence the EMR response significantly for L-alanine (up to $10 \%$ ).

\subsubsection{Output factor}

Output factors are determined when normalizing the central axis dose in water (maximum dose) from a specific field size to the central axis dose from a $10 \times 10 \mathrm{~cm}^{2}$ field size (Charles et al., 2014). Then, smaller the field, the output factor suffers reduction and affect the uncertainties in dosimetry measurements.

\subsubsection{Materials and methods}

Eight EPResize ${ }^{\circledR}$ dosimeters were irradiated at the Groupe Hospitalier Pitié-Salpêtrière (Paris, France), wherein four of them were filled with alanine powder and the other four with alanine pellets presented by Chen, Graeff and Baffa (2005). A 6 MV clinical linear 
accelerator $2100 \mathrm{C}$ from Varian irradiated all the samples with $40 \mathrm{~Gy}$ in fields of $10 \mathrm{x} 10 \mathrm{~cm}^{2}$ and $6 \times 6 \mathrm{~mm}^{2}$, for output factor measurement, which could be compared with previous results obtained with different detectors using the same machine and setup, presented by Bassinet et al. (2013). The equation used to determine the output factors in non-standard fields related to the EMR response was

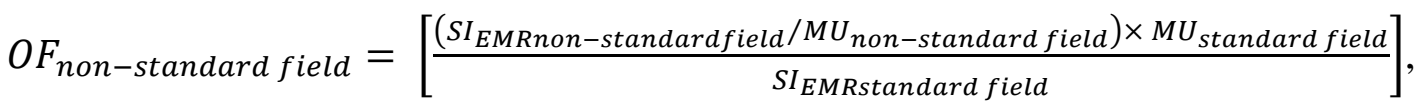

where OF is the output factor of the non-standard field studied, SIEMR is the EMR response obtained when the detector is irradiated with the same dose as for the standard field and in the non-standard field, and MU is the monitor unit used in each field to deliver the intended dose. The same equation was considered for all the output factors determination studied. The reference value (as 1 ) is for a $10 \times 10 \mathrm{~cm}^{2}$ field size.

Also, with an X-ray irradiator from Xstrahl SARRP $220 \mathrm{kV}$ with $33 \mathrm{~cm} \mathrm{SSD} \mathrm{and}$ reference depth of $2 \mathrm{~cm}$ in a $6 \mathrm{~cm}$ solid water phantom, an EPResize ${ }^{\circledR}$ filled with alanine and lithium formate was irradiated to create a dose-response curve with doses from 50 to $150 \mathrm{~Gy}$. For output factor irradiation, five different field sizes were used, and the measurements were compared to an EBT 3 film, performed and analyzed by collaboration with IRSN. All the analyses were made with an X-band EMX Bruker spectrometer and the EMR parameters are presented in table 12 .

Table 12 - EMR parameters readout used for output factor studies

\begin{tabular}{cc}
\hline EMR Parameter & $\begin{array}{c}\text { EPResize }^{\circledR} \\
\text { output factor }\end{array}$ \\
\hline Center magnetic field & $348.477 \mathrm{mT}$ \\
Microwave power & $2 \mathrm{~mW}$ \\
Modulation amplitude & $0.5 \mathrm{mT}$ \\
Sweep width & $15 \mathrm{mT}$ \\
Time constant & $81.92 \mathrm{~ms}$ \\
Gain & $6.32 \times 10^{3}$ \\
Sweep time & $40.96 \mathrm{~s}$ \\
Number of scans & 5 \\
Repetition & 10 \\
Inner diameter quartz tube & $2 \mathrm{~mm}$ \\
\hline
\end{tabular}

\subsubsection{Results and discussion}

The output factor for the EPResize ${ }^{\circledR}$ irradiated at the Groupe Hospitalier PitiéSalpêtrière presented response within the range of the previous results with other detectors, 
presenting agreement with different dosimetric techniques (table 13), showing deviation between the passive detectors [LiF microcube (Bassinet et al., 2010) and EBT2 film (Huet et $a l ., 2012$ )] around $2 \%$ as presented in the literature (Bassinet et al., 2013). The agreement between the EPResize ${ }^{\circledR}$ alanine pellet and the LiF microcube was even smaller $(\sim 0.4 \%)$ than the one presented between the LiF microcube and the EBT2 film $(\sim 0.7 \%)$. The relative standard deviation presented was around 5\% for the dose of $40 \mathrm{~Gy}$. The pellets presented smaller relative standard deviation than the powder. The spatial resolution was in accordance with the suggested in the literature (Duggan and Coffey II, 1998), and the detector was repositioned in the center, as qualitatively shown in figure 34 , when a verifying irradiation was performed with an EBT2 film to ensure centralization.

\begin{tabular}{cc} 
Table 13 - Output factors maeasured with different \\
detectors in a $6 \times 6 \mathrm{~mm}^{2}$ field size, irradiated with a Novalis \\
with jaws size of 8 × $8 \mathrm{~mm}^{2}$ and equipped with microMLC \\
\hline Detector & Output factor \\
\hline EBT2 & 0.585 \\
LiF microtubes & 0.591 \\
EDGE diode & 0.630 \\
PTW 60016 diode & 0.629 \\
PTW 31018 microLion chamber & 0.597 \\
PTW 31014 PinPoint chamber & 0.552 \\
SFD diode & 0.583 \\
EPResize ${ }^{\circledR}$ alanine powder & 0.564 \\
EPResize $^{\circledR}$ pellets & 0.594 \\
\hline
\end{tabular}

Figure 34 - EBT2 film irradiated previously showing the field delimitation and the location of the EPResize ${ }^{\circledR}$, ensuring centralization for the irradiation performed with a $6 \times 6 \mathrm{~mm}^{2}$ field for output factor determination.

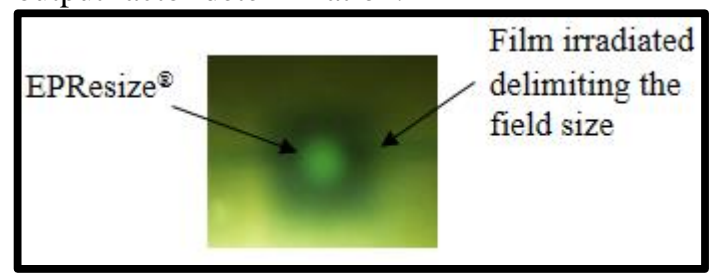

The dose-response curves obtained with the $220 \mathrm{kV} \mathrm{X}$-ray for alanine and lithium formate are presented in figure 35, in which both materials presented linear behavior with dose and still a relative standard deviation around 5\%, with lithium formate being more

\footnotetext{
${ }^{7}$ BASSINET, C. et al. Small fields output factors measurements and correction factors determined for several detectors for a CyberKnife ${ }^{\circledR}$ and linear accelerators equipped with microMLC and circular cones. Medical Physics, v. 40, n. 7, p. 71725-13, 2013.
} 
sensitive and with less associated error than L-alanine. The dose-response curves equation and correlation coefficients are presented in table 14, as well as the output factors values in which an open field $(=1)$ was considered as reference. According to literature, a disadvantage of EPResize $^{\circledR}$, for these considerations and within these parameters and procedure adopted, is poor reproducibility ( $\pm 5 \%$ ) (Duggan and Coffey II, 1998).

Figure 35 - EMR dose-response curve of EPResize ${ }^{\circledR}$ filled with L-alanine and lithium formate irradiated with a $220 \mathrm{kV}$ X-ray irradiator.

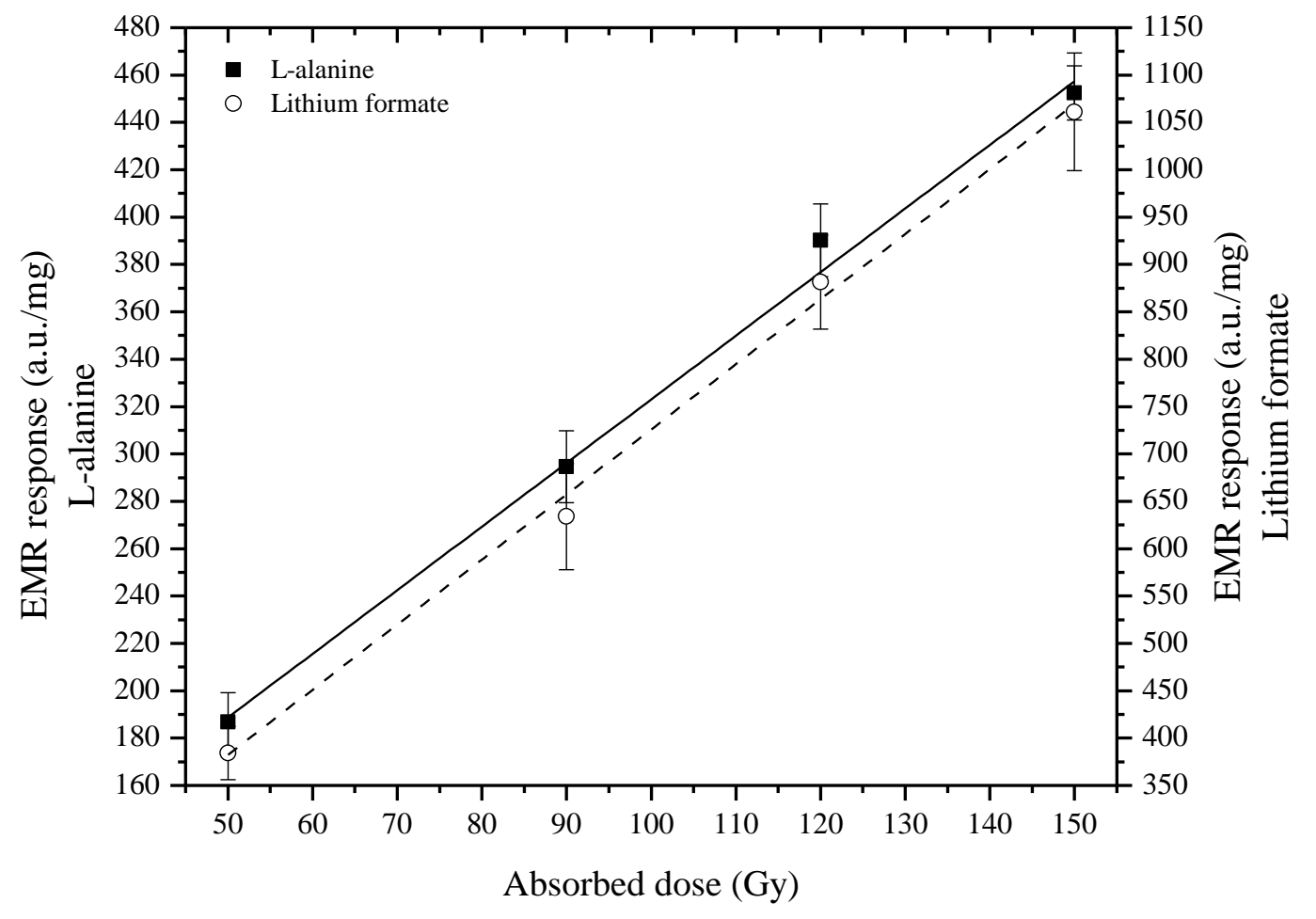


Table 14 - EMR dose-response curve equation and correlation coefficient for an EPResize ${ }^{\circledR}$ filled with L-alanine and lithium formate when irradiated with a $220 \mathrm{kV}$ X-ray irradiator and output factor values for different field sizes. An open field was considered the reference field (value equal to 1$)$, or as the standard field.

EBT 3

EPResize $^{\circledR} \quad$ EPResize $^{\circledR}$
L-alanine
Lithium formate

Equation

$\mathbf{R}^{2}$

Detection limit (Gy)

\begin{tabular}{cc}
\hline \multicolumn{2}{c}{ EMR dose-response curve } \\
\hline $\mathrm{SI}_{\mathrm{EMR}}=54.39+2.69 \mathrm{D}_{\mathrm{a}}$ & $\mathrm{SI}_{\mathrm{EMR}}=38.98+6.89 \mathrm{D}_{\mathrm{a}}$ \\
0.9945 & 0.9966
\end{tabular}

18.80

15.83

\begin{tabular}{clll}
\hline Field size & \multicolumn{3}{c}{ Output factor } \\
\hline $10 \times 10 \mathrm{~mm}^{2}$ & 0.590 & 0.584 & 0.551 \\
$5 \times 5 \mathrm{~mm}^{2}$ & 0.548 & 0.504 & 0.502 \\
$3 \times 3 \mathrm{~mm}^{2}$ & 0.517 & 0.492 & 0.512 \\
$3 \times 9 \mathrm{~mm}^{2}$ & 0.540 & 0.513 & 0.495 \\
$\varnothing 4 \mathrm{~mm}$ & 0.527 & 0.510 & 0.508 \\
\hline
\end{tabular}

The agreement between the three different detectors was around $2 \%$ to $5 \%$. EPResize ${ }^{\circledR}$ showed higher response agreement between each other, around $2 \%$, as the detectors presented in the work reported previously (Bassinet et al., 2013). The deviation between L-alanine EPResize $^{\circledR}$ and EBT3 was around 3\%, and between lithium formate EPResize ${ }^{\circledR}$ and EBT3, it was around $4 \%$. The calculated output factor presented agreement as the field size decreased. Only for EPResize ${ }^{\circledR}$ lithium formate some incoherence was observed, but as the relation is in the order of 2 and $3 \%$, it is not conclusive, as the measurement standard deviation is higher.

\subsubsection{Field profile}

To determine a cross-beam profile, doses are normalized in accordance with the central axis value. AAPM recommends that for the reference plane, the cross-beam profile should not have differences higher than $2 \%$ for each pair of points located symmetrically (Khan, 2003).

\subsubsection{Materials and methods}

EPResize $^{\circledast}$ devices filled with L-alanine and lithium formate were irradiated with a UNIQUE 6 MV clinical linear accelerator for a cross-beam profile study of square fields sizes 
of $1 \times 1 \mathrm{~cm}^{2}, 2 \times 2 \mathrm{~cm}^{2}$ and $3 \times 3 \mathrm{~cm}^{2}$, with $20 \mathrm{~Gy}$ target dose. The detectors were positioned in a $30 \times 30 \mathrm{~cm}^{2}$ square acrylic plate, filling a cross section with dosimeters in $\mathrm{X}$ and $\mathrm{Y}$ planar axis, with build-up of $3 \mathrm{~cm}$ (slabs were missing for proper $5 \mathrm{~cm}$ build-up). The analyses were carried out with the JEOL EMR X-band spectrometer and the parameters are presented in table 15. The results were compared to the treatment planning software field profiles and normalized by the central axis dose (target dose: 100\%).

Table 15 - Parameters used for the EMR readout of EPResize ${ }^{\circledR}$ samples used in the field profile study.

\begin{tabular}{ccc}
\hline EMR Parameter & \multicolumn{2}{c}{$\begin{array}{c}\text { EPResize }^{\circledR} \\
\text { field profile }\end{array}$} \\
& L-alanine & Lithium formate \\
\hline Center magnetic field (mT) & 345.183 & 345.364 \\
Microwave power (mW) & 3 \\
Modulation amplitude (mT) & 1.0 \\
Sweep width (mT) & 10 \\
Time constant (s) & 0.3 \\
Gain & 10,000 \\
Sweep time (min) & 1 \\
Number of scans & 5 \\
Inner diameter quartz tube & 3 \\
\hline
\end{tabular}

3.2.4.2. Results and discussion

The highest difficulty about determining the field profile was the poor precision of the detector. Besides that, the dose profiles for the different field sizes are presented in figure 36 for L-alanine EPResize ${ }^{\circledR}$ and in figure 37 for lithium formate EPResize ${ }^{\circledR}$ detectors. 
Figure 36 - Dose profiles for different field sizes $\left(1 \mathrm{x} 1 \mathrm{~cm}^{2}, 2 \mathrm{x}\right.$ $2 \mathrm{~cm}^{2}$ and $3 \times 3 \mathrm{~cm}^{2}$ ) with the EPResize ${ }^{\circledR}$ detector filled with Lalanine, compared to the treatment planning data.
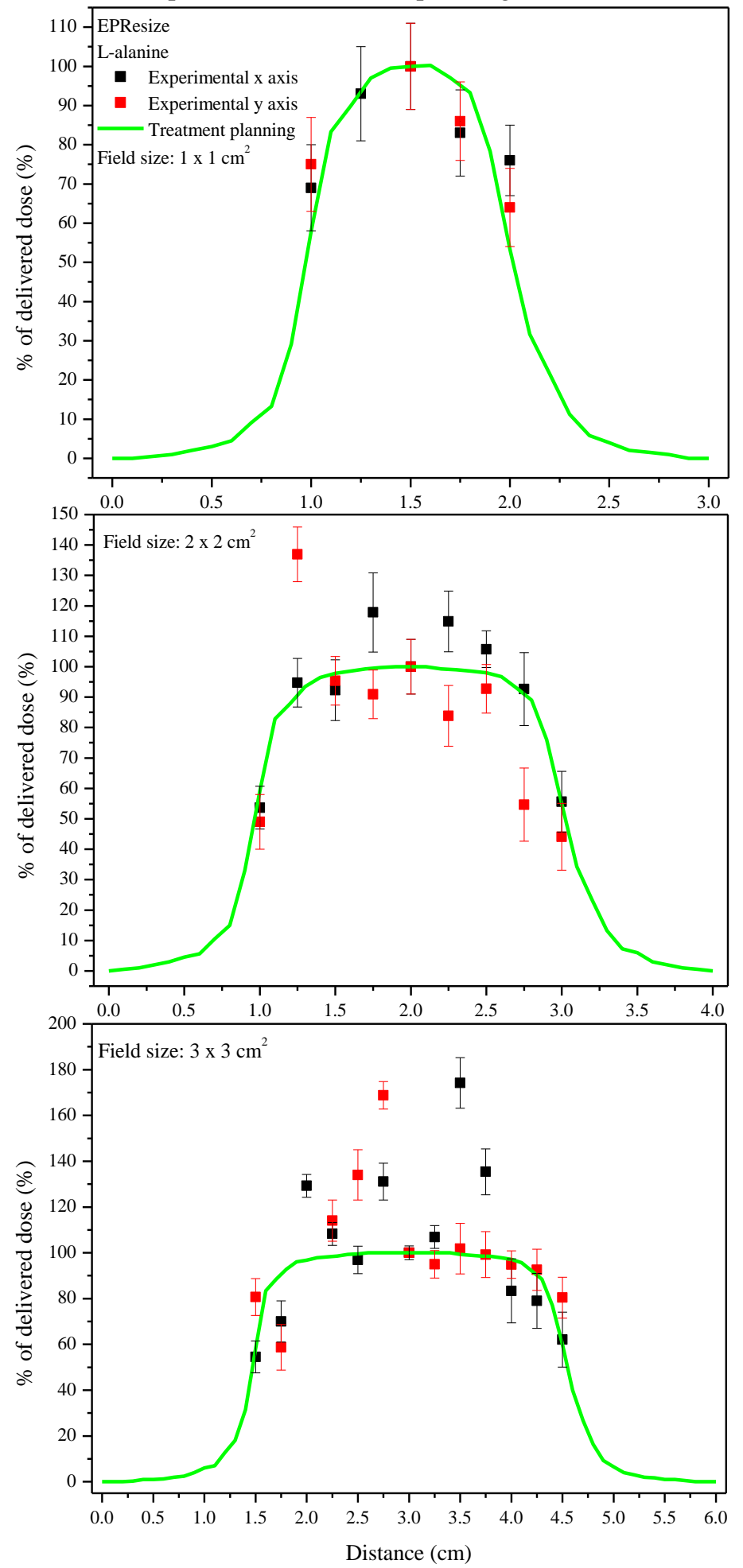
Figure 37 - Dose profiles for different field sizes $\left(1 \mathrm{x} 1 \mathrm{~cm}^{2}, 2 \mathrm{x}\right.$ $2 \mathrm{~cm}^{2}$ and $3 \times 3 \mathrm{~cm}^{2}$ ) with the EPResize ${ }^{\circledR}$ detector filled with lithium formate, compared to the treatment planning data.
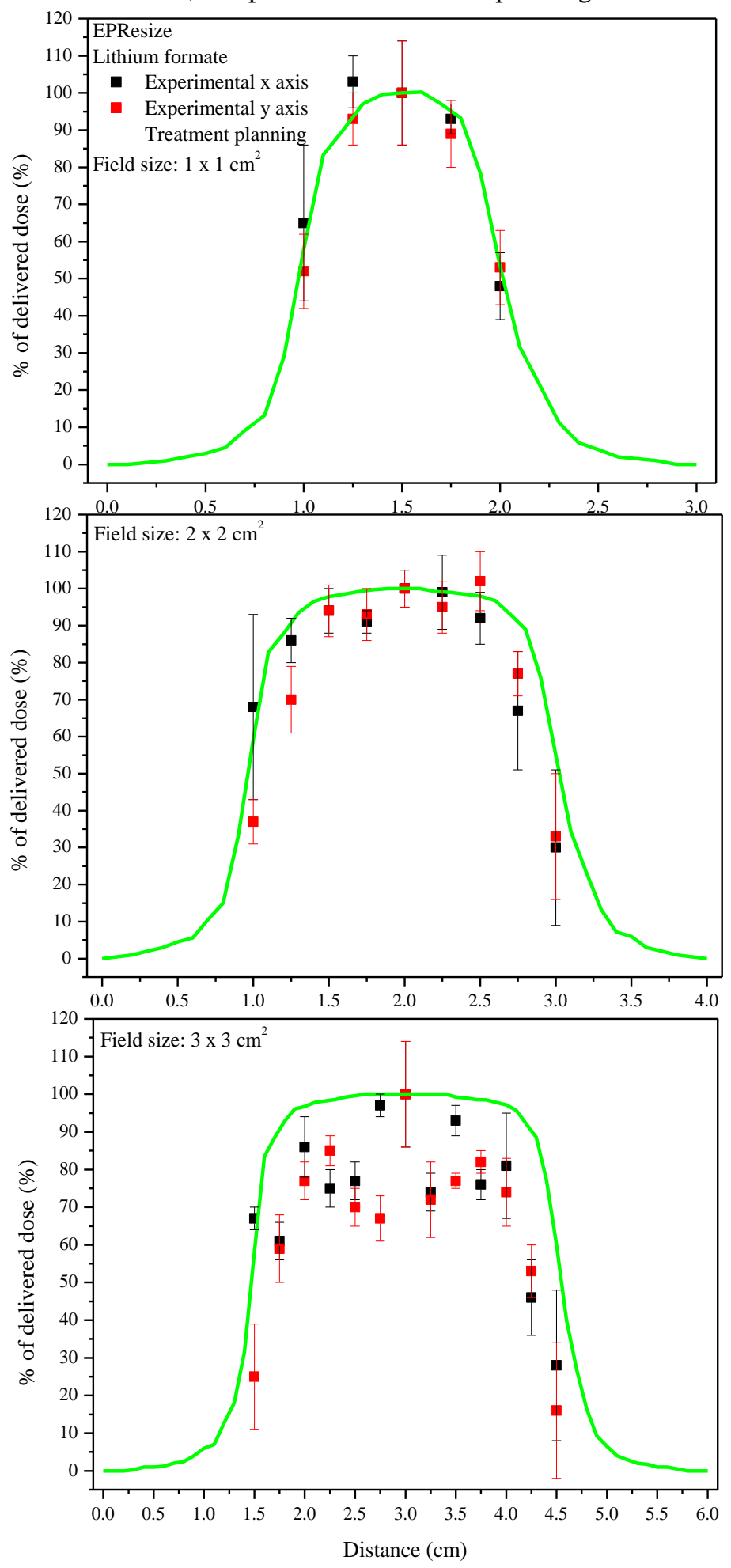

Considering the volume effect, it can be significant if the detector is larger than $1 / 4$ of the lateral field dimension (Wuerfel, 2013). This was not a problem, though, as the EPResize ${ }^{\circledR}$ 
diameter is of $0.25 \mathrm{~cm}$. In figure 38 , the field profile curves and a representation of the EPResize $^{\circledR}$ detector placed in the center of the field are shown.

Figure 38 - Planned dose profile for each field size and a representation of the EPResize $^{\circledR}$ detector volume position in relation to the center of fields.

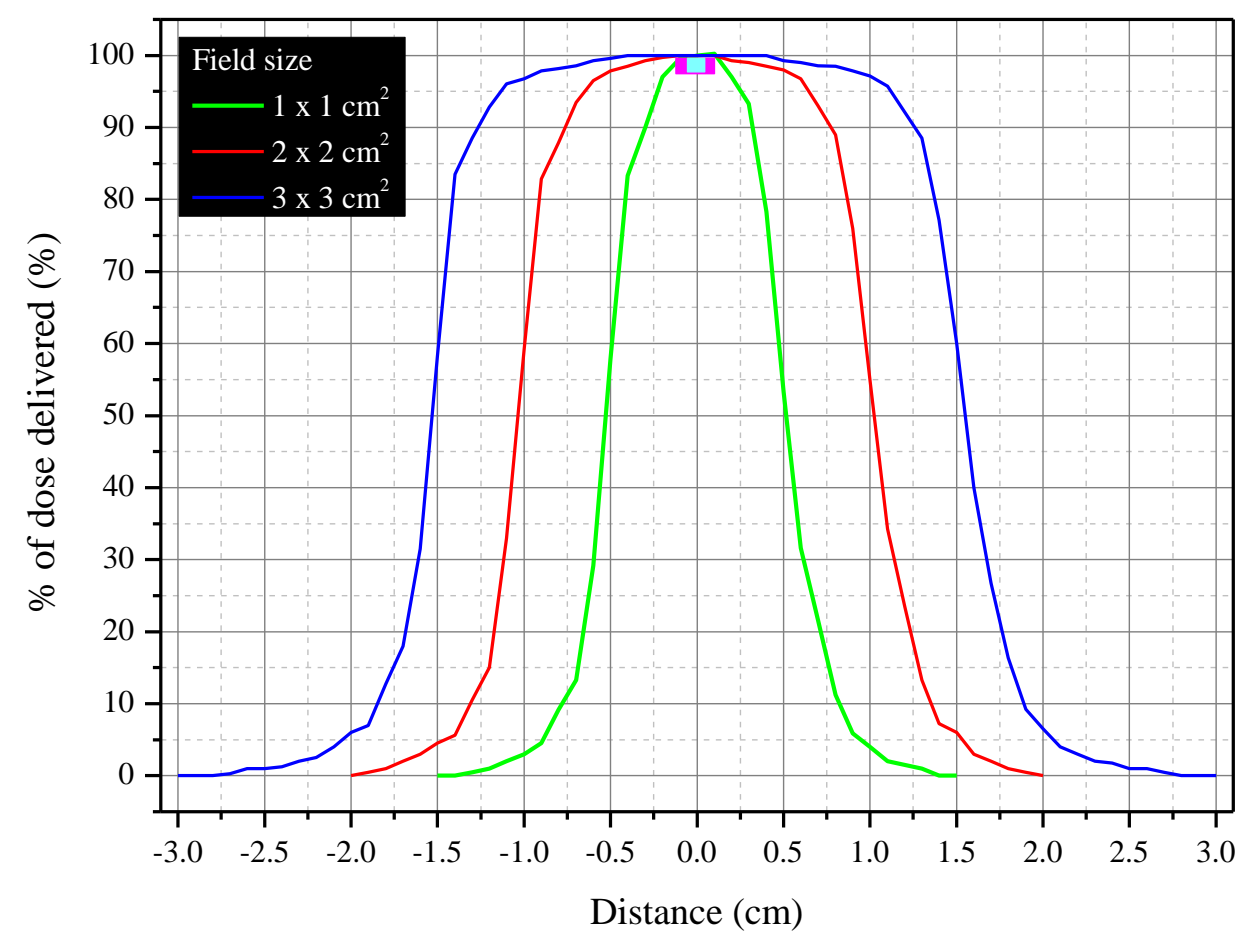

As the dose is averaged over the detector volume, if the variation of dose is high, it will influence the absorbed dose, affecting the readout and the reproducibility of the detector, as the absorbed dose is not homogenous. Therefore, the dose in the center might be underestimated (important to consider for output factors experiments) and the penumbra is blurred (important for field profile experiments). This means that the deviation analysis must consider the volume effect. But, even if EPResize ${ }^{\circledast}$ satisfied this condition, its lack of precise repeatability would compromise the experiment. Without improving the system, it is not possible to precise the dose delivery when calculating output factors and the agreement of symmetric point in field profiles is not in the basis of $2 \%$ (for L-alanine from 6 to $35 \%$ and for lithium formate from 4 to $66 \%$ ).

\subsection{EXPERIMENTAL SIMULATION OF A STEREOTACTIC TREATMENT}

Brain lesions have long been treated with SRS, with machines designed to deliver accurate and precise high doses. Initially each metastasis would be treated separately, with an 
individual isocenter, but with the development of new technologies it is possible to deliver complex dose distribution with a single isocenter (Lau et al., 2014), reducing treatment time. RapidArc $^{\circledR}$ implements the volumetric modulated arc therapy (VMAT), producing highly conformal dose distribution varying the dose rate dynamic and, simultaneously, the gantry speed rotation and the ability of the multileaf collimator (MLC) aperture (Pavoni et al., 2017).

SRS employs the delivery of high doses, implying a margin of error smaller than for conventional radiotherapy, as small inaccuracies in target location can lead to overdosage to the surrounding healthy tissue (Van Esch et al., 2017). Therefore, immobilization, treatment planning and dose delivery must be well established.

Intending to verify the SRS accuracy with VMAT technique, it must include an endto-end audit, with a head phantom corresponding to a real patient (Dimitriadis et al., 2017), with treatment planning and dose delivery dosimetry (Duggan and Coffey II, 1998). To experimentally simulate reality, the use of an anthropomorphic head phantom was suggested (Coffey et al., 1993; Drzymala et al., 1994) with inserts for different kinds of detectors, allowing the reproducibility of a three-dimensional treatment, using standard head frames, fiducial markers and images (Duggan and Coffey II, 1998).

\subsubsection{Materials and methods}

Previous proper calibration was performed with L-alanine powder with doses up to 35 Gy. The samples were irradiated with a UNIQUE $6 \mathrm{MV}$ linear accelerator from Varian, the setup had a $10 \times 10 \mathrm{~cm}^{2}$ field size, a $100 \mathrm{~cm}$ SSD, $1.5 \mathrm{~cm}$ build-up region and $15 \mathrm{~cm}$ slabs for backscattering, following the standard protocol for absorbed dose in water TRS-398 (IAEA, 2001).

The head phantom is composed by different slices, from 1 to 9 , as figure 39 shows. Each slice has holes with nylon, where L-alanine was inserted, in accordance with the scheme presented in figure 40, such that each hole simulated one lesion, as the portrayal of a multiple metastasis, with different volumes, SRS treatment. 
Figure 39 - Anthropomorphic head phantom used to experimentally simulate a stereotactic treatment. On the left: frontal vision; on the right: lateral vision, where the different slices from 1 to 9 can be seen.

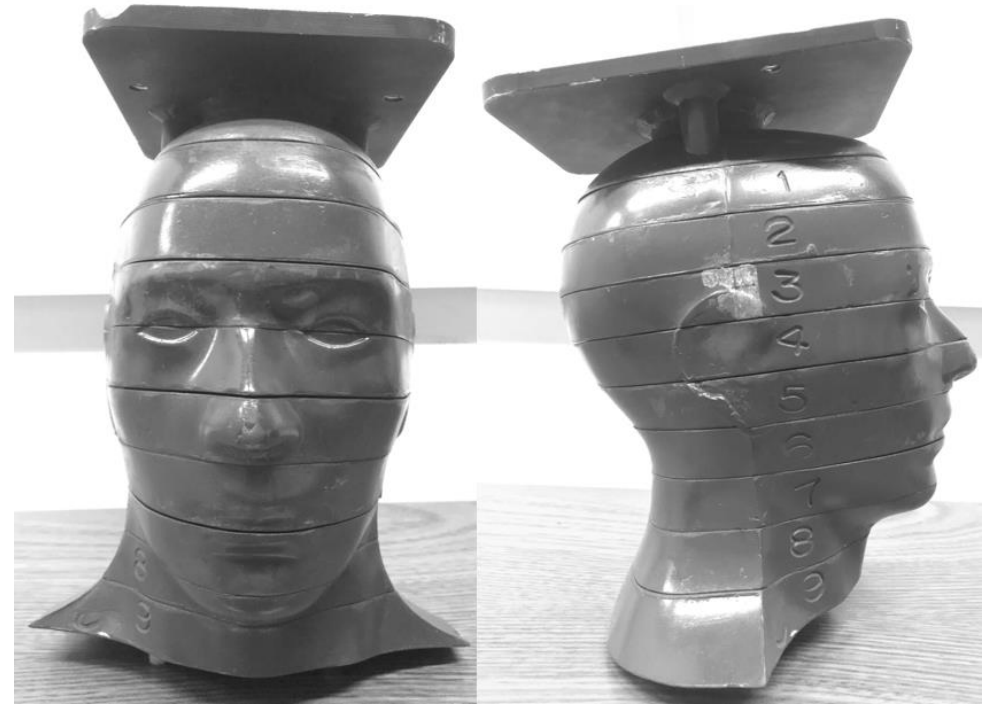

Figure 40 - Anthropomorphic head slices showing the location of the lesions (detectors), characteristic of a multiple lesions SRS treatment. The white points are nylon caps confining the radio-sensitive material L-alanine.

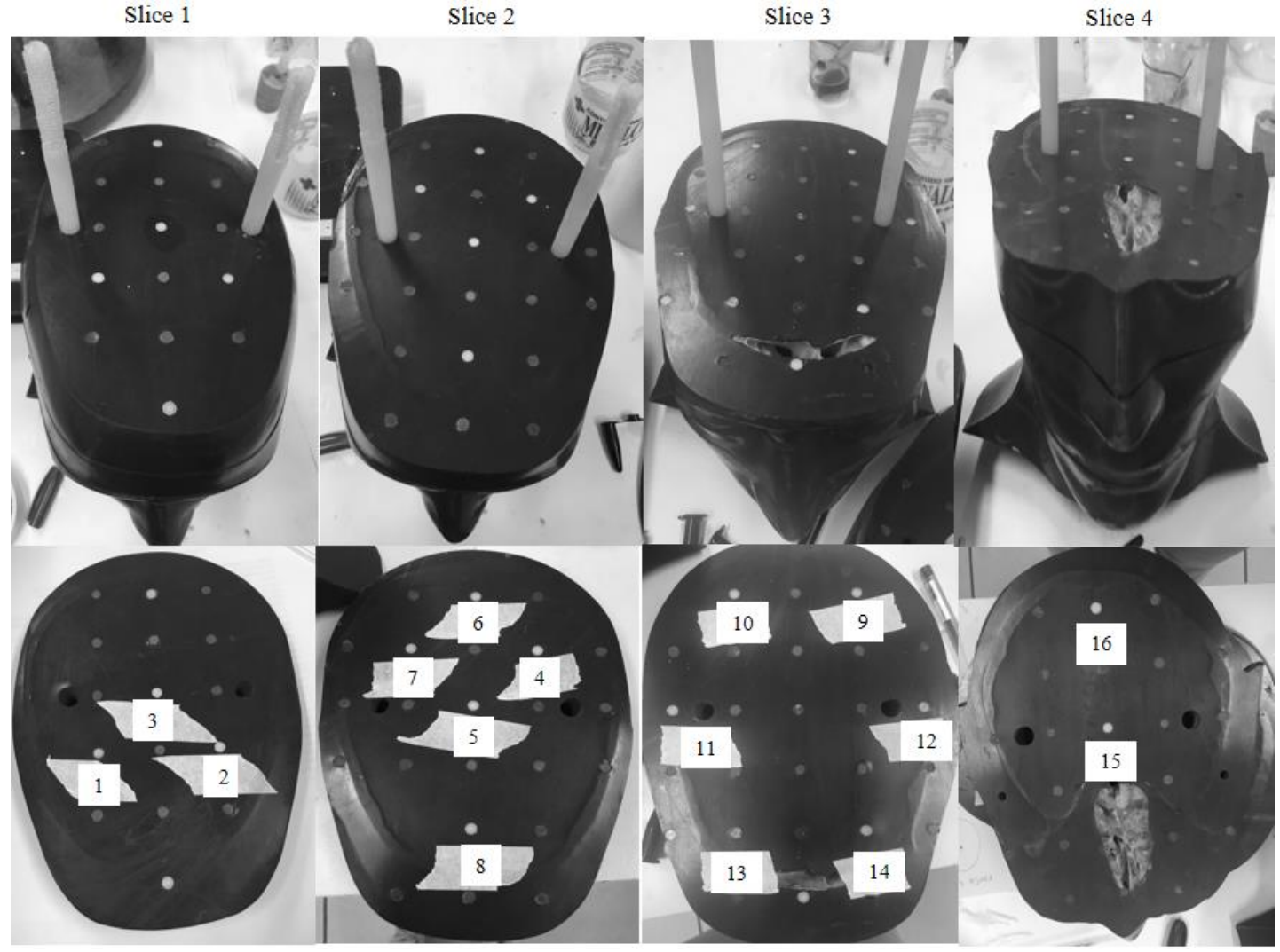

The anthropomorphic head phantom was immobilized with a frameless stereotactic thermoplastic head mask, as to attach the fiducial coordinate system. The setup was scanned 
via computed tomography (CT) and imported to the treatment planning system (TPS) software, where the coordinate system and the lesions were identified.

Thus, the head phantom was irradiated according to a SRS treatment with two complete arcs, as the specifications presented in table 16, with target dose of 20 Gy. The absorbed doses detected were determined in agreement with the previous calibration, and compared to the doses calculated by the treatment plan.

The analyses were carried out with the EMR X-band spectrometer from JEOL, and the parameters used for calibration and for the head phantom readout are presented in table 17.

Table 16 - SRS arcs information obtained from the treatment planning.

\begin{tabular}{cccccc}
\hline & $\begin{array}{c}\text { Gantry initial } \\
\text { rotation }\end{array}$ & $\begin{array}{c}\text { Collimator } \\
\text { angulation }\end{array}$ & $\begin{array}{c}\text { Field X } \\
(\mathbf{c m})\end{array}$ & $\begin{array}{c}\text { Field Y } \\
(\mathbf{c m})\end{array}$ & $\begin{array}{c}\text { SSD } \\
(\mathbf{c m})\end{array}$ \\
\hline Arc 1 & $181^{\circ}$ & $30^{\circ}$ & 14.2 & 11.7 & 90.9 \\
Arc 2 & $179^{\circ}$ & $330^{\circ}$ & 14.2 & 11.7 & 90.9 \\
\hline
\end{tabular}

Table 17 - EMR parameters readout for the studies surrounding the stereotactic experimental simulation.

\begin{tabular}{ccc}
\hline \multirow{2}{*}{ EMR Parameter } & \multicolumn{2}{c}{ Stereotactic simulation } \\
\cline { 2 - 3 } & Calibration & Head phantom \\
\hline Center magnetic field (mT) & 345.211 & 344.782 \\
Microwave power (mW) & 3.0 & 3.0 \\
Modulation amplitude (mT) & 1.0 & 1.0 \\
Sweep width (mT) & 10 & 10 \\
Time constant (s) & 0.3 & 0.3 \\
Gain & 5,000 & 5,000 \\
Sweep time (min) & 1 & 1 \\
Number of scans & 3 & 9 \\
Inner diameter quartz tube & \multicolumn{2}{c}{3} \\
\hline
\end{tabular}

\subsubsection{Results and discussion}

As the EPResize ${ }^{\circledast}$ presented no suitable response and high uncertainty, this study was conducted with L-alanine. The calibration irradiation for dose-response curve construction is in figure 41, where the correlation coefficient and the equation used to relate EMR signal intensity and absorbed dose are also presented 
Figure 41 - Dose-response curve of L-alanine powder used as reference for the anthropomorphic head irradiation. The red line represents the linear fit, presenting also the correlation coefficient and the equation that relates absorbed dose and EMR signal intensity.

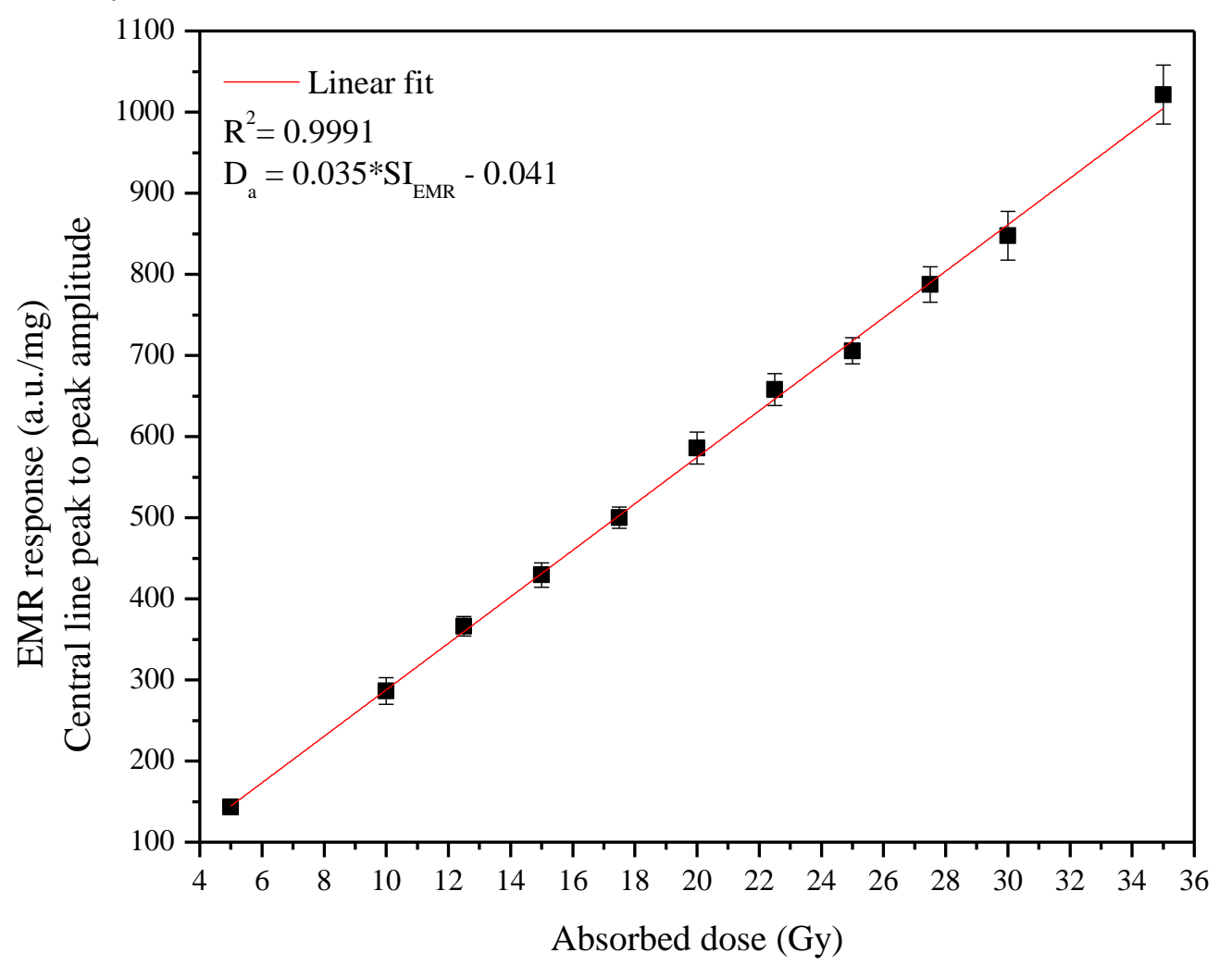

With the equation presented in figure 41, the EMR signal of each alanine detector placed in the positions shown in figure 40, was related to dose, determining the experimental dose accused. The result of each position and relation with the TPS dose is presented in table 18 and figure 42, where the deviation related to planned dose was determined considering the minimum and maximum dose calculated in the detector position. For the experimental dose, the deviation is related to the repeatability of 5 readouts. 
Table 18 - Doses calculated by the treatment planning and experimentally verified for the anthropomorphic head irradiation study. For planned doses, the deviation is related to the standard deviation between minimum and maximum dose presented in the position delimited.

\begin{tabular}{ccccccc}
\hline Slice & Detector & $\begin{array}{c}\text { Planned } \\
\text { dose }(\mathbf{G y})\end{array}$ & $\begin{array}{c}\text { Planned dose } \\
\text { deviation }(\boldsymbol{\%})\end{array}$ & $\begin{array}{c}\text { Experimental } \\
\text { dose }(\mathbf{G y})\end{array}$ & $\begin{array}{c}\text { Experimental } \\
\text { repeatability (\%) }\end{array}$ & $\begin{array}{c}\text { Difference (\%) } \\
\text { Planned } \boldsymbol{x} \text { Experimental }\end{array}$ \\
\hline \multirow{1}{*}{$\mathbf{1}$} & 1 & 16.37 & 2.04 & 16.37 & 0.90 & 0.02 \\
& 2 & 3.35 & 43.05 & 2.55 & 3.52 & 19.12 \\
& 3 & 4.60 & 29.44 & 2.43 & 2.53 & 43.62 \\
\hline \multirow{2}{*}{$\mathbf{2}$} & 4 & 18.04 & 2.30 & 18.89 & 2.06 & 3.25 \\
& 5 & 17.72 & 3.28 & 18.25 & 1.72 & 2.11 \\
& 6 & 22.95 & 1.50 & 22.46 & 0.41 & 1.51 \\
& 7 & 8.88 & 15.00 & 9.26 & 1.40 & 2.95 \\
& 8 & 6.16 & 13.08 & 6.01 & 1.89 & 1.74 \\
& 9 & 7.14 & 16.93 & 7.52 & 1.27 & 1.40 \\
$\mathbf{3}$ & 10 & 18.97 & 2.00 & 19.35 & 1.69 & 0.64 \\
& 11 & 4.00 & 22.70 & 3.34 & 1.95 & 6.20 \\
& 12 & 4.08 & 32.15 & 4.04 & 2.24 & 4.03 \\
\hline \multirow{2}{*}{$\mathbf{4}$} & 13 & 3.71 & 37.90 & 3.40 & 2.55 & 11.65 \\
& 14 & 16.3 & 2.97 & 15.43 & 1.44 & 0.88 \\
\hline
\end{tabular}

Figure 42 - Graphical comparison between experimental and planned dose of the anthropomorphic head phantom study. The error bars correspond to the standard deviations of each technique.

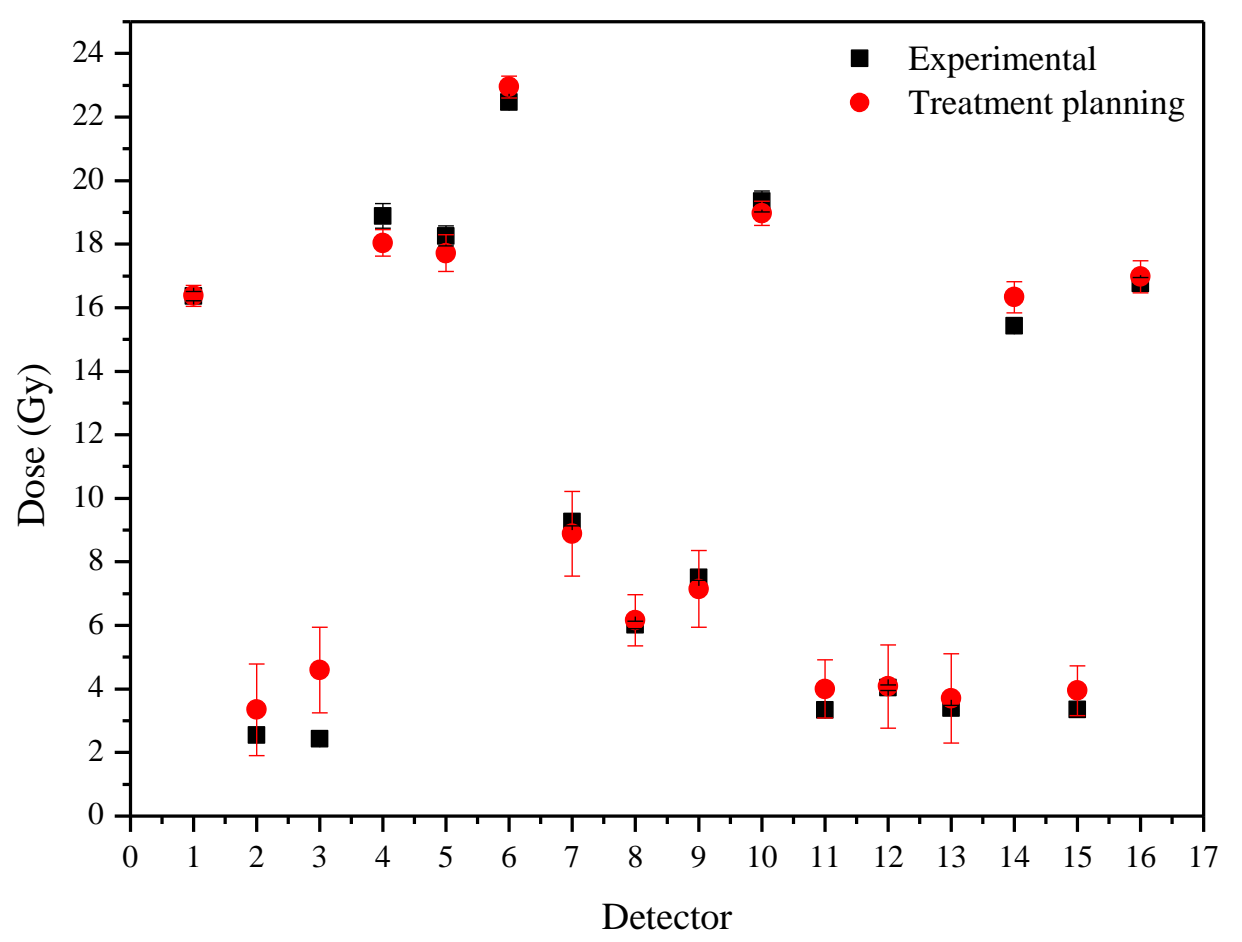


Seven dosimeters were optimized in the TPS with the target dose (detectors 1, 4, 5, 6, 10, 14, and 16); the other dosimeters received scattered radiation. Considering this the standard deviation of certain doses in the treatment planning (e.g. detectors 2, 3, 7-9, 11-13 and 15) and the good reproducibility of experimental measurements (only detector 2 presented value higher than 3\%), the values presented good agreement, except for detectors 2 , $3,11,13$ and 15, which are also those that presented high deviation for planned dose and were not optimized in the TPS. 


\section{ALTERNATIVE MATERIALS FOR EMR DOSIMETRY}

Radiation exposure evaluation, either clinical or accidental, is recommended regarding the safety of the ones exposed. The medical use of radiation became common and regular, despite the fact that the risk of any radioactive accident is real and relevant, such as for nuclear reactors (Lelieveld, Kunkel and Lawrence, 2012) and other overexposure causes (Coeytaux et al., 2015). Finding different daily materials able to perform this detection makes them able to become radiation markers, being an option of absorbed dose evaluation in ordinary scenarios.

EMR spectroscopy had already been investigated for accidental dosimetry, using biological compounds (Trivedi and Greenstock, 1993; Rossi et al., 2000; Schauer et al., 2001; Trompier et al., 2009) or even sugars and other materials (Ikeya, Miyajima and Okajima, 1984; Nakajima, 1988; Barthe et al., 1989; Ikeya and Ishii, 1989; Nakajima, 1989; Kai, Ikeya and Miki, 1990; Nakajima and Otsuki, 1990; Trivedi and Greenstock, 1993; Bassinet, Trompier and Clairand, 2010; Kinoshita, José and Baffa, 2010; Trompier, Bassinet and Clairand, 2010; Israelsson, Gustafsson and Lund, 2013; Sholom and McKeever, 2016). Some examples of real scenarios that EMR dosimetry was used to evaluate dose are:

- Hiroshima and Nagasaki, Japan - attacked by an atomic bomb (Ikeya, Miyajima and Okajima, 1984);

- Chernobyl (Pripyat, Ukrainian SSR) - reactor accident (Serezhenkov et al., 1992);

- Goiânia, Brazil - source discarded incorrectly (Rossi et al., 2000);

- $\quad$ Lia, Georgia - three people exposed to a ${ }^{90} \mathrm{Sr}$ source (Clairand et al., 2006).

Since then, the search for new materials for EMR dosimetry has intensified, and many studies have been published, as already presented in 2.4. This section is divided in three different (yet similar) lines: first, three ammonium compounds were studied; second, the lithium, potassium and sodium compounds, which also originated the third line, about sulfites.

\subsection{AMMONIUM COMPOUNDS}

Ammonium tartrate has been reported and investigated due to its linearity with dose, better dose resolution than alanine (Olsson et al., 1999), its similarity with tissue equivalency (Olsson, Lund and Lund, 2000). It has also been investigated with different kind of beams and energies (Bartolotta et al., 2001; Marrale et al., 2006). The good behavior of ammonium 
tartrate influenced the study of other ammonium compounds, such as ammonium formate (Gustafsson et al., 2004) and ammonium dithionate (Danilczuk et al., 2008), both presenting higher sensitivity than L-alanine. With this, the proposal to study other ammonium compounds, like ammonium acetate $\left(1.17 \mathrm{~g} / \mathrm{cm}^{3}\right)$, ammonium carbonate $\left(1.50 \mathrm{~g} / \mathrm{cm}^{3}\right)$ and ammonium sulfate $\left(1.77 \mathrm{~g} / \mathrm{cm}^{3}\right)$ emerged.

\subsubsection{Materials and methods}

In addition to the alternative ammonium compounds analyzed, ammonium tartrate was also studied. All the compounds were from Sigma-Aldrich, used in their pure powder crystalline form, these being:

- Ammonium acetate $\left(1.2 \mathrm{~g} / \mathrm{cm}^{3}\right)-\mathrm{NH}_{4} \mathrm{CH}_{3} \mathrm{CO}_{2}$;

- Ammonium carbonate $\left(1.5 \mathrm{~g} / \mathrm{cm}^{3}\right)-\left(\mathrm{NH}_{4}\right)_{2} \mathrm{CO}_{3}$;

- Ammonium sulfate $\left(1.8 \mathrm{~g} / \mathrm{cm}^{3}\right)$ - $\left(\mathrm{NH}_{4}\right)_{2} \mathrm{SO}_{4}$;

- Ammonium tartrate $\left(1.6 \mathrm{~g} / \mathrm{cm}^{3}\right)-\left(\mathrm{NH}_{4}\right)_{2} \mathrm{C}_{4} \mathrm{H}_{4} \mathrm{O}_{6}$.

First, the behavior of ammonium tartrate was verified. Samples were irradiated with a ${ }^{60} \mathrm{Co}$ gamma source from IRSN, and the analysis was carried out with different EMR spectrometers operating in X-, K- and Q-band comparing the spectra acquired with different frequencies. Two spectrometers were already mentioned in the previous section, such as the X-band (3.2.3.1) and the Q-band (3.2.1.1) from Bruker. As for K-band, a spectrometer built with an ER $067 \mathrm{KG}$ microwave bridge and a Bruker probe operating with a frequency of 24 $\mathrm{GHz}$ was used. For X- and Q-band, dose-response curves were constructed, comparing the linearity obtained when analyzing in different systems and verifying the dosimetry with Qband. The main parameters are presented in table 19.

Table 19 - Microwave power and modulation amplitude values used for X- and Q-band dose-response study of ammonium tartrate.

\begin{tabular}{ccc}
\hline \multirow{2}{*}{ EMR parameters } & \multicolumn{2}{c}{ Ammonium tartrate } \\
\cline { 2 - 3 } & X-band & Q-band \\
\hline Power $(\mathbf{m W})$ & 0.201 & 1.000 \\
Modulation amplitude (mT) & 0.09 & 0.30 \\
\hline
\end{tabular}

Preliminarily, the alternative ammonium compounds were irradiated with the same X-ray irradiator presented in 3.2.3.1, when the machine was still not calibrated in dose basis, 
considering then the irradiation time as a parameter. The analyses were performed with the Bruker X-band spectrometer, presenting no conclusive results. Then the investigation was performed with the irradiation of the samples with a $50 \mathrm{kV}$ X-ray, using doses from 5 to 100 Gy (dose in air). At the time, the analyses were carried out with the X-band EMR spectrometer from JEOL, and ammonium acetate was not considered as it did not present environmental stability. The parameters used for readout with the two different X-band spectrometers are in table 20.

Table 20 - Main EMR parameters used to perform readout with the alternative ammonium compounds with Bruker and JEOL X-band spectrometers.

\begin{tabular}{|c|c|c|c|c|c|}
\hline \multirow{3}{*}{ EMR parameter } & \multicolumn{3}{|c|}{ X-band Bruker } & \multicolumn{2}{|c|}{ X-band JEOL } \\
\hline & \multicolumn{5}{|c|}{ Ammonium } \\
\hline & Acetate & Carbonate & Sulfate & Carbonate & Sulfate \\
\hline Power $(\mathbf{m W})$ & & 2.0 & & 2.0 & \\
\hline Modulation amplitude (mT) & & 0.3 & & 0.7 & \\
\hline Gain & & - & & 500 & 10,000 \\
\hline Scans & & 5 & & 2 & \\
\hline Repetition & & 5 & & 3 & \\
\hline
\end{tabular}

\subsubsection{Results and discussion}

As shown in table 19 , for $\mathrm{X}$-band, the microwave power is low $(0.201 \mathrm{~mW})$ due to the fast saturation presented by ammonium tartrate. Figure 43 explores the behavior of ammonium tartrate with increasing microwave power in different scenarios: a) illustrates the relation between EMR signal and microwave power when the readout of the sample is performed with different modulation amplitude $(0.02 \mathrm{mT}$ and $0.09 \mathrm{mT})$; b) is about the microwave power saturation curve for samples irradiated with different doses (from 10 to 500 Gy), justifying the choice of microwave power. 
Figure 43 - Ammonium tartrate microwave power saturation study relating EMR response microwave power with different modulation amplitudes (a) and with different absorbed doses (b).
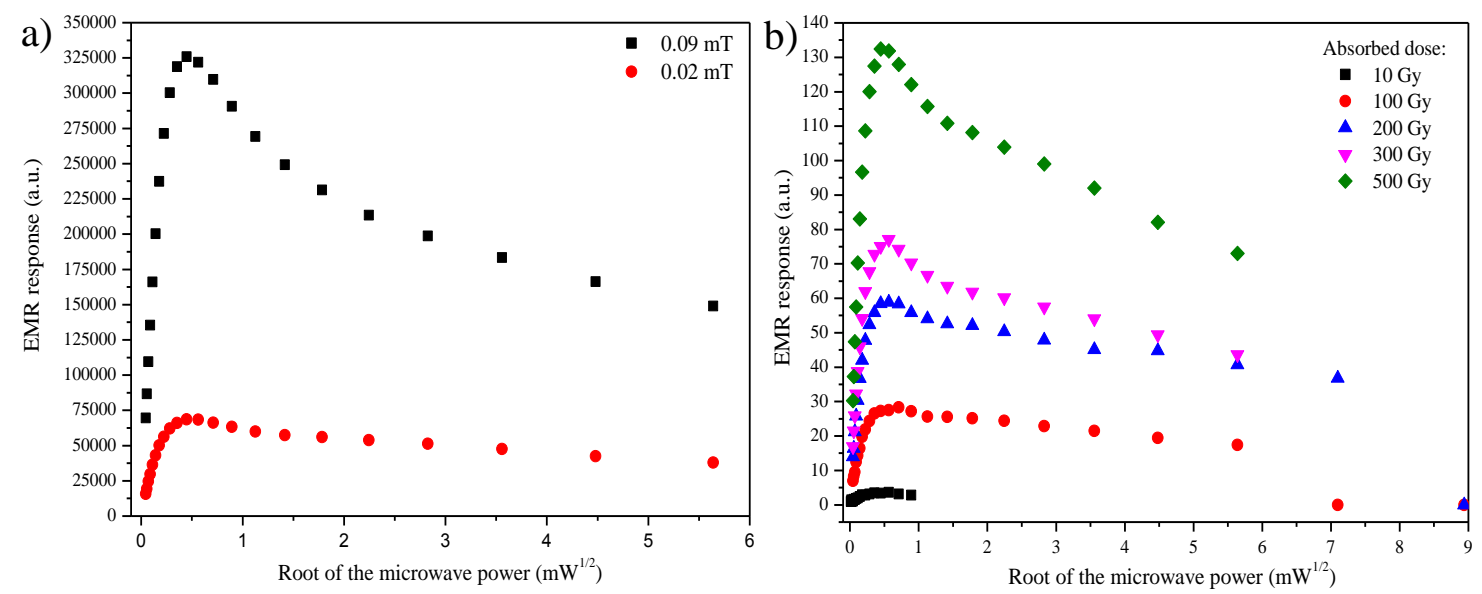

The ammonium tartrate spectrum presented a single line when analyzed with the three different frequencies, showing no line broadening (figure 44). Then, the single peak corresponds to the dosimetric signal, which, for dose-response curve construction, was normalized by mass and presented linear response for X-band (figure 45). For Q-band (figure 46), two kinds of analyses were carried out: normalization by mass and normalization by Quality(Q)-factor (not considering the sample mass). Graphically, for Q-band, it is possible to observe that the linear fit adjusted better when normalized by Q-factor. In addition fitting information is presented in table 21, showing also a comparison with X-band. Q-factors characterize resonant cavities, indicating how efficiently they can store microwave energy. Higher Q-factors imply higher spectrometer sensitivity. As Q-band can present changes in the Q-factor values from one measurement to another, influencing the EMR signal amplitude (not significantly observed in X-band), corrections must be done to guarantee accurate experimental results (Eaton et al., 2010; Guilarte, Trompier and Duval, 2016). These variations are not because of the spectrometer response, but due to sample properties (Nagy et al., 2000). 
Figure 44 - Ammonium tartrate spectra acquired with different EMR spectrometer frequencies, such as X-band (9.5 GHz), K-band (24 GHz) and Q-band (35 GHz).

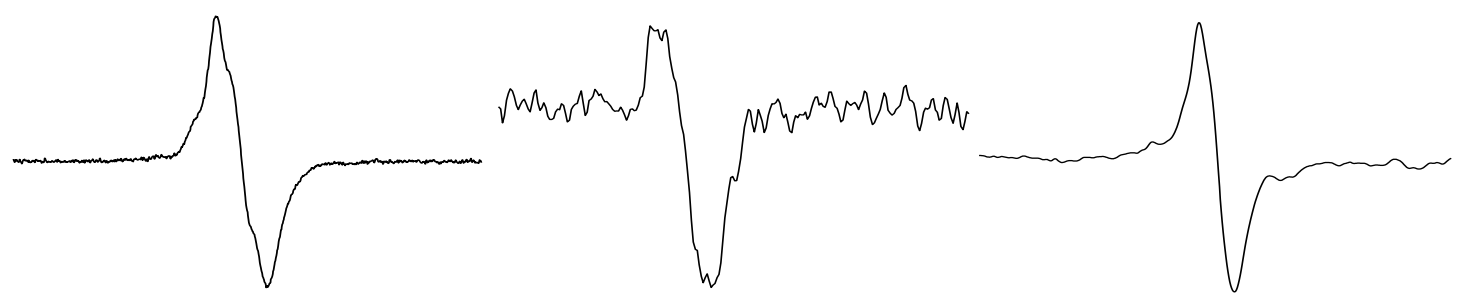

Figure 45 - Dose-response curve and linear fit of ammonium tartrate with X-band EMR spectroscopy normalized by mass irradiated with ${ }^{60} \mathrm{Co} \gamma$-rays for doses from 0 to $25 \mathrm{~Gy}$.

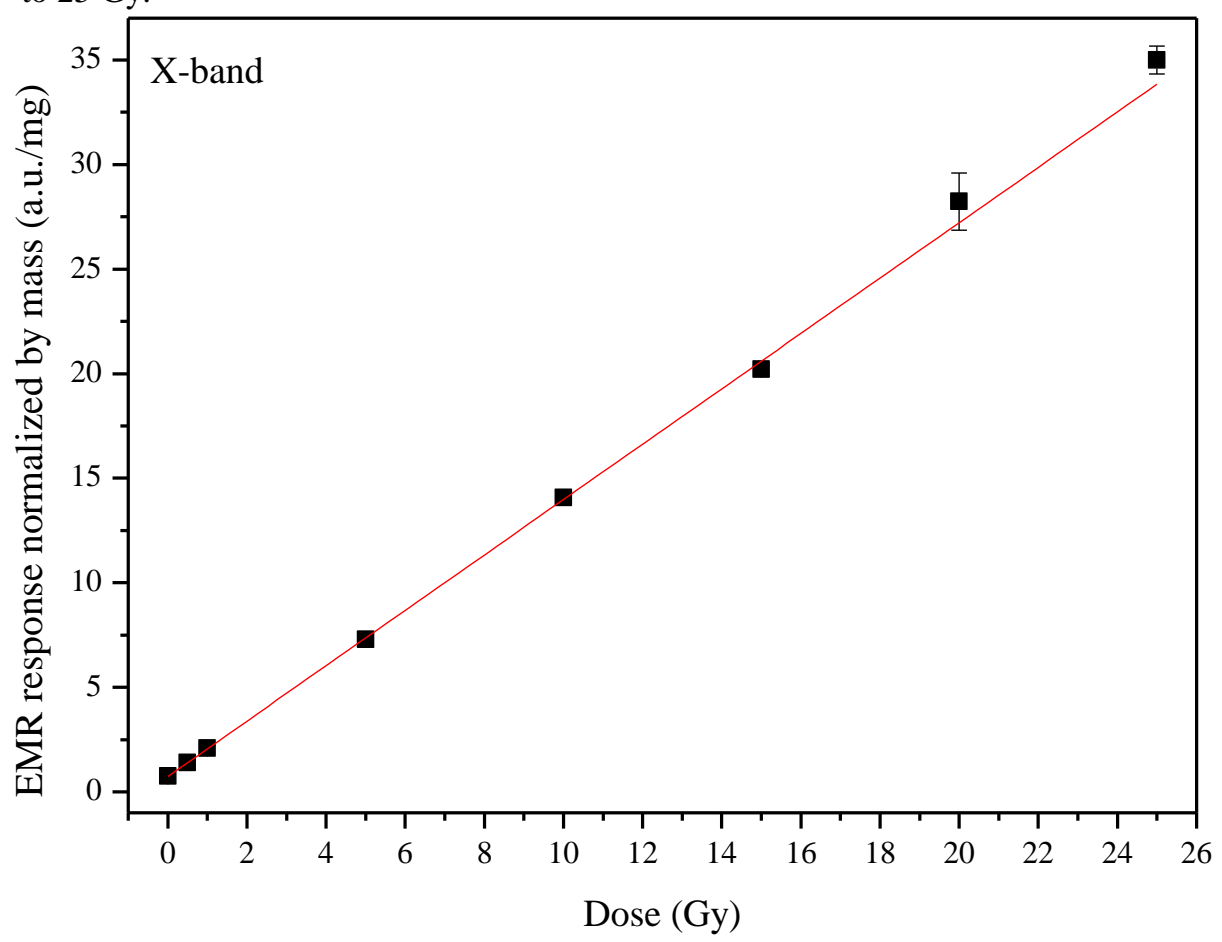


Figure 46 - Ammonium tartrate dose-response curve and linear fit with Q-band EMR spectrometer. The graphic presents two different methods of analysis: normalization by mass (black) and by Q-factor (blue).

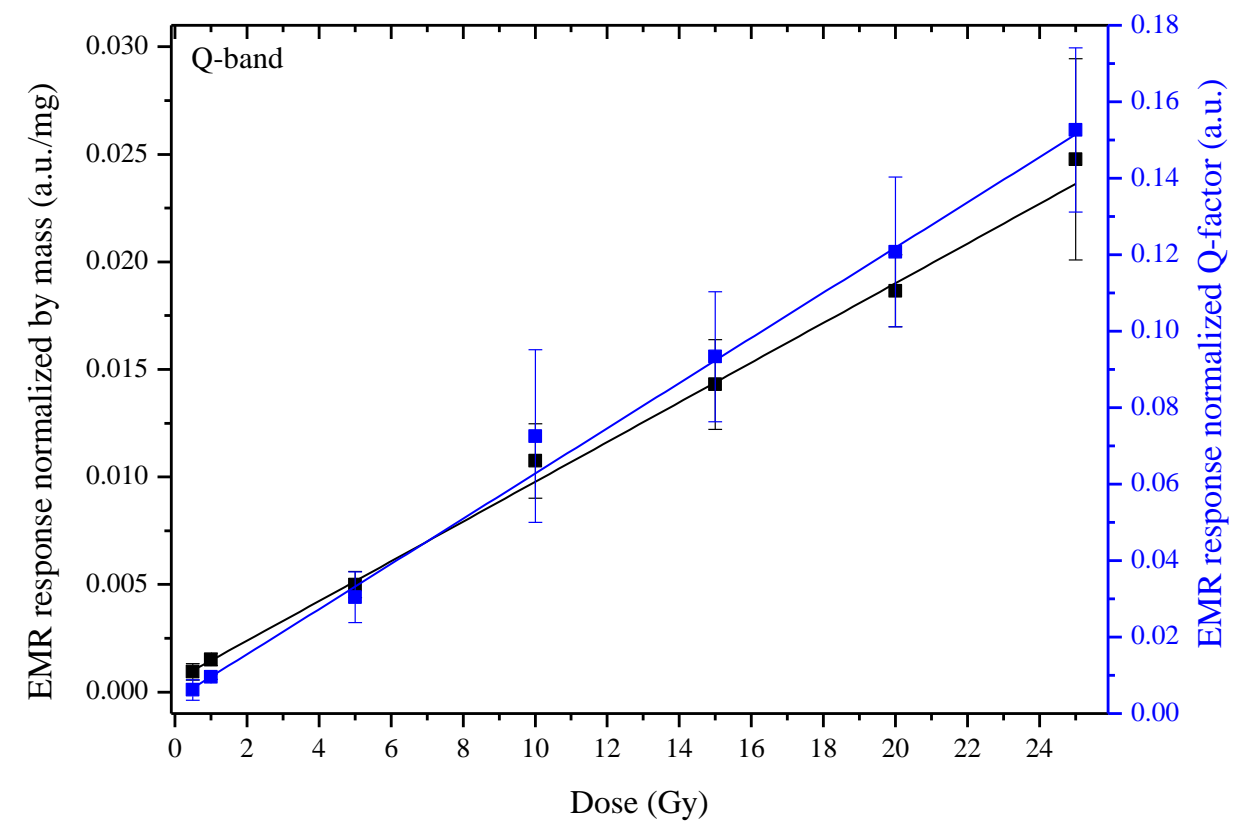

Table 21 - Ammonium tartrate fitting parameters obtained when considering a linear behavior of dose-response curve acquired with X-and Q-band.

\begin{tabular}{cccc}
\hline Fitting & \multirow{2}{*}{ X-band } & \multicolumn{2}{c}{ Q-band } \\
\cline { 3 - 4 } parameter & & Mass & Q-factor \\
\hline $\mathbf{R}^{\mathbf{2}}$ & 0.9992 & 0.9969 & 0.9959 \\
Slope & 1.32 & $9.24 \times 10^{-4}$ & $3.67 \times 10^{-3}$ \\
Intercept & 0.74 & $5.40 \times 10^{-4}$ & $5.91 \times 10^{-3}$ \\
\hline
\end{tabular}

Ammonium tartrate K-band presented the worst resolution (figure 44) due to the spectrometer's setup. When the noise was too high and the number of scans was not enough to improve that, the idea was to illustrate that there is no line splitting when applying a higher microwave frequency. The magnitudes order ends up being different for each spectrometer used, and as arbitrary units, it is not possible to directly compare the results obtained.

About the ammonium compounds, none of them presented a satisfactory relation with irradiation time in the first trial. Next, when tested with UV irradiation, the ammonium acetate melted completely, showing no environmental stability. When irradiated with the $50 \mathrm{kV} \mathrm{X}$ ray, only ammonium sulfate presented suitable EMR response, both with single line spectrum (figure 47), as presented in figure 48. For comparison, in figure 49, ammonium sulfate doseresponse curve is plotted with lithium formate curve. For proper normalization, lithium 
formate data should be multiplied by a factor of 20 . table 22 presents the curves parameters (not normalized).

Figure 47 - Ammonium carbonate and ammonium sulfate EMR single line spectrum irradiated with 100 Gy by a 50 kV X-ray.

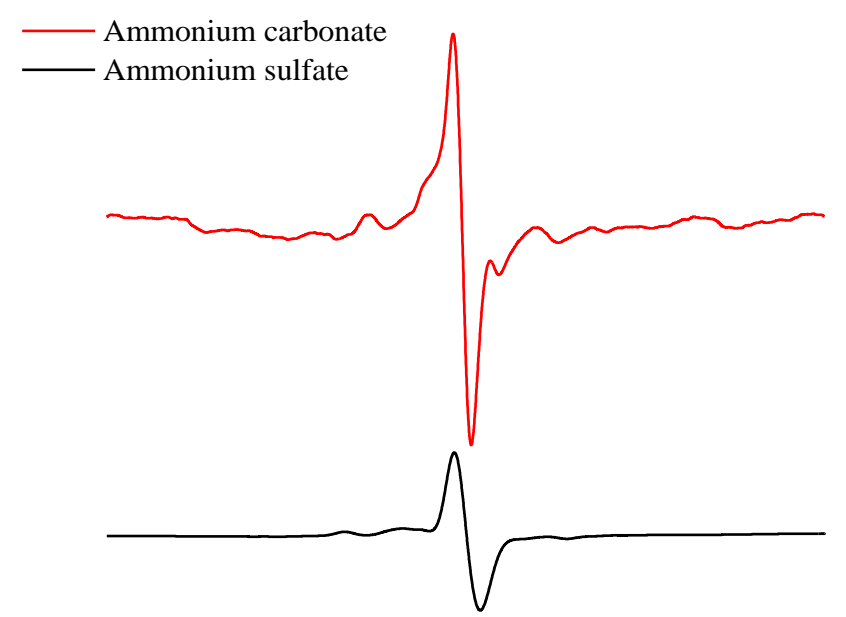

Figure 48 - Dose- response relation for ammonium sulfate and carbonate irradiated with a $50 \mathrm{kV} \mathrm{X-ray.} \mathrm{The} \mathrm{graphic} \mathrm{has} \mathrm{two} \mathrm{different} \mathrm{Y}$-axes: the black one is for ammonium carbonate (not dose-related); the blue one is for ammonium sulfate. The EMR responses are normalized by mass and readout gain for proper comparison.

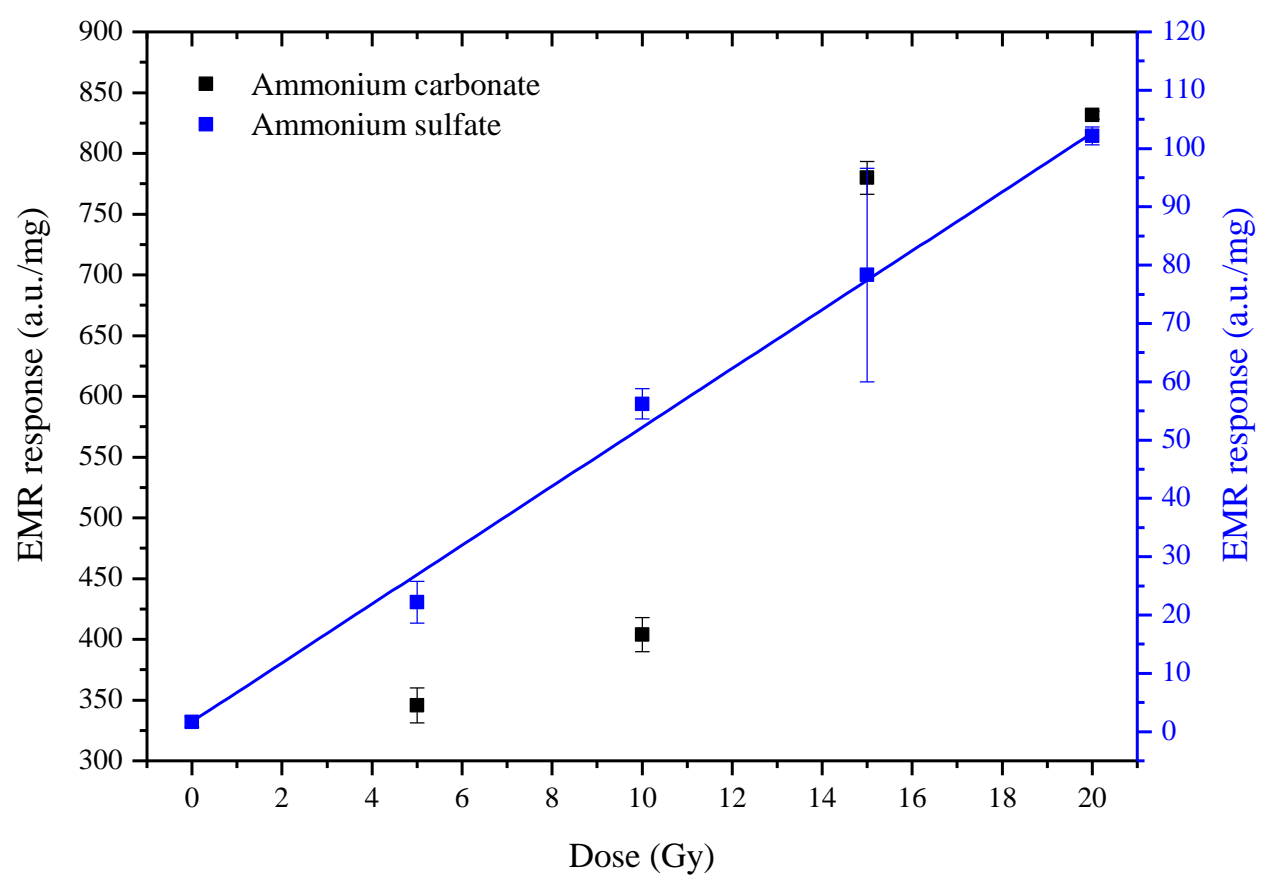


Figure 49 - Ammonium sulfate dose-response curve in comparison with the lithium formate curve. Lithium formate presents higher EMR response, but a correction multiplying by a factor of 20 would measure the real difference between the two irradiated compounds.

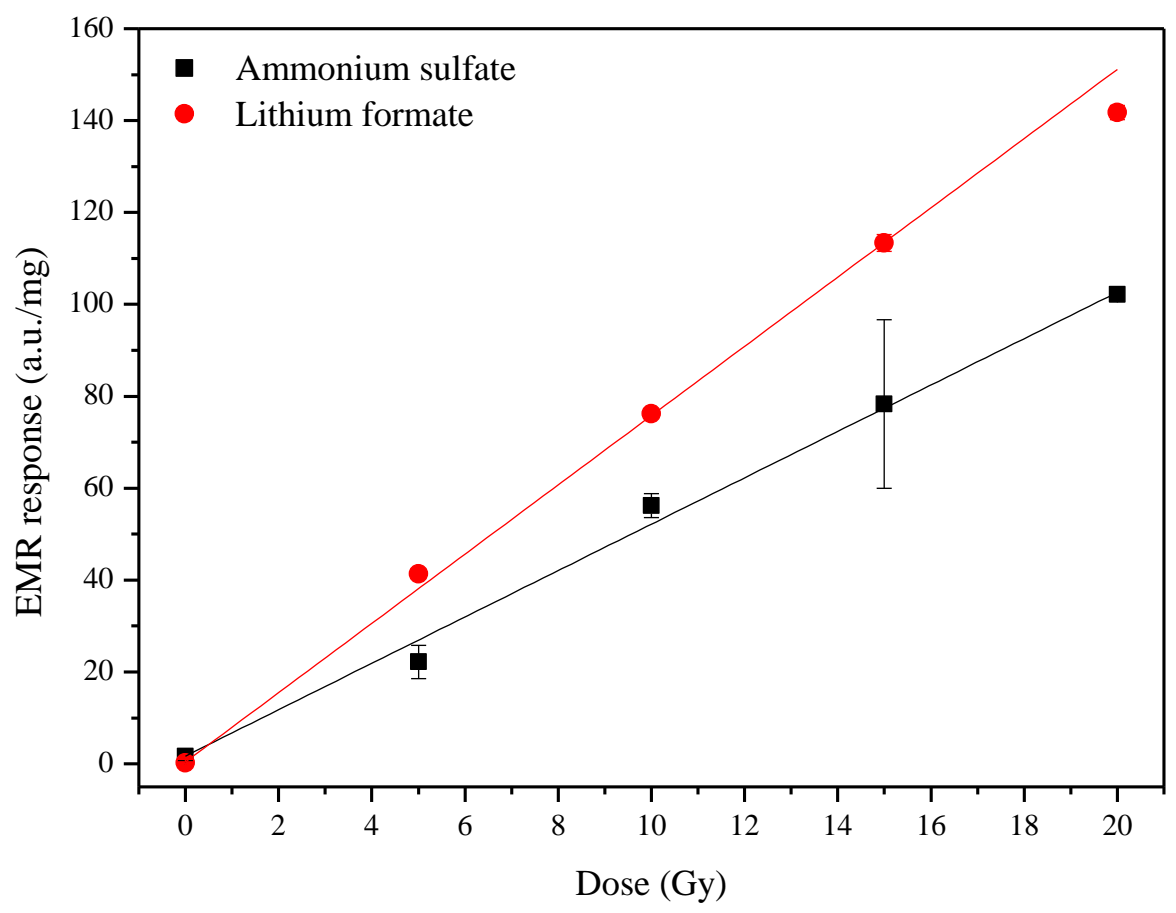

Table 22 - Comparison between dose-response curve parameters of ammonium sulfate and lithium formate. The data was not normalized by EMR readout gain, so, for correction, lithium formate results should be multiplied by a factor of 20 .

\begin{tabular}{ccc}
\hline $\begin{array}{c}\text { Fitting } \\
\text { parameter }\end{array}$ & $\begin{array}{c}\text { Ammonium } \\
\text { sulfate }\end{array}$ & $\begin{array}{c}\text { Lithium } \\
\text { formate }\end{array}$ \\
\hline $\mathbf{R}^{\mathbf{2}}$ & 0.9983 & 0.9964 \\
Slope & 5.0 & 7.5 \\
Intercept & 1.7 & 0.4 \\
\hline
\end{tabular}

Lithium formate is 30 times more sensitive than ammonium sulfate, applying the correct normalization factor in the values presented in table 22. Even so, ammonium sulfate presented interesting characteristics as a single line spectrum and linearity for dose-response curve. 


\section{2. $\quad$ LITHIUM, POTASSIUM AND SODIUM COMPOUNDS}

Materials based on light elements were selected, such as the alkaline compounds of lithium, sodium, and potassium. These compounds have low atomic numbers, which could bring their effective atomic number $\left(\mathrm{Z}_{\mathrm{eff}}\right)$ and their radiation properties closer to water. This is especially important for low energies, in which the photoelectric effect is predominant (Johns and Cunningham, 1983). Out of the 16 compounds studied, only three of them - lithium carbonate (Popoca and Ureña-Núñez, 2009; Herrera, Ureña-Núñez and Loya, 2005), sodium carbonate (Ureña-Núñez and Ballesteros, 2009), and sodium citrate (Tuner and Korkmaz, 2010) - have already been described with gamma radiation for EMR dosimetry. Considering the behavior of dithionates (Lund et al., 2005), sodium dithionite was selected. All the compounds are presented in common materials in the environment, as presented in table 23, facilitating the detection of radioactive markers. They were all compared to lithium formate, already presented before in the previous section.

Table 23 - List of the lithium, potassium and sodium compounds studied and information where they could be found in daily life.

\begin{tabular}{|c|c|c|}
\hline \multicolumn{2}{|c|}{ Compound } & Where to find? \\
\hline Lithium & $\begin{array}{c}\text { carbonate } \\
\text { hydroxide } \\
\text { phosphate } \\
\text { sulfate }\end{array}$ & $\begin{array}{l}\text { Drug for the treatment of bipolar disorder (WHO, 2015). } \\
\text { Greases for steel and metallurgy. } \\
\text { Powder with fluorescent properties. } \\
\text { Drug for bipolar disorder and possible improvement of } \\
\text { cement paste (Yuhai, Changqing and Xiaosheng, 2014). }\end{array}$ \\
\hline Potassium & $\begin{array}{c}\text { carbonate } \\
\text { iodate } \\
\text { permanganate } \\
\text { phosphate }\end{array}$ & $\begin{array}{l}\text { Applied in industry, laboratory, food, and safety. } \\
\text { Used for the iodination of cooking salt. } \\
\text { Applied to water treatment and disinfection, synthesis of } \\
\text { organic compounds, analytical use, fruit preservation, } \\
\text { survival kits, fire service and others. } \\
\text { Used as a fertilizer, food additive and fungicide. }\end{array}$ \\
\hline Sodium & $\begin{array}{c}\text { formate } \\
\text { phosphate } \\
\text { tetraborate }\end{array}$ & $\begin{array}{l}\text { Applied in textile industry, concrete longevity, food } \\
\text { industry, buffer solution and heating pad. } \\
\text { Domestic use as softener in laundering and applied in food, } \\
\text { brick, toothpaste, cotton and cleaning water industry. } \\
\text { Applied in food industry, and used in medicine as an } \\
\text { anticoagulant. } \\
\text { Applied in industry, biological sciences, geosciences, } \\
\text { photography and laboratory. } \\
\text { Used in textile and food industry and in structural biology as } \\
\text { a cryoprotectant. } \\
\text { Used in food industry and water treatment. } \\
\text { Known as Borax, it is used as a cleaning domestic product, } \\
\text { food additive and other applications. }\end{array}$ \\
\hline
\end{tabular}




\subsubsection{Materials and methods}

Crystalline samples of lithium, potassium, and sodium compounds were investigated for EMR dosimetry. All the compounds were commercially obtained (table 24) and used without previous purification because the purpose was to easily investigate available materials that could be used in the case of any unforeseen scenario.

\begin{tabular}{|c|c|c|}
\hline \multicolumn{2}{|c|}{ Compound } & Brand \\
\hline \multirow{4}{*}{ Lithium } & Carbonate & \\
\hline & Hydroxide & Sigma-Aldrich \\
\hline & Phosphate & Alfa Aesar \\
\hline & Sulfate & Sigma-Aldrich \\
\hline \multirow{4}{*}{ Potassium } & Carbonate & Momp \\
\hline & Iodate & MIETCK \\
\hline & Permanganate & Synth \\
\hline & Phosphate & Reagen \\
\hline \multirow{7}{*}{ Sodium } & Acetate & Merck \\
\hline & Carbonate & 11. \\
\hline & Citrate & Mallinckrodt \\
\hline & Dithionite & Merck \\
\hline & Formate & Sigma-Aldrich \\
\hline & Phosphate & Synth \\
\hline & Tetraborate & Nuclear \\
\hline
\end{tabular}

Samples were all irradiated in air using a $50 \mathrm{kV}$ MAGNUM $^{\circledR}$ X-ray tube from Moxtek, with a tungsten target. This source was calibrated with a 10x5-6 Radcal Corporation ionization chamber. The uncertainty at $50 \mathrm{kV}$ is $1.5 \%$, at a confidence level of $95.45 \%$, following national and international guidelines, with a half-value layer (HVL) of $0.1 \mathrm{~mm} \mathrm{Al}$, a dose rate of $28.17 \mathrm{~Gy} / \mathrm{min}$, with an effective energy of $8.3 \mathrm{keV}$. The X-ray source spatial distribution was characterized with an EBT3 gafchromic film, with proper positioning of the samples for irradiation. The relation between the spectrum and dose was tested, with doses from 5 to $100 \mathrm{~Gy}$. For the fading study, samples were irradiated with $100 \mathrm{~Gy}$, stored in the dark in the laboratory in ordinary conditions, with air-conditioning at $21^{\circ} \mathrm{C}$ and $40 \%$ air humidity, approximately. The samples were read 1 week later. 
Analyses were performed with the EMR X-band spectrometer from JEOL. Table 25 and table 26 present the parameters used for the analysis of each compound; for optimization of the signal, microwave power and modulation amplitude studies were done. The EMR signal of each compound was considered differently, according to which system reported less standard deviation with readout repeatability; some compounds considered main line peak-topeak amplitude, while others considered sum of peaks. Still with the JEOL analysis software, the experimental $\mathrm{g}$ factor of each peak observed in the compounds spectra was determined using a $\mathrm{Mn}^{2+}$ marker as reference.

\begin{tabular}{|c|c|}
\hline EMR parameter & \\
\hline Sweep width $(\mathrm{mT})$ & $1.5 \times 10$ \\
\hline Time constant (s) & 0.3 \\
\hline Sweep time (min) & 1 \\
\hline Number of scans & 3 \\
\hline Repetition & 5 \\
\hline
\end{tabular}

Table 26 - Different EMR parameters used for each studied compound after proper optimization of the signal.

\begin{tabular}{|c|c|c|c|c|c|c|}
\hline \multirow[b]{2}{*}{ Compound } & \multirow[t]{2}{*}{ EMR parameter } & \multirow{2}{*}{$\begin{array}{c}\text { Central } \\
\text { field } \\
(\mathbf{m T})\end{array}$} & \multirow{2}{*}{$\begin{array}{c}\text { Microwave } \\
\text { power } \\
(\mathrm{mW})\end{array}$} & \multicolumn{2}{|c|}{$\begin{array}{c}\begin{array}{c}\text { Modulation amplitude } \\
(\mathrm{mT})\end{array} \\
\end{array}$} & \multirow{2}{*}{ Gain } \\
\hline & & & & $\begin{array}{c}\text { Model } \\
\text { spectrum }\end{array}$ & $\begin{array}{l}\text { Dosimetry } \\
\text { purpose }\end{array}$ & \\
\hline \multirow{5}{*}{ Lithium } & Carbonate & 335.974 & 2 & 0.1 & 0.5 & $10 \times 1000$ \\
\hline & Hydroxide & 336.950 & 3 & 0.1 & 0.7 & $10 \times 1000$ \\
\hline & Formate & 335.860 & 2.5 & 0.2 & 1.0 & $5 \times 100$ \\
\hline & Phosphate & 335.939 & 3 & 0.04 & 0.2 & $10 \times 1000$ \\
\hline & Sulfate & 336.732 & 2.5 & 0.2 & 1.0 & $10 \times 1000$ \\
\hline \multirow{4}{*}{ Potassium } & Carbonate & 336.266 & 2 & - & - & $10 \times 1000$ \\
\hline & Iodate & 336.494 & 3 & 0.2 & 1.0 & $10 \times 1000$ \\
\hline & Permanganate & 336.710 & 2 & 0.1 & 0.7 & $10 \times 100$ \\
\hline & Phosphate & 336.687 & 2 & 0.8 & 0.8 & $10 \times 1000$ \\
\hline \multirow{7}{*}{ Sodium } & Acetate & 336.207 & 3 & 0.2 & 1.0 & $10 \times 100$ \\
\hline & Carbonate & 335.893 & 2.5 & 0.1 & 0.6 & $10 \times 1000$ \\
\hline & Citrate & 336.758 & 1 & 0.1 & 0.7 & $5 \times 1000$ \\
\hline & Dithionite & 339.598 & 3 & 0.2 & 1.0 & $5 \times 100$ \\
\hline & Fomate & 335.842 & 2 & 0.1 & 0.8 & $5 \times 100$ \\
\hline & Phosphate & 337.770 & 2.5 & 0.5 & 0.5 & $10 \times 1000$ \\
\hline & Tetraborate & 336.768 & 2.5 & 0.2 & 1.0 & $10 \times 1000$ \\
\hline
\end{tabular}

Regarding the behavior of the compound upon interaction with radiation, the Zeff was calculated, considering the empirical formula equation for X-ray absorption (Murty, 1965):

$$
Z_{E M P e f f}=\sqrt[2.94]{\sum f_{n} z_{n}^{2.94}}
$$


in which $f_{n}$ and $z_{n}$ is the total number of fractions of electrons and atomic number of each $n$ element. The X-ray mass attenuation curve was obtained (Berger et al., 2015) by comparing the results always to water and soft tissue data.

\subsubsection{Results and discussion}

Only potassium iodate had no EMR signal after irradiation. The EMR spectra of lithium carbonate, lithium phosphate, sodium acetate, sodium carbonate, sodium citrate, sodium dithionite and sodium formate were noteworthy. figure 50 shows their spectra under irradiation with $100 \mathrm{~Gy}$, with low modulation amplitude for line resolution. Under the optimum measuring conditions used in this work, no EPR signal was observed when not exposed to radiation. 
Figure 50 - X-band EMR spectra of the different compounds irradiated with $100 \mathrm{~Gy}$, all recorded with low modulation amplitude aiming signal resolution.

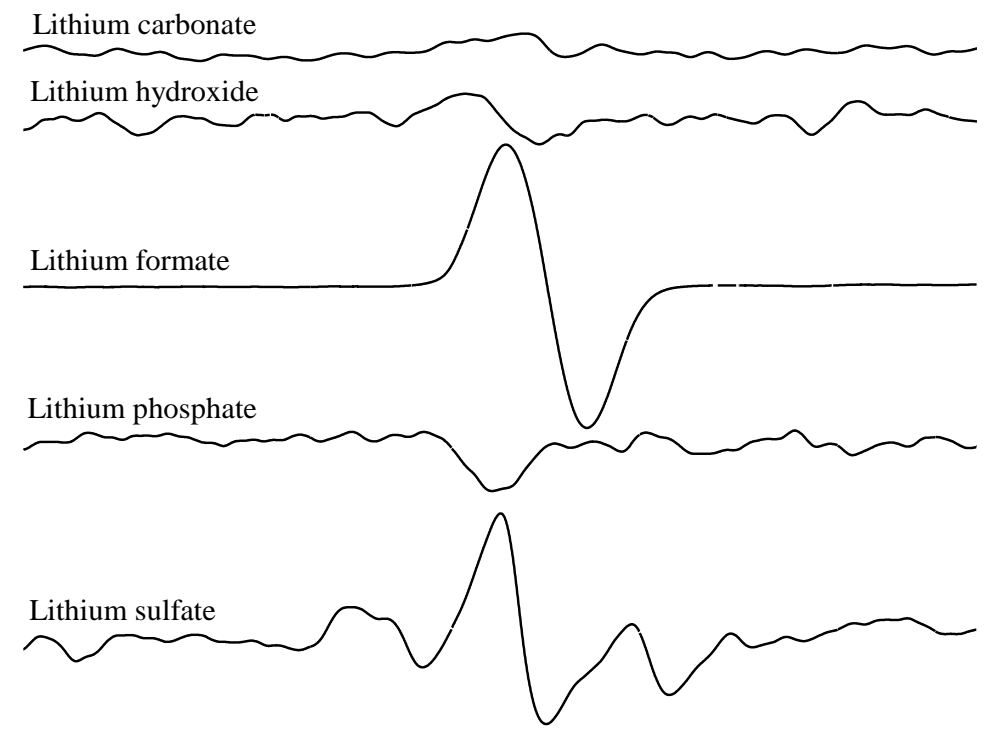

Potassium iodate
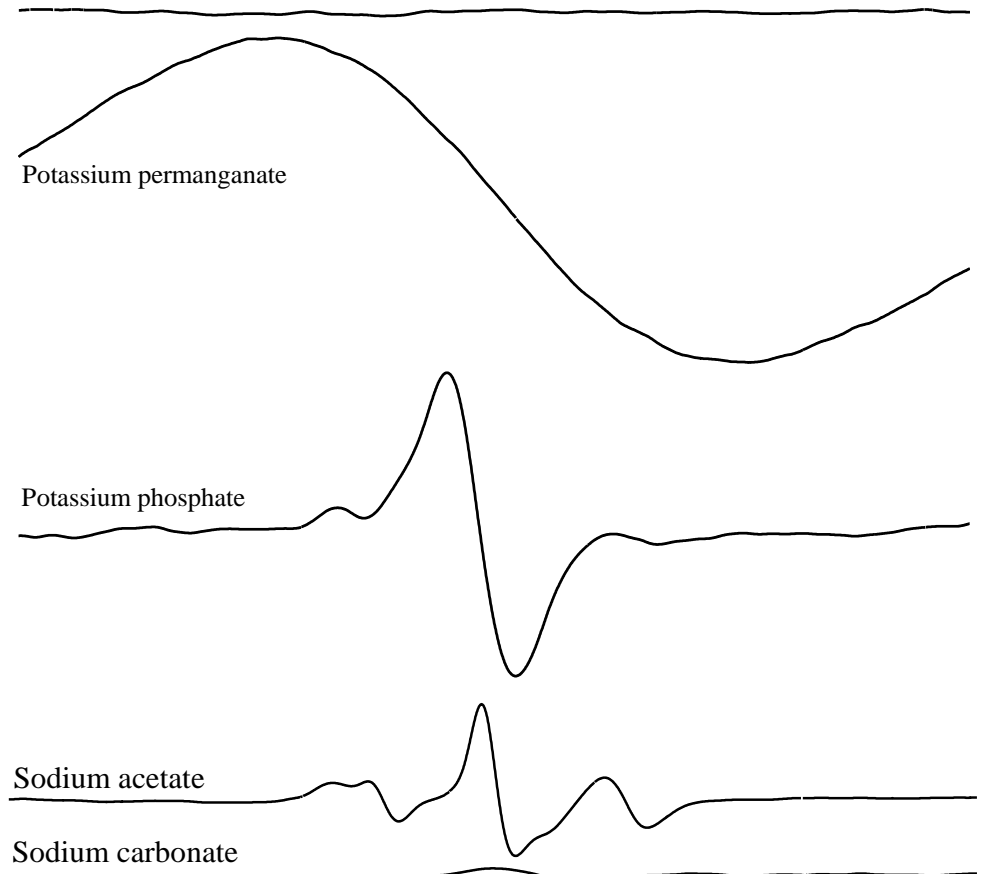

Sodium carbonate

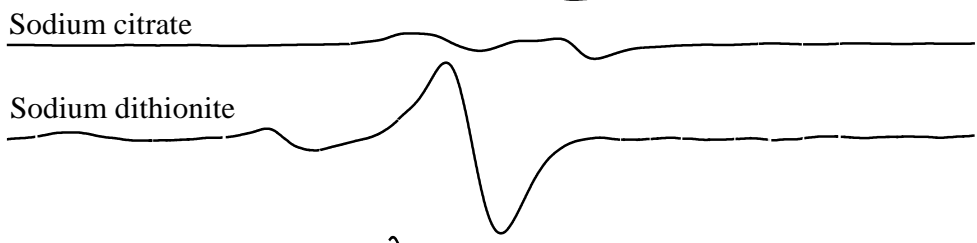

Sodium formate

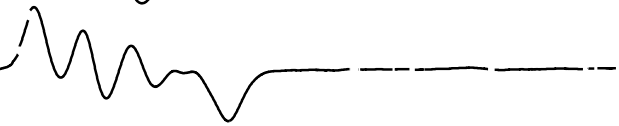

Sodium phosphate 
The most efficient method for the analysis was the standard peak-to-peak amplitude of the main line. The method based on the sum of peaks only showed better results for sodium acetate; for sodium citrate, the first peak was used. The best method of signal quantification was determined per linearity and standard deviation obtained, considering different peak responses or sums, as identified in the following figures (figure 51 to 57). Different peak analyses were considered according to crystalline anisotropy, searching for the best balance between absorbed dose and signal response, also improving the sensitivity (Haskell, Hayes and Kenner, 1998). The dose-response curves were delimited only until 20 Gy and are presented in figure 51 to 57, with discrimination of the EMR peak chosen for analysis and the fitting parameters, which are also presented and compared in table 27.

Figure 51 - Lithium carbonate dose-response curve and the EMR spectrum recorded at each irradiation dose, highlighting the peak-to-peak amplitude. The curve linear fitting and parameters are also presented, considering the dose range from 0 to $20 \mathrm{~Gy}$.

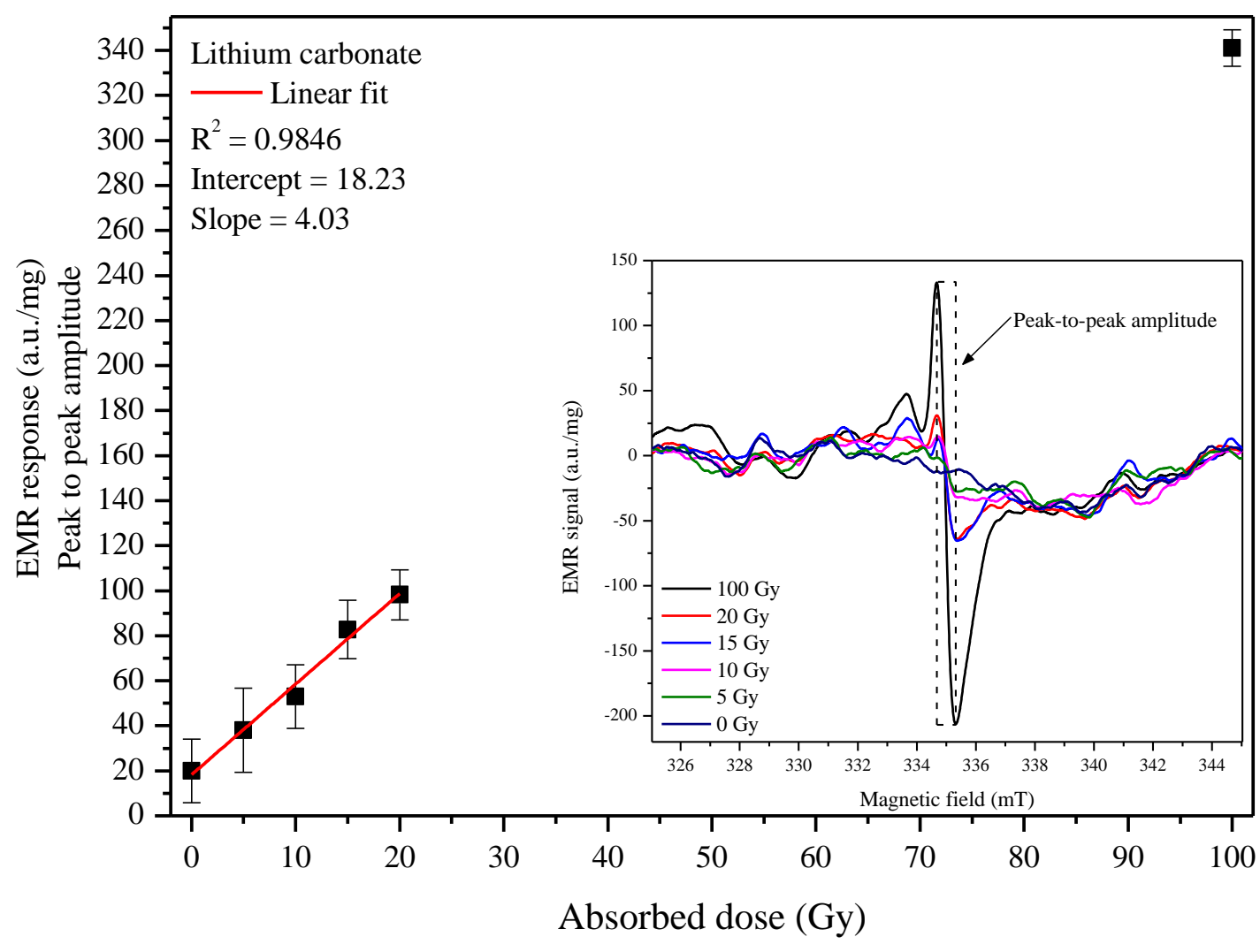


Figure 52 - Lithium formate dose-response curve and its linear fit coefficients, for the dose interval until $20 \mathrm{~Gy}$. The EMR spectrum recorded at each dose is presented, highlighting the single line dosimetric peak.

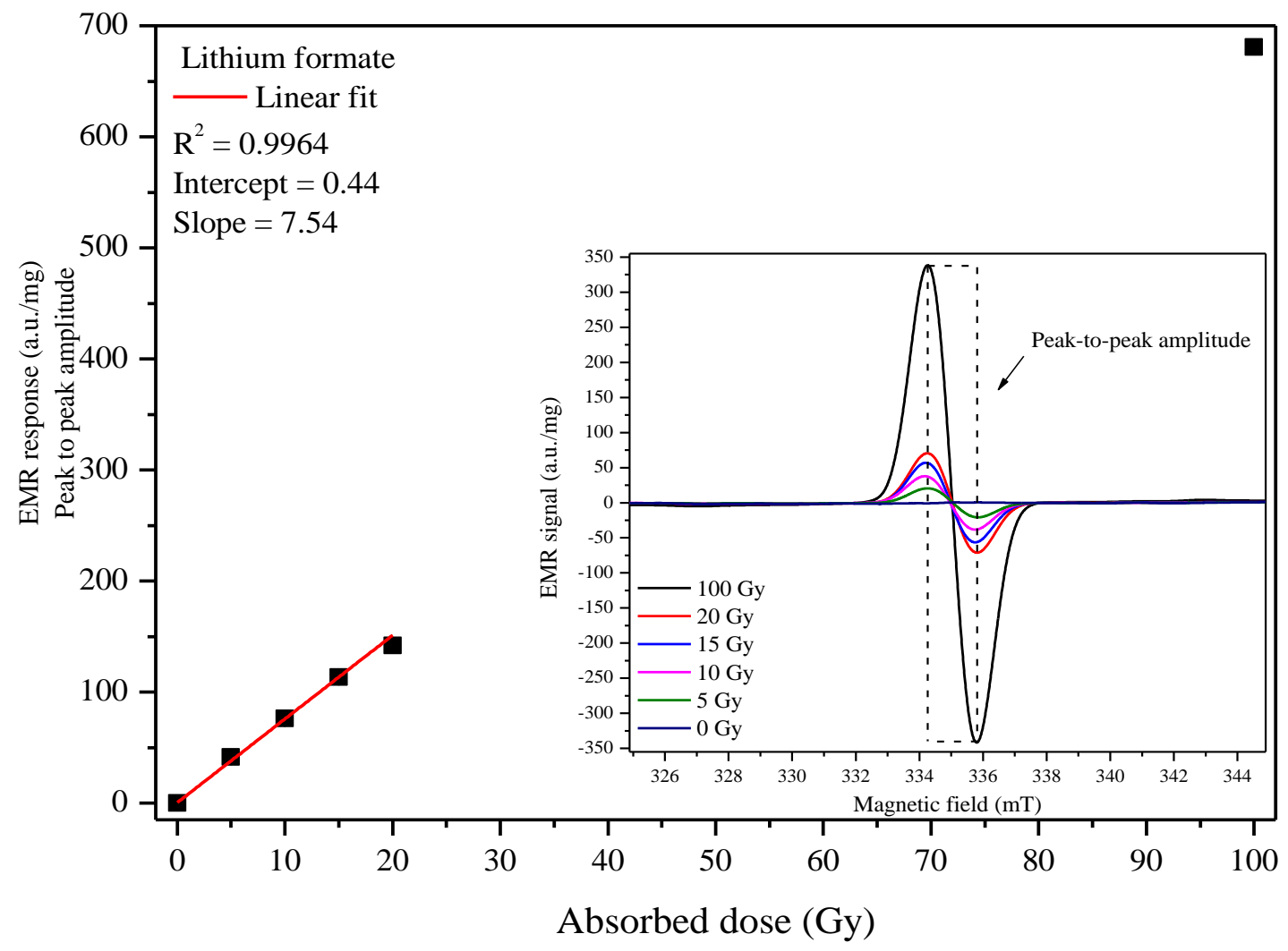

Figure 53 - Sodium acetate dose-response curve. The spectrum presents three peaks and the dosimetric response is considered as the sum of peaks, with linear fitting in the range of 0 to $20 \mathrm{~Gy}$ and the respective parameters. The EMR spectra up to $100 \mathrm{~Gy}$ are also presented.

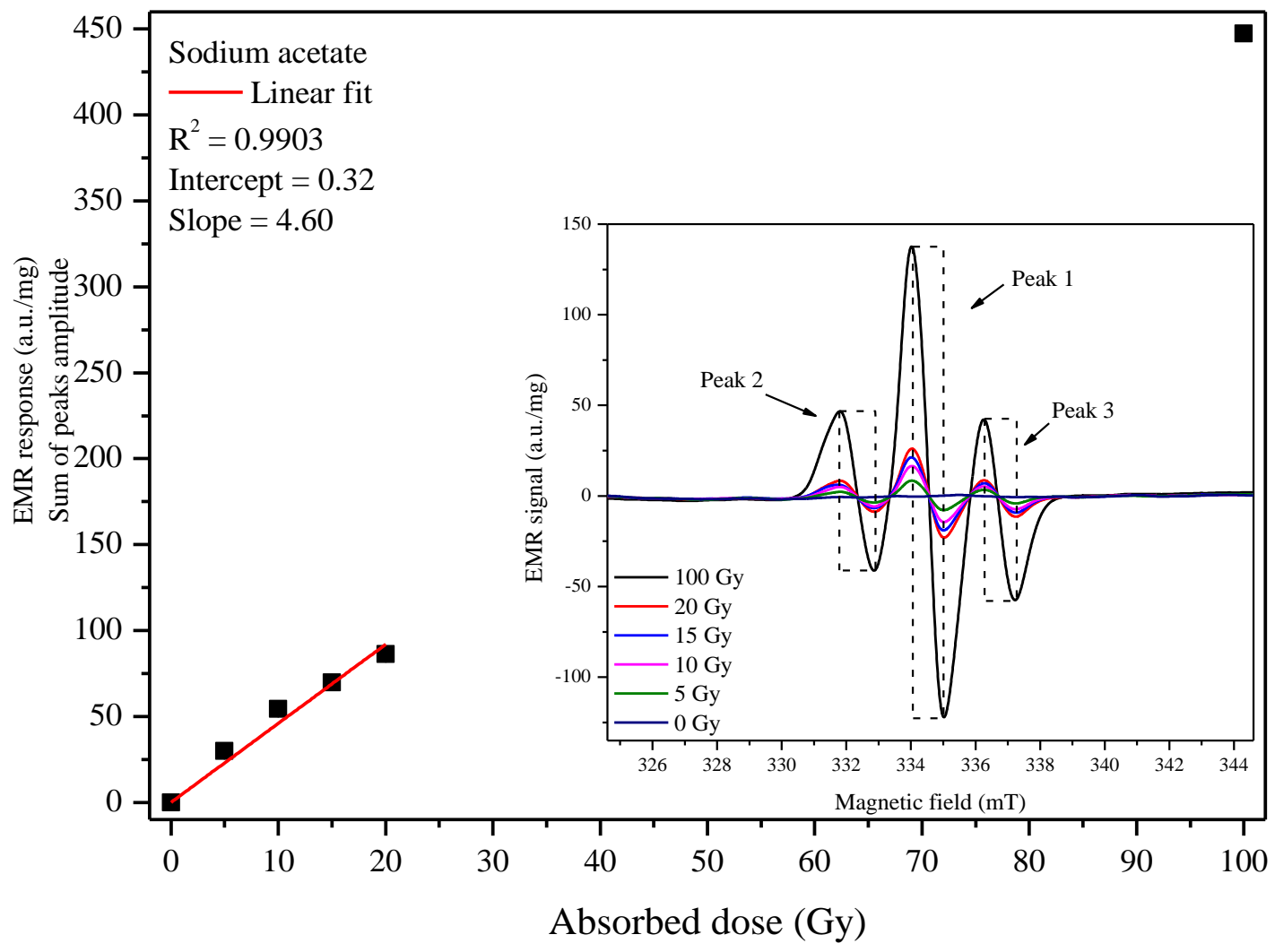


Figure 54 - Sodium carbonate single peak dose-response curve and fitting parameters for the range of 0 to $20 \mathrm{~Gy}$. Also, the EMR spectrum for each dose is presented, showing the peak increase up to $100 \mathrm{~Gy}$.

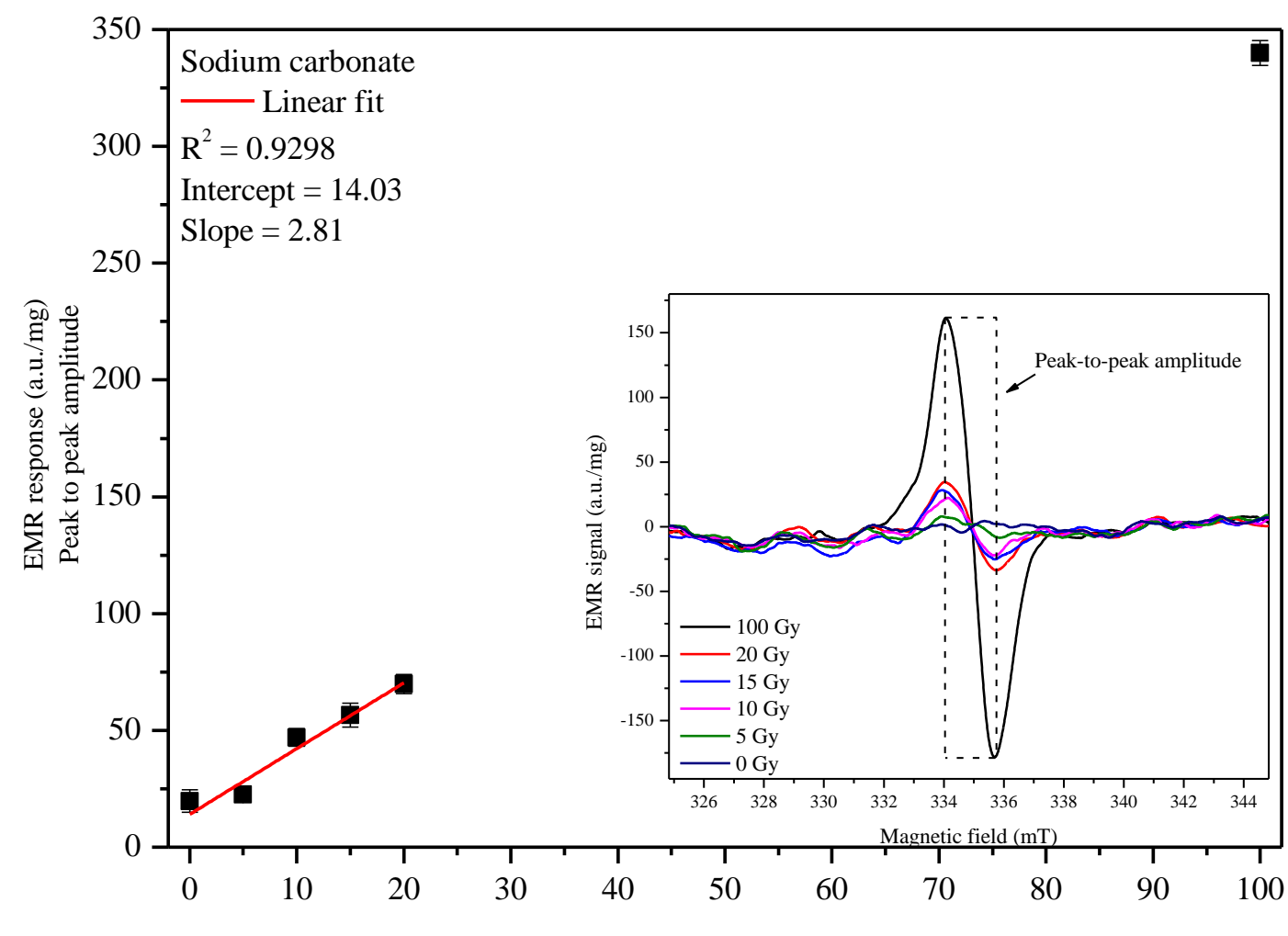

Absorbed dose (Gy)

Figure 55 - Sodium citrate dose-response curve with a linear behavior in the range up to $20 \mathrm{~Gy}$, with its parameters informed below. The dosimetric signal is considered as the first peak of the spectrum, determined as peak 1. The EMR signal growth is present for doses until $100 \mathrm{~Gy}$.

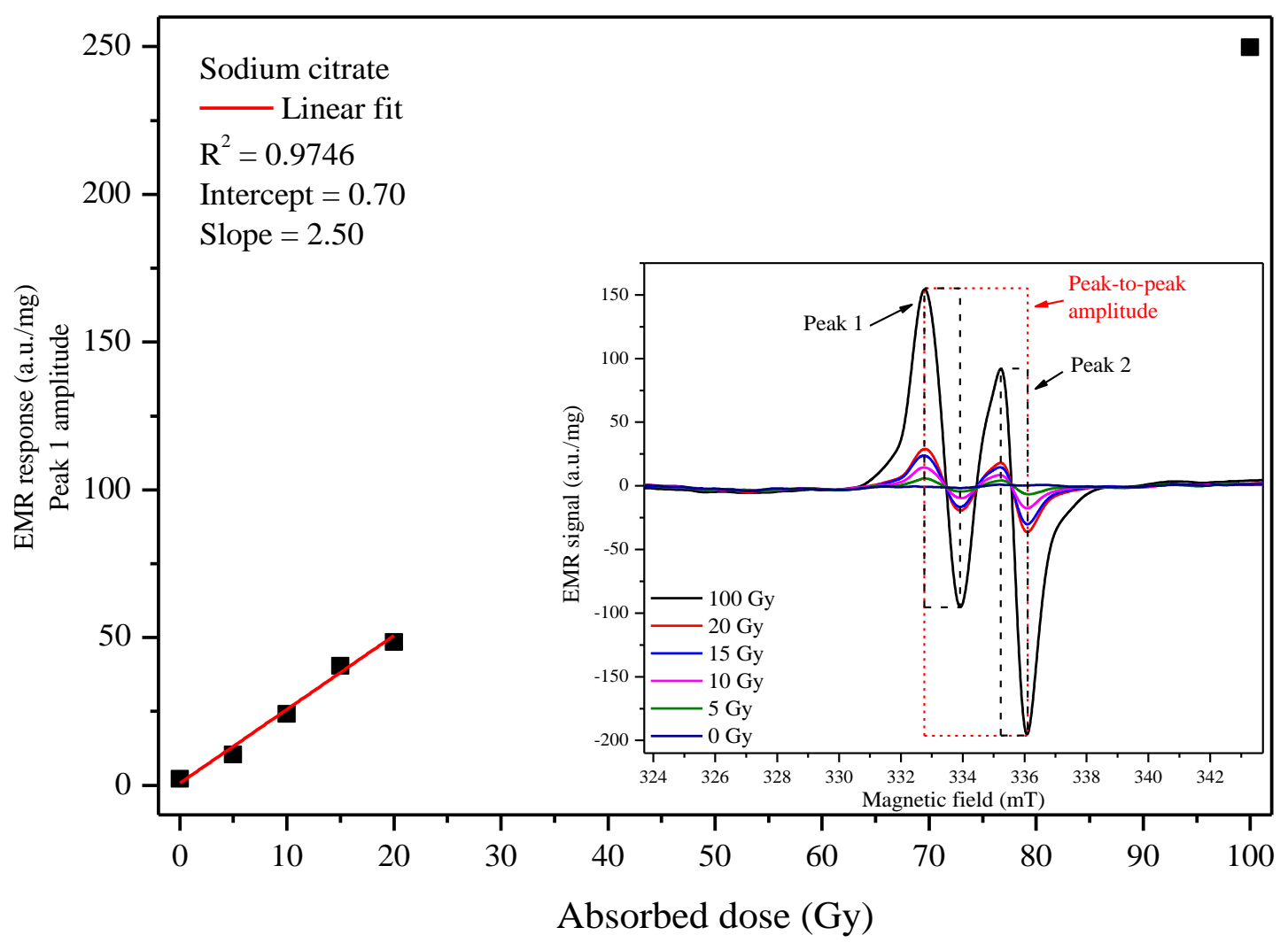


Figure 56 - Sodium dithionite presents a linear behavior for doses up to $20 \mathrm{~Gy}$, and the fitting parameters are shown below. The dosimetric peak is considered as the amplitude of the most intense peak (peak 3), since for low doses, peak 1 and 2 have poor resolution. The EMR spectra from 0 until $100 \mathrm{~Gy}$ are discriminated.

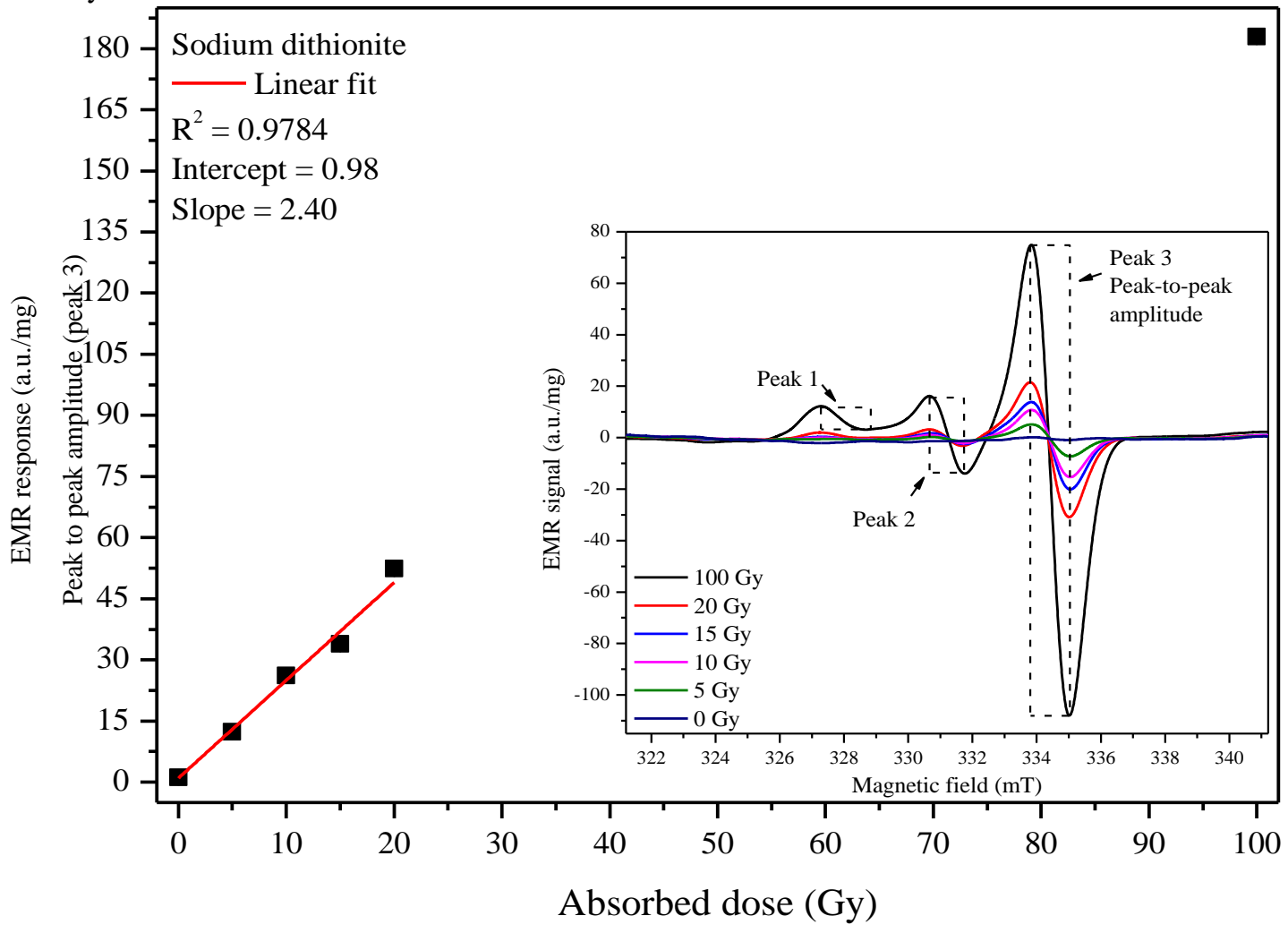

Figure 57 - Sodium formate dose-response curve with a linear fit up to $20 \mathrm{~Gy}$, and its parameters. The compound presents a three peak spectrum, where the dosimetric peak is considered as the amplitude from the maximum to the minimum peak. EMR spectra up to 100 Gy are also presented.

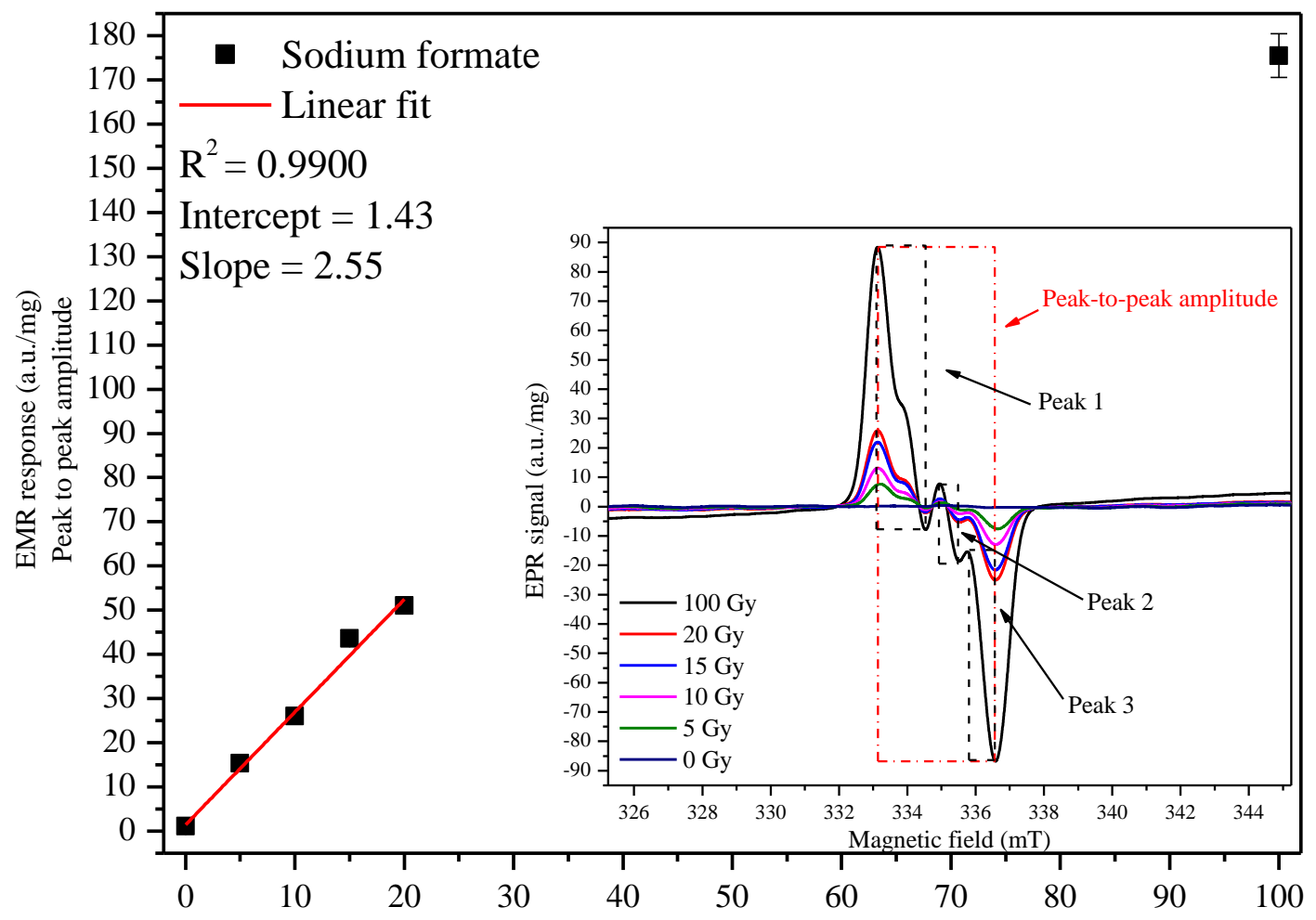

Absorbed dose (Gy) 
Table 27 - List of compounds and their respective parameters used to plot the dose-response curves. The angular coefficient is compared to lithium formate as reference. The standard deviation represents the interval obtained for each dose point in the dose-response curve. Here, the coefficients were normalized by the readout gain.

\begin{tabular}{|c|c|c|c|c|c|}
\hline Compound & $\begin{array}{c}\text { Analysis } \\
\text { method }\end{array}$ & $\mathbf{R}^{2}$ & $\begin{array}{c}\text { Normalized } \\
\text { angular } \\
\text { coefficient }\end{array}$ & $\begin{array}{c}\text { Standard } \\
\text { deviation } \\
(\%)\end{array}$ & $\begin{array}{l}\text { Detection } \\
\text { limit }(\mathbf{G y})\end{array}$ \\
\hline $\begin{array}{l}\text { Lithium } \\
\text { carbonate }\end{array}$ & $\begin{array}{c}\text { Main line } \\
\text { peak-to-peak } \\
\text { amplitude }\end{array}$ & 0.9846 & 4.0 & $2.4-49.3$ & 5 \\
\hline $\begin{array}{l}\text { Lithium } \\
\text { formate }\end{array}$ & $\begin{array}{l}\text { Main line } \\
\text { peak-to-peak } \\
\text { amplitude }\end{array}$ & 0.9964 & 150.0 & $0.8-1.6$ & 2 \\
\hline $\begin{array}{l}\text { Sodium } \\
\text { acetate }\end{array}$ & Sum of peaks & 0.9903 & 4.6 & $0.2-3.6$ & 4 \\
\hline $\begin{array}{l}\text { Sodium } \\
\text { carbonate }\end{array}$ & $\begin{array}{c}\text { Main line peak- } \\
\text { to-peak } \\
\text { amplitude }\end{array}$ & 0.9298 & 2.8 & $1.6-14.0$ & 7 \\
\hline $\begin{array}{c}\text { Sodium } \\
\text { citrate }\end{array}$ & $\begin{array}{l}\text { Amplitude } \\
\text { peak } 1\end{array}$ & 0.9746 & 5 & $0.5-4.3$ & 4.5 \\
\hline $\begin{array}{c}\text { Sodium } \\
\text { dithionite }\end{array}$ & $\begin{array}{c}\text { Main line } \\
\text { peak-to-peak } \\
\text { amplitude }\end{array}$ & 0.9784 & 48.0 & $0.4-3.3$ & 5 \\
\hline $\begin{array}{l}\text { Sodium } \\
\text { formate }\end{array}$ & $\begin{array}{l}\text { Main line } \\
\text { peak-to-peak } \\
\text { amplitude }\end{array}$ & 0.9900 & 52.0 & $0.9-2.8$ & 5 \\
\hline
\end{tabular}

For table 27, the angular coefficient (slope) was normalized by the gain used in EMR measurement of each compound; as for the dose-response curve analysis, it was not considered. Also, the detection limit presented was calculated by the method described previously in Wieser et al. (2008), also applied by Fattibene et al. (2011). Analyzing the linear fittings, lithium formate, by far, has the higher sensitivity, followed by sodium formate and sodium dithionite. Sodium acetate is behind lithium formate for linearity and detection limit. Considering EMR response and linear fitting parameters, sodium formate presented more suitable behavior as an EMR dosimeter.

Sodium dithionite displayed the most stable behavior, with $0.2 \%$ variation, followed by sodium citrate $(1 \%)$ and sodium formate $(3 \%)$. The three compounds with less stability were sodium acetate $(19 \%)$, sodium carbonate $(21 \%)$ and lithium carbonate $(40 \%)$. The results achieved for lithium formate agreed with the literature data (Vestad et al., 2003), as fading after one month was low (2\%).

Other properties that can interfere with the behavior of the irradiated material are the density and atomic effective number, all calculated and displayed in table 28. Concerning the EMR analysis, the experimental $g$ factor for each peak radiated induced is also presented. It is 
important to highlight that this is the empirical Zeff, and, for better accuracy, it is necessary to consider the energy range of the beam studied (Shivaramu and Ramprasath, 2000). 
Table 28 - Different properties of the compounds studied. The EMR signal peaks are considered for the radical induced by radiation for a maximum absorbed dose of $100 \mathrm{~Gy}$.

\begin{tabular}{|c|c|c|c|c|c|c|c|c|c|}
\hline \multicolumn{2}{|c|}{ Compound } & Chemical formula & $\begin{array}{c}\text { Molecular } \\
\text { weight }\end{array}$ & $\mathbf{Z}_{\text {EMPeff }}$ & $\begin{array}{r}\text { Density } \\
\left(\mathrm{g} / \mathrm{cm}^{3}\right)\end{array}$ & $\begin{array}{l}\text { EMR } \\
\text { peaks }\end{array}$ & \multicolumn{3}{|c|}{$\begin{array}{c}\mathrm{g} \text { factor of the radiation } \\
\text { induced signal }\end{array}$} \\
\hline \multicolumn{2}{|c|}{ Water } & $\mathrm{H}_{2} \mathrm{O}$ & 18.00 & 7.42 & 1.00 & - & & - & \\
\hline \multirow{5}{*}{ Lithium } & Carbonate & $\mathrm{Li}_{2} \mathrm{CO}_{3}$ & 73.89 & 7.25 & 2.11 & 3 & & 2.0094 & \\
\hline & Hydroxide & $\mathrm{LiOH}$ & 23.95 & 7.02 & 1.46 & 1 & & 2.0035 & \\
\hline & Formate & $\mathrm{HCO}_{2} \mathrm{Li} \cdot \mathrm{H}_{2} \mathrm{O}$ & 69.97 & 7.23 & 1.48 & 1 & & 2.0099 & \\
\hline & Phosphate & $\mathrm{Li}_{3} \mathrm{PO}_{4}$ & 115.79 & 10.59 & 2.41 & 1 & & 2.0096 & \\
\hline & Sulfate & $\mathrm{Li}_{2} \mathrm{SO}_{4}$ & 109.94 & 11.45 & 2.22 & 3 & 1.9924 & 2.0048 & 2.0184 \\
\hline \multirow{4}{*}{ Potassium } & Carbonate & $\mathrm{K}_{2} \mathrm{CO}_{3}$ & 138.21 & 15.87 & 2.43 & 1 & & 2.0057 & \\
\hline & Iodate & $\mathrm{KIO}_{3}$ & 214.00 & 43.59 & 3.89 & - & & - & \\
\hline & Permanganate & $\mathrm{KMnO}_{4}$ & 158.03 & 19.13 & 2.70 & 1 & & 2.0047 & \\
\hline & Phosphate & $\mathrm{KH}_{2} \mathrm{PO}_{4}$ & 136.09 & 14.22 & 2.34 & 3 & & 2.0013 & \\
\hline \multirow{7}{*}{ Sodium } & Acetate & $\mathrm{CH}_{3} \mathrm{CO}_{2} \mathrm{Na} \cdot 3 \mathrm{H}_{2} \mathrm{O}$ & 136.08 & 8.05 & 1.53 & 3 & 1.9945 & 2.0079 & 2.0210 \\
\hline & Carbonate & $\mathrm{Na}_{2} \mathrm{CO}_{3}$ & 105.99 & 9.37 & 2.54 & 1 & & 2.0097 & \\
\hline & Citrate & $\mathrm{C}_{6} \mathrm{H}_{5} \mathrm{O}_{7} \mathrm{Na}_{3} \cdot 2 \mathrm{H}_{2} \mathrm{O}$ & 294.10 & 8.38 & 1.70 & 2 & 2.0009 & & 2.0146 \\
\hline & Dithionite & $\mathrm{Na}_{2} \mathrm{~S}_{2} \mathrm{O}_{4}$ & 174.11 & 12.69 & 2.19 & 3 & 1.9646 & 1.9848 & 2.0041 \\
\hline & Formate & $\mathrm{HCO}_{2} \mathrm{Na}$ & 68.01 & 8.91 & 1.92 & 3 & 2.0024 & 2.0118 & 2.0173 \\
\hline & Phosphate & $\mathrm{Na}_{2} \mathrm{HPO}_{4}$ & 141.96 & 11.10 & 1.62 & 2 & 1.9933 & & 2.0056 \\
\hline & Tetraborate & $\mathrm{Na}_{2} \mathrm{~B}_{4} \mathrm{O}_{7}$ & 201.22 & 7.86 & 1.73 & 1 & \multicolumn{3}{|c|}{2.0046} \\
\hline
\end{tabular}


Considering the $\mathrm{g}$ factor, there is an intrinsic probable error in the fourth decimal place of $0.0002 \sim 0.0005$ (Ikeya, 1993), and some radicals that constitute the studied compounds had already been presented, such as the ones in table 29. For crystalline samples (the case of this study), there is a variation in $\mathrm{g}$ factor according to the magnetic field direction, resulting in another intrinsic standard deviation, with the need for an average of $g$ factors for different directions, which is one reason for the deviations between the values in table 28 and table 29 . Therefore, to describe and define $\mathrm{g}$ factors precisely, a profound study must be done covering all the variations.

Table 29 - $\mathrm{g}$ factors reported in the literature of some radicals that constitute the spectra of the lithium, potassium and sodium compounds studied.

\begin{tabular}{|c|c|c|c|c|}
\hline Radical & & $\mathrm{g}$ factor & & Reference \\
\hline $\mathrm{CO}^{-}$ & & 2.0054 & & $\begin{array}{c}\text { (Negron-Mendonza et al., } \\
\text { 2015) }\end{array}$ \\
\hline \multirow{3}{*}{$\mathrm{CO}_{2}^{-}$} & 19975 & 2.0014 & 2.0032 & (Ovennal and Whiffen, 1961) \\
\hline & & 2.0006 & & (Murali et al., 2001) \\
\hline & 1.9965 & 2.0008 & 2.0032 & (Vestad et al., 2004b) \\
\hline \multirow{2}{*}{$\mathrm{CO}_{3}^{-}$} & 2.0066 & 2.0086 & 2.0184 & (Chantry et al., 1962) \\
\hline & & 2.0036 & & (Murali et al., 2001) \\
\hline $\mathrm{SO}_{3}^{-}$ & & 2.0039 & & (Sharaf and Hassan, 2004) \\
\hline
\end{tabular}

For comparison with tissue and water data, the mass attenuation coefficient curve is shown in figure 58 , covering the clinical energy range $(0.02-25 \mathrm{MeV})$, with zoom in for the region investigated, and as predicted, as the Zeff decreases, so does the attenuation showing that the materials with closer zeff for low energy range behave similarly. 
Figure 58 - Mass attenuation coefficient curve of the compounds that presented suitable doseresponse curve. The energy range agreed with the clinical range on going from diagnostic Xrays to megavoltage $(0.02-25 \mathrm{MeV})$, also including lower values, such as $0.008-0.02 \mathrm{MeV}$, in accordance with the beam used. It is possible to see a zoom in of the zone in which the previous irradiation was performed.

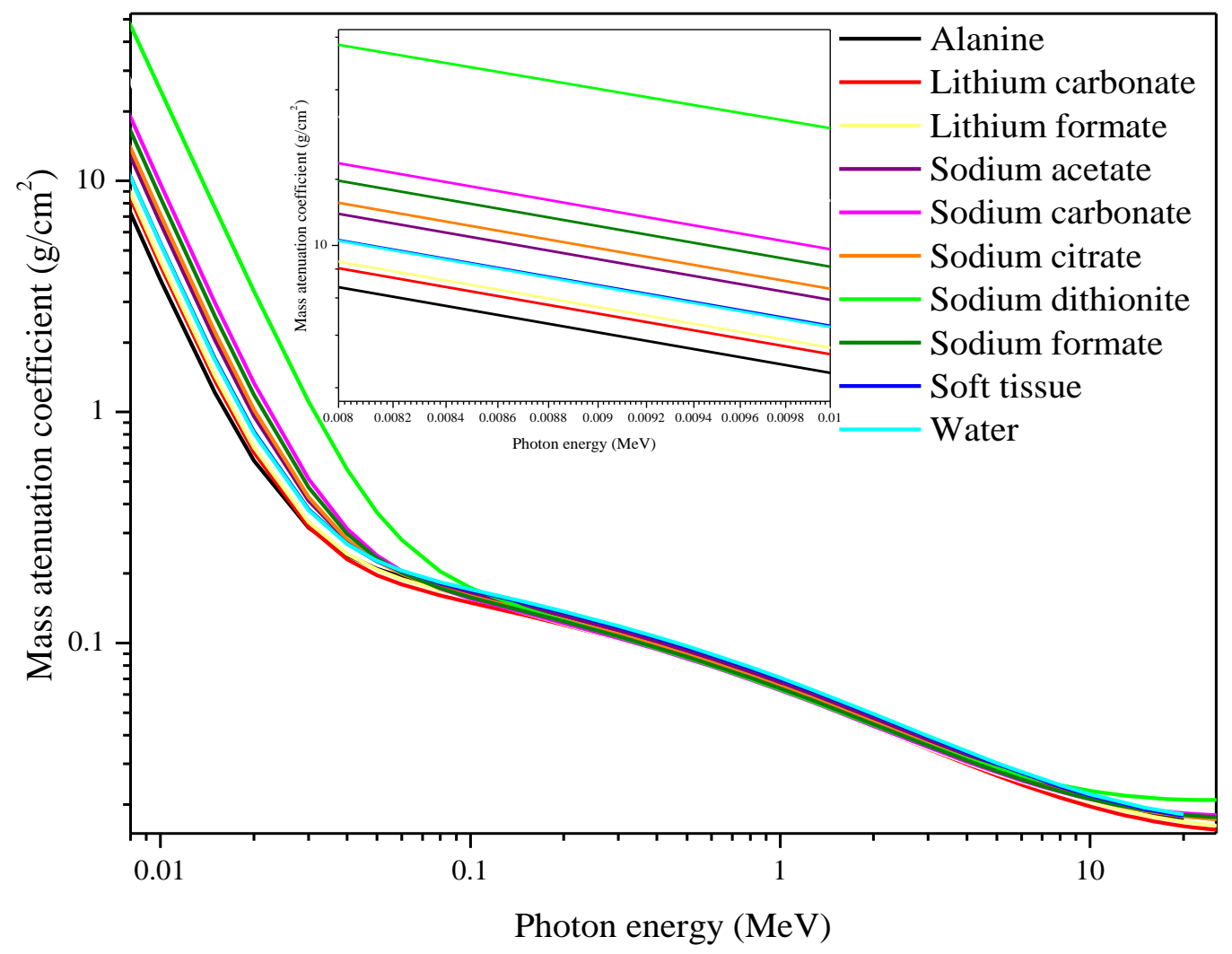

Because they have lower atomic number, lithium compounds like lithium carbonate, lithium formate, and lithium hydroxide are among the materials that resemble water the most in terms of density and effective atomic number. As for the mass attenuation coefficient curves, sodium acetate and sodium citrate are better suits. Considering the physical-chemical properties and the mass attenuation coefficient (but not the EMR response), sodium acetate is the most suitable material. For the evaluation about the EMR signal, the fitting, correlation coefficient $\left(\mathrm{R}^{2}\right)$, standard deviation and fading were considered, resulting in sodium formate, sodium dithionite and sodium citrate. Considering mainly EMR response over all the analyses, sodium formate was the most promising new material, as summarized in table 30. 
Table 30 - Summary showing which compound presented the best behavior in terms of each characteristic studied.

\begin{tabular}{ccccc}
\hline & Density & $\mathrm{z}_{\mathrm{eff}}$ & $\begin{array}{c}\text { Mass attenuation } \\
\text { coefficient curve }\end{array}$ & $\begin{array}{c}\text { EMR } \\
\text { signal }\end{array}$ \\
\hline $\begin{array}{c}\text { Lithium carbonate } \\
\text { Lithium formate }\end{array}$ & $\mathrm{X}$ & $\mathrm{X}$ & $\mathrm{X}$ & $\mathrm{X}$ \\
$\begin{array}{c}\text { Sodium acetate } \\
\text { Sodium carbonate }\end{array}$ & & $\mathrm{X}$ & $\mathrm{X}$ & \\
$\begin{array}{c}\text { Sodium citrate } \\
\text { Sodium dithionite }\end{array}$ & & $\mathrm{X}$ & $\mathrm{X}$ \\
Sodium formate & & & & $\mathrm{X}$ \\
\hline
\end{tabular}

All the materials on table 30 could be employed in an unforeseen scenario for dose estimation purposes. Only lithium formate was investigated, but the others were not investigated and compared to each other in the same conditions to provide a critical appraisal of their performance as dosimeters. Regarding the application of these compounds, they can all be found in laboratories and have several uses that range from medications to different industrial areas, so they are promptly available during an emergency. Only potassium carbonate and potassium phosphate presented no stability regarding humidity, being easily melted in ambient conditions; beside, after five months, no EPR signal was observed for sodium phosphate irradiated with 100 Gy. Evidently, for clinical dosimetry purposes, more research must be conducted with irradiation beams and conditions employed in radiodiagnosis and radiotherapy.

\subsection{SULFITES}

A sulfite is a sulfurous acid $\left(\mathrm{H}_{2} \mathrm{SO}_{3}\right)$ which contains the negative form $\mathrm{SO}^{-}$, commonly used as food preservative and additive. Part of sulfites are the bisulfites $\left(\mathrm{HSO}_{3}^{-}\right)$and metabisulfites $\left(\mathrm{S}_{2} \mathrm{O}_{5}{ }^{2-}\right)$, in which the radical anions $\bullet \mathrm{SO}_{3}{ }^{2-}, \cdot \mathrm{HSO}_{3}{ }^{-}$and $\bullet \mathrm{S}_{2} \mathrm{O}_{5}{ }^{2-}$ are detectable by EMR spectroscopy. These radicals are characterized by a single line EMR spectrum as presented in figure 59. 
Figure 59 - EMR signal of different sulfites and their chemical structure, all of them characterized by one single line EMR spectrum.
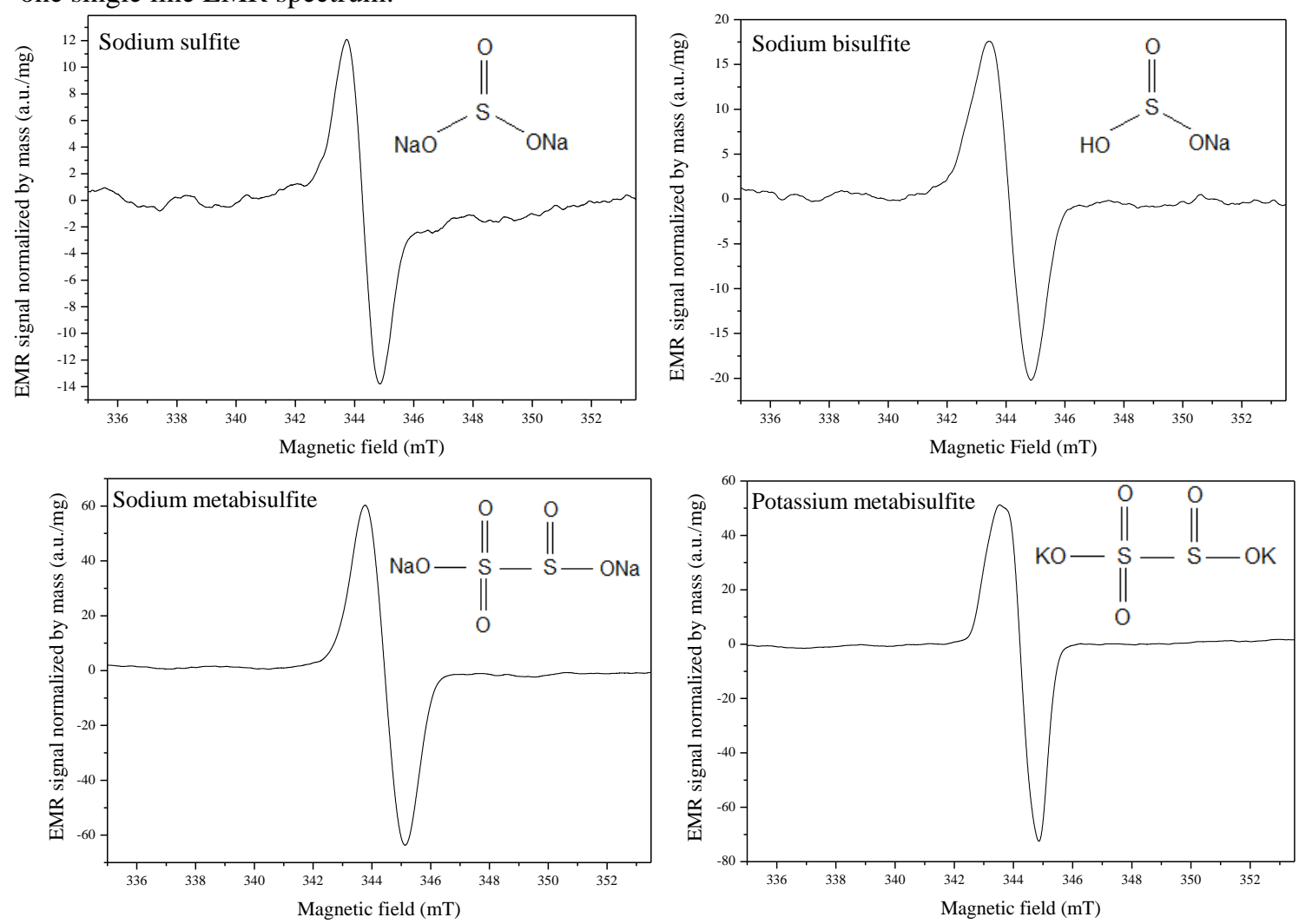

Some aspects of inorganic EMR dosimeters for medical radiotherapy have already been discussed (Bogushevich and Ugolev, 2000) and showed that alkaline earth dithionates $\left(\mathrm{S}_{2} \mathrm{O}_{6}{ }^{2-}\right)$ have great potential. Irradiated dithionates exhibit a single, narrow line stable at room temperature attributed to $\cdot \mathrm{SO}_{3}{ }^{-}$radical anions (Baran et al., 2006; Danilczuk et al., 2008). The oxidation of dithionates $\left(\mathrm{S}_{2} \mathrm{O}_{6}{ }^{2-}\right)$ could result in sulfites $\left(\mathrm{SO}_{3}{ }^{2-}\right)$, which could further result in dithionites $\left(\mathrm{S}_{2} \mathrm{O}_{4}{ }^{2-}\right.$ ) (Murthy, Eager and McCallum, 1971), being also detectable by EMR spectroscopy as shown with sodium dithionite in the previous section. Some properties of each sulfite are presented in table 31.

Table 31 - Some chemical and physical properties of the sulfites studied.

\begin{tabular}{cccccc}
\hline & $\begin{array}{c}\text { Chemical } \\
\text { formula }\end{array}$ & $\begin{array}{c}\mathbf{M} \\
(\mathrm{g} / \mathbf{m o l})\end{array}$ & $\begin{array}{c}\text { Density } \\
\left(\mathbf{g} / \mathbf{c m}^{3}\right)\end{array}$ & $\mathrm{z}_{\text {eff }}$ & $\begin{array}{c}\text { EMR } \\
\text { g factor }\end{array}$ \\
\hline $\begin{array}{c}\text { Potassium } \\
\text { metabisulfite } \\
\text { Sodium } \\
\text { bisulfite }\end{array}$ & $\mathrm{K}_{2} \mathrm{~S}_{2} \mathrm{O}_{5}$ & 222.32 & 2.34 & 15.5 & 2.0008 \\
$\begin{array}{c}\text { Sodium } \\
\text { metabisulfite }\end{array}$ & $\mathrm{NaHSO}_{3}$ & 104.06 & 1.48 & 12.1 & 2.0000 \\
$\begin{array}{c}\text { Sodium } \\
\text { sulfite }\end{array}$ & $\mathrm{Na}_{2} \mathrm{~S}_{2} \mathrm{O}_{5}$ & 190.10 & 1.48 & 12.4 & 2.0022 \\
\hline
\end{tabular}




\subsubsection{Materials and methods}

Crystals of potassium metabisulfite (Synth), sodium bisulfite (Sigma-Aldrich), sodium metabisulfite (Reagen), and sodium sulfite (Nuclear) were all commercially obtained. Irradiation was performed with a linear accelerator Siemens Mevatron $6 \mathrm{MV}$, with dose in water between 1 and $20 \mathrm{~Gy}$, for dose-response curve investigation. The materials were placed between solid water slabs with thickness to allow proper build-up $(1.5 \mathrm{~cm})$ and backscattering conditions $(15 \mathrm{~cm})$ in a $10 \times 10 \mathrm{~cm}^{2}$ field and $100 \mathrm{~cm}$ SSD, as recommended by TRS-398 (IAEA, 2001).

The analyses of the radical production by ionizing radiations were carried out with the JEOL EMR X-band spectrometer. The saturation parameters were studied for each compound and the signal shape regarding the modulation amplitude. The experimental parameters are presented in table 32. The signal intensity was considered in two ways: as the peak-to-peak amplitude of the main line obtained by the first derivative of the absorption spectrum normalized by the mass; and as the recorded area of EMR absorption line by means of the double integral of the signal. The double integration was performed with the JEOL analysis software also normalized by mass quantity. To confirm the assigned of the induced radicals by radiation, spectra simulation with the JEOL software was compared with experimental results.

Table 32 - EMR spectrometer parameters for the sulfites study.

\begin{tabular}{|c|c|c|c|c|}
\hline Parameter & $\begin{array}{c}\text { Potassium } \\
\text { metabisulfite }\end{array}$ & $\begin{array}{l}\text { Sodium } \\
\text { bisulfite }\end{array}$ & $\begin{array}{c}\text { Sodium } \\
\text { metabisulfite }\end{array}$ & $\begin{array}{l}\text { Sodium } \\
\text { sulfite }\end{array}$ \\
\hline Center magnetic field (mT) & 337.055 & 337.180 & 336.852 & 336.968 \\
\hline Microwave power (mW) & 2.5 & 4.0 & 2.0 & 3.0 \\
\hline $\begin{array}{c}\text { Modulation amplitude } \\
(\mathbf{m T})\end{array}$ & 1.0 & 1.4 & 1.4 & 1.0 \\
\hline Sweep width (mT) & \multicolumn{4}{|c|}{10} \\
\hline Time constant (s) & \multicolumn{4}{|c|}{0.3} \\
\hline Gain & \multicolumn{4}{|c|}{$10 \times 100$} \\
\hline Sweep time (min) & \multirow{2}{*}{\multicolumn{4}{|c|}{$\begin{array}{l}1 \\
3\end{array}$}} \\
\hline Number of scans & & & & \\
\hline Sample mass (mg) & $\sim 80$ & $\sim 85$ & $\sim 60$ & $\sim 90$ \\
\hline $\begin{array}{l}\text { Quartz tube inner } \\
\text { diameter }(\mathbf{m m})\end{array}$ & \multicolumn{4}{|c|}{4} \\
\hline
\end{tabular}




\subsubsection{Results and discussion}

The dose-response curve is presented considering the main peak-to-peak amplitude compared to the area of the double integration for each compound in figure 60. More than in the peak-to-peak method, the double integration is affected by signal noise, base line drift, and background signal, highlighted in the case of zero dose for potassium metabisulfite, in which the signal had a poor baseline compared to the other doses and compounds, as shown in figure 61. 
Figure 60 - Dose-response curve by EMR peak-to-peak amplitude and double integration method for each sulfite.

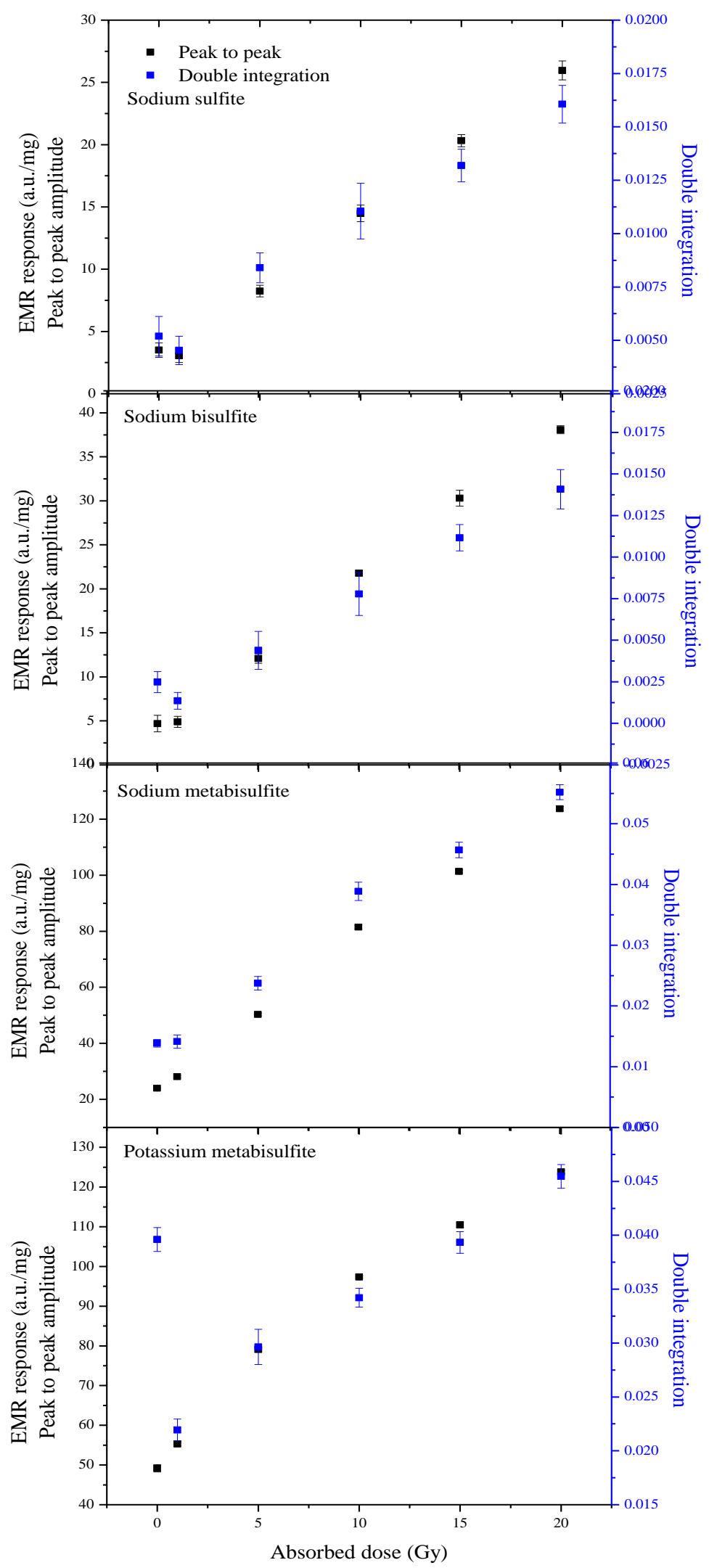


Figure 61 - Sulfites spectra obtained for doses from 0 to $20 \mathrm{~Gy}$.
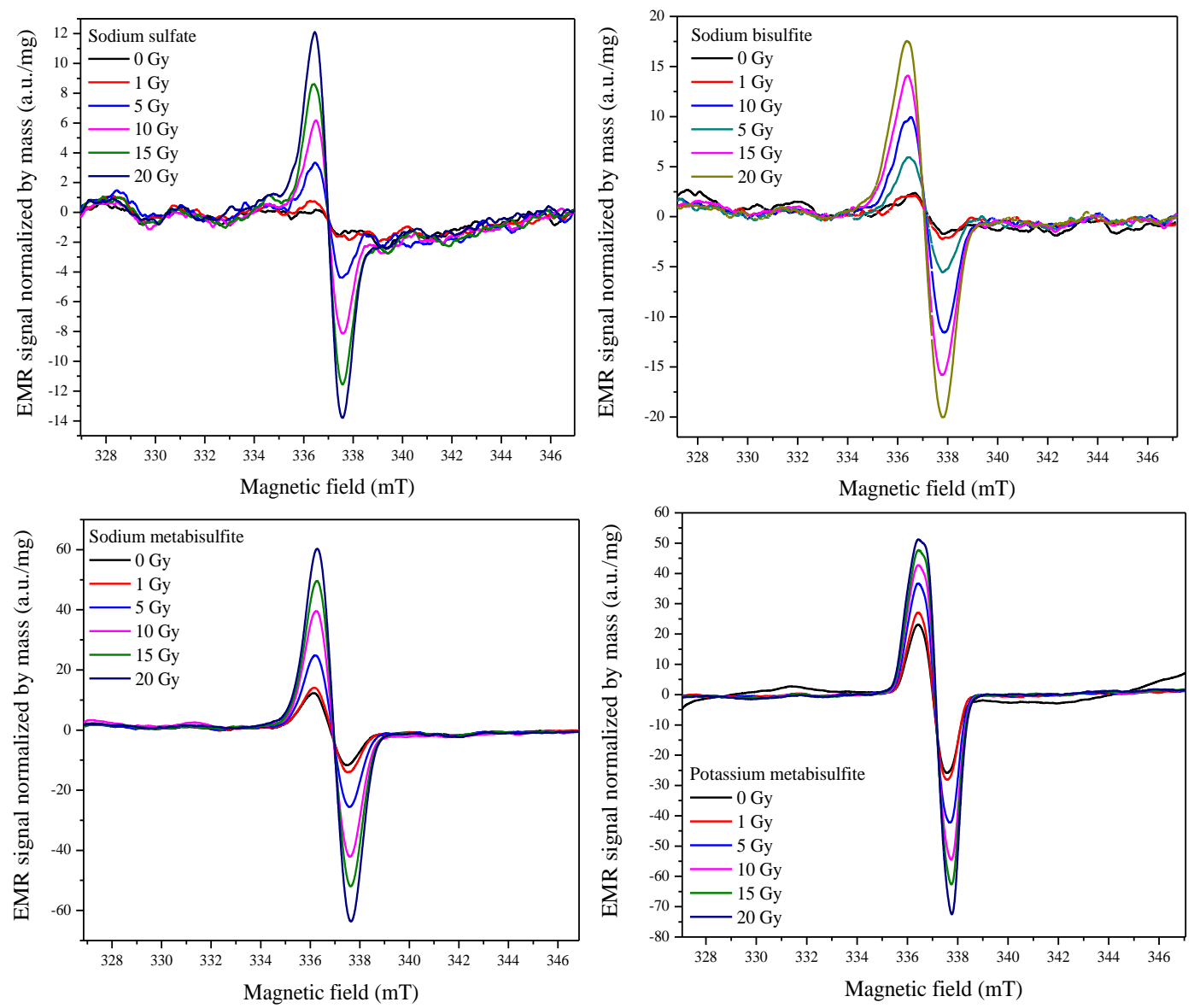

Table 33 shows the dose-response equations and the correlation coefficients $\left(\mathrm{R}^{2}\right)$ for each material. Only the peak-to-peak analysis of potassium metabisulfite presented a polynomial behavior.

Table 33 - Equations and correlation coefficients for each sulfite for the corresponding analysis method.

Peak to peak

Double integration

\begin{tabular}{|c|c|c|c|c|c|c|}
\hline & Equation & $\mathbf{R}^{2}$ & $\begin{array}{l}\text { Detection } \\
\text { limit }\end{array}$ & Equation & $\mathbf{R}^{2}$ & $\begin{array}{l}\text { Detection } \\
\text { limit }\end{array}$ \\
\hline $\begin{array}{l}\text { Sodium } \\
\text { sulfite }\end{array}$ & $\mathrm{D}_{\mathrm{a}}=0.9 * \mathrm{SI}_{\mathrm{EMR}}-2$ & 0.9952 & 0.7 Gy & $\mathrm{D}_{\mathrm{a}}=1744 * \mathrm{SI}_{\mathrm{EMRdi}}-8$ & 0.9752 & $5.3 \mathrm{~Gy}$ \\
\hline $\begin{array}{l}\text { Sodium } \\
\text { bisulfite }\end{array}$ & $\mathrm{D}_{\mathrm{a}}=0.6 * \mathrm{SI}_{\mathrm{EMR}}-2$ & 0.9968 & $0.7 \mathrm{~Gy}$ & $\mathrm{D}_{\mathrm{a}}=1571 * \mathrm{SI}_{\mathrm{EMRdi}}-2$ & 0.9685 & $0.8 \mathrm{~Gy}$ \\
\hline $\begin{array}{c}\text { Sodium } \\
\text { metabisulfite }\end{array}$ & $\mathrm{D}_{\mathrm{a}}=0.2 * \mathrm{SI}_{\mathrm{EMR}}-5$ & 0.9963 & $2.6 \mathrm{~Gy}$ & $\mathrm{D}_{\mathrm{a}}=467 * \mathrm{SI}_{\mathrm{EMRdi}}-6$ & 0.9908 & $4.2 \mathrm{~Gy}$ \\
\hline $\begin{array}{l}\text { Potassium } \\
\text { metabisulfite }\end{array}$ & $\mathrm{D}_{\mathrm{a}} *(58-\mathrm{D})=10 * \mathrm{SI}_{\mathrm{EMR}}-504$ & 0.9962 & 5 Gy & $\mathrm{D}_{\mathrm{a}}=826 * \mathrm{SI}_{\text {EMRdi }}-18$ & 0.9869 & $4.8 \mathrm{~Gy}$ \\
\hline
\end{tabular}


Table 34 resumes the uncertainty components during the process to determine dose, concerning the experimental procedure and analysis. The metabisulfites, which presented the highest amplitudes, also presented the smallest standard deviations related to readout reproducibility and repeatability.

Table 34 - Uncertainties budget concerning the sulfites EMR readout and analyses.

\begin{tabular}{|c|c|c|c|c|c|}
\hline & \multirow[b]{2}{*}{$\begin{array}{l}\text { Sodium } \\
\text { sulfite }\end{array}$} & \multirow[b]{2}{*}{$\begin{array}{l}\text { Sodium } \\
\text { bisulfite }\end{array}$} & \multirow[b]{2}{*}{$\begin{array}{c}\text { Sodium } \\
\text { metabisulfite }\end{array}$} & \multirow[b]{2}{*}{$\begin{array}{c}\text { Potassium } \\
\text { metabisulfite }\end{array}$} \\
\hline & & & & & \\
\hline \multirow{5}{*}{$\begin{array}{c}\text { Experimental } \\
\text { EMR measurement }\end{array}$} & Reproducibility & $5.5 \%$ & $3.4 \%$ & $0.8 \%$ & $0.9 \%$ \\
\hline & Repeatability & $3.1 \%$ & $4.1 \%$ & $1.4 \%$ & $0.7 \%$ \\
\hline & Calibration & $7 \%$ & $7 \%$ & $1 \%$ & $1 \%$ \\
\hline & Sample & & & & \\
\hline & $\begin{array}{l}\text { anisotropy in the } \\
\text { cavity }\end{array}$ & $2.9 \%$ & $10.1 \%$ & $0.1 \%$ & $0.9 \%$ \\
\hline Analysis & Intercept & $14.4 \%$ & $13.2 \%$ & $4.4 \%$ & $0.04 \%$ \\
\hline \multirow{3}{*}{$\begin{array}{c}\text { Peak-to-peak } \\
\text { Dose-response curve }\end{array}$} & & & & & \\
\hline & $\begin{array}{l}\text { First order } \\
\text { coefficient }\end{array}$ & $3.1 \%$ & $2.5 \%$ & $2.7 \%$ & $0.1 \%$ \\
\hline & $\begin{array}{l}\text { Second order } \\
\text { coefficient }\end{array}$ & - & - & - & $0.1 \%$ \\
\hline
\end{tabular}

Analyzing the EMR spectrum, the most probable radical anion is $\cdot \mathrm{SO}_{3}{ }^{-}$for all the sulfites studied. Sulphur and oxygen, in their stable form, present nuclear spins equal to zero, resulting in a single line spectrum (Chantry et al., 2006; Gustafsson et al., 2013). For comparison purposes, a simulated spectrum was compared with the sodium sulfite experimental spectrum, as shown in figure 62. The signal intensities presented, from the most intense to the least intense, were: sodium metabisulfite, potassium metabisulfite, sodium bisulfite and sodium sulfite, observing that chemical structures composed by more elements showed greater intensity of signal, due to the larger quantity of free electrons. Also, comparing potassium and sodium metabisulfite, it was observed that the spectrum intensity increased as the atomic number decreased, because although the lighter elements have stronger chemical bonds, they tend to donate electrons easily when present in a larger chemical structure, creating a greater number of free radicals to be detected by EMR. 
Figure 62 - Comparison between the experimental EMR spectrum of sodium sulfite and the simulated $\mathrm{SO}_{3}{ }^{-}$EMR spectrum.

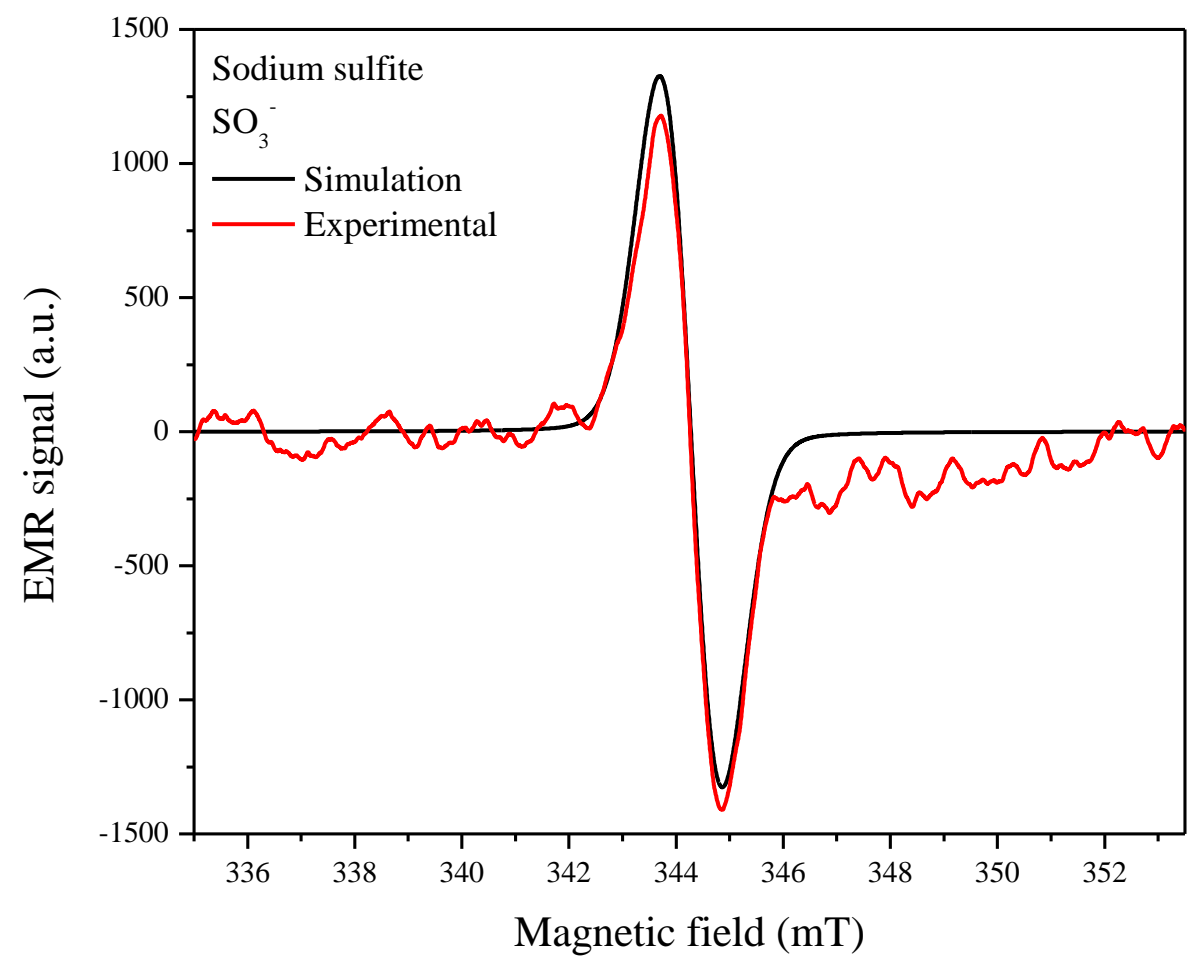

Sulfites presented a proportional response with radiation, fit to be used as EMR dosimeters. Their presence in several products facilitates the use in case of an unforeseen scenario. Also, analysis makes it possible to conclude that structures with elements with lower atomic numbers present a stronger EMR signal, which, in a clinical view, is also better if they presented less density and smaller effective atomic numbers, gradually compared to tissue or water. As a reference, sulfites dose-response curves were compared to L-alanine, shown in figure 63, while the slopes of each curve are displayed in table 35. 
Figure 63 - Sulfites and L-alanine dose-response curves. The parameters were normalized for comparison.

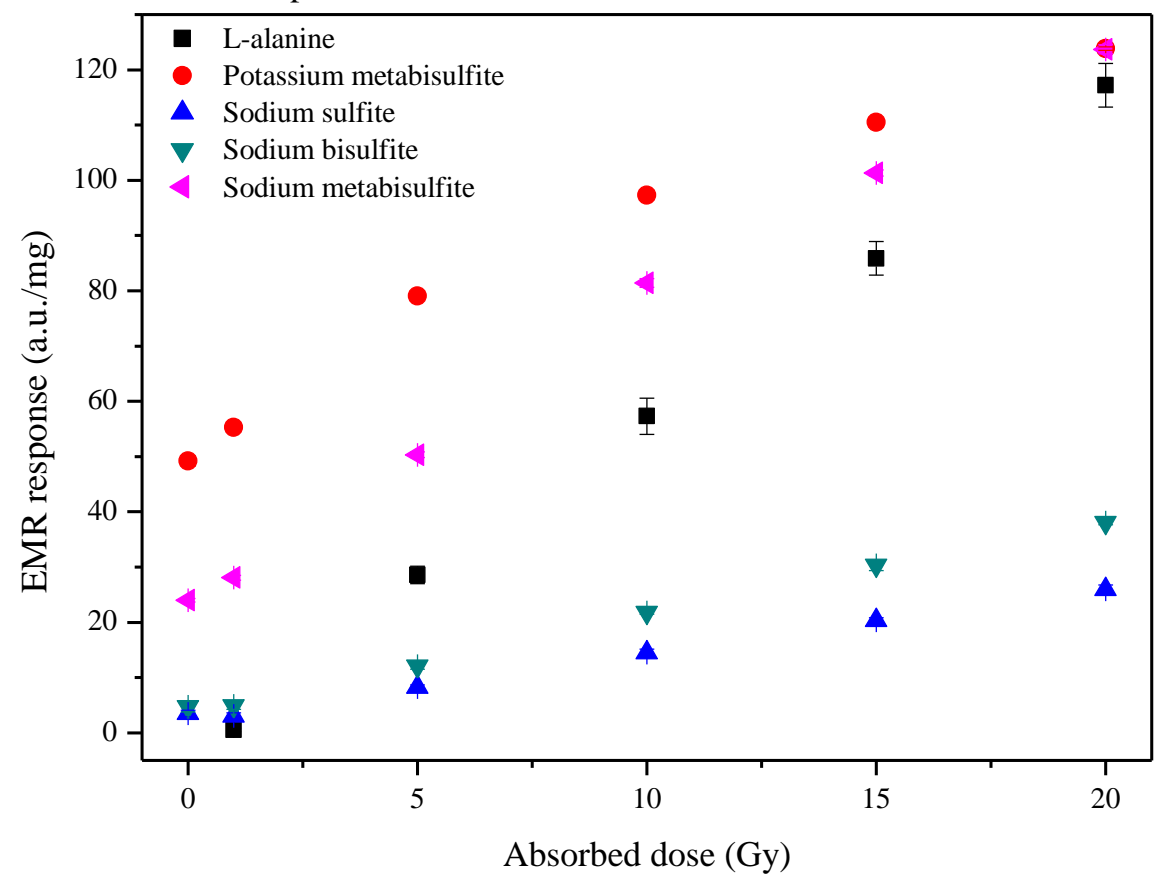

Table 35 - Slopes of L-alanine and sulfites dose-response curve.

\begin{tabular}{cc}
\hline & $\begin{array}{c}\text { Dose-response curve } \\
\text { Slope }\end{array}$ \\
\hline L-alanine & 6.2 \\
Potassium metabisulfite & 3.4 \\
Sodium bisulfite & 1.7 \\
Sodium metabisulfite & 1.2 \\
Sodium sulfite & 5.2 \\
\hline
\end{tabular}

In comparison with L-alanine, sodium metabisulfite has the closest response and sensitivity (20\% less), maintaining alanine as the most suitable material for EMR dosimetry. Anyway, the presence of sulfite in ordinary situations turns the investigation interesting if food with these additives could also present any EMR response. 


\section{CONCLUSION}

Clinical dosimetry presents several difficulties and requirements, necessary for quality assurance. The new system presented, called EPResize ${ }^{\circledR}$, still needs investigation for clinical purposes (when using doses up to $\pm 25 \mathrm{~Gy}$ ). As for comparison with treatment planning system, EMR dosimetry with L-alanine continues to be precise and in accordance with the planned doses, verifying the treatment accuracy.

Many are the materials found in nature or processed in laboratory that can exhibit an EMR response with dose and be applied in different scenarios/situations. Among the ones presented, the sulfites presented the best EMR response, and are possibilities for the future in EMR dosimetry.

Although divided in two sections, all the intent of this thesis covers EMR dosimetry, showing the difficulties and challenges of this technique. Applied EMR spectroscopy is still an open scientific field with many opportunities and investigations to be conducted, with contributions not only for clinical or accident scenarios, but also for industry and other purposes. 


\section{REFERENCES ${ }^{8}$}

ABDUL-HADI, T. et al. An experimental method to calculate the on-axis dose in small field for stereotactic radiotherapy. International Journal of Cancer Therapy and Oncology, v. 4, n. 4, p. 1-9, 2016.

ADOLFSSON, E. et al. Response of lithium formate EPR dosimeters at photon energies relevant to the dosimetry of brachytherapy. Medical Physics, v. 37, n. 9, p. 4946-4959, 2010.

ADOLFSSON, E. et al. Investigation of signal fading in lithium formate EPR dosimeters using a new sensitive method. Physics in Medicine and Biology, v. 57, n. 8, p. 2209-2207, 2012.

ALFONSO, R. et al. A new formalism for reference dosimetry of small and nonstandard fields. Medical Physics, v. 35, n. 11, p. 5179-5186, 2008.

ALVES, G. G. et al. Accuracy for dose planning for prostate radiotherapy in the presence of metallic implants evaluated by electron spin resonance dosimetry. Brazilian Journal of Medical and Biological Research, v. 48, n. 7, p. 644-649, 2015.

ALZIMAMI, K. S.; MAGHRABY, A. M.; BRADLEY, D. A. Comparative study of some new EPR dosimeters. Radiation Physics and Chemistry, v. 95, p. 109-112, 2014.

ATTIX, F. H. Introduction to radiological physics and radiation dosimetry. Madison: John Wiley\& Sons, 1986.

BAFFA, O.; KINHOSITA, A. Clinical applications of alanine/electron spin resonance dosimetry. Radiation Environment Biophysics, v. 53, n. 2, p. 233-240, 2014.

BARAN, M. P. et al. Barium dithionate as an EPR dosemeter. Radiation Protection Dosimetry, v. 120, n. 1-4, p. 202-204, 2006.

BARTHE, J. et al. Dose evaluation from textile fibers: a post-determination of initial ESR signal. Applied Radiation and Isotopes, v. 40, n. 10-12, p. 1029-1033, 1989.

BARTOLOTTA, A. et al. Response characterization of ammonium tartrate solid state pellets for ESR dosimetry with radiotherapeutic photon electron beams. Physics in Medicine and Biology, v. 46, p. 461-471, 2001.

BASSINET, C. et al. Characterization of ${ }^{7} \mathrm{LiF}: \mathrm{Mg}$, Ti TLD micro-cubes. Radiation Measurements, v. 47, n. 3-6, p. 646-648, 2010.

BASSINET, C.; TROMPIER, F.; CLAIRAND, I. Radiation accident dosimetry on glass by TL and EPR spectroscopy. Health Physics, n. 98, v. 2, p. 400-405, 2010.

\footnotetext{
${ }^{8}$ In accordance with the Vancouver citation style.
} 
BASSINET, C. et al. Small fields output factors measurements and correction factors determined for several detectors for a CyberKnife ${ }^{\circledR}$ and linear accelerators equipped with microMLC and circular cones. Medical Physics, v. 40, n. 7, p. 071725-13, 2013.

BERGER, M. J. et al. XCOM: photon cross sections database. NIST Standard Reference Database 8 (XGAM), 2015.

BERLINER, L. J. From spin labeled proteins to in vivo EPR applications. European Biophysics Journal, v. 39, n. 4, p. 579-588, 2010.

BOGUSHEVICH, S. E.; UGOLEV, I. I. Inorganic EPR dosimeter for medical radiology. Applied Radiation and Isotopes, v. 52, n. 5, p. 1217-1219, 2000.

BORGONOVE, A. F. et al. Energy dependence of different materials in ESR dosimetry for clinical X-ray 10 MV beam. Radiation Measurements, v. 42, n. 6-7, p. 1227-1232, 2007.

BRAVO-MIRANDA, C. et al. Measurement of rectum dose by in vivo alanine/ESR dosimetry in gynecological ${ }^{192}$ Ir HDR brachytherapy. Radiation Measurements, v. 75, p. 45$52,2015$.

CHANTRY, G. W. et al. The structure, electron resonance and optical spectra of trapped $\mathrm{CO}_{3}{ }^{-}$ and $\mathrm{NO}_{3}$. Molecular Physics, v. 5, n. 6, p. 589-599, 1962.

CHANTRY, G. W. et al. The optical and electron resonance spectra of $\mathrm{SO}_{3}{ }^{-}$. Molecular Physics, v. 5, n. 3, p. 233-239, 2006.

CHARLES, P. H. et al. A practical and theoretical definition of very small field size for radiotherapy output factor measurements. Medical Physics, v. 41, n. 4, p. 041707-1-0417078,2014

CHEN, F.; COVAS, D. T.; BAFFA, O. Dosimetry of blood irradiation using an alanine/ESR dosimeter. Applied Radiation and Isotopes, v. 55, n. 1, p. 13-16, 2001.

CHEN, F.; GRAEFF, C. F. O.; BAFFA, O. Preliminary evaluation of second harmonic direct detection scheme for low-dose range in alanine/EPR dosimetry. Physics in Medicine and Biology, v. 47, n. 8, p. 1357-1367, 2002.

CHEN, F.; GRAEFF, C. F. O.; BAFFA, O. K-band EPR dosimetry: small-field beam profile determination with miniature alanine dosimeter. Applied Radiation Isotopes, v. 62, n. 2, p. 267-271, 2005.

CHEN, F.; GRAEFF, C. F. O.; BAFFA, O. Response of L-alanine and 2-methylalanine minidosimeters for K-band (24 GHz) EPR dosimetry. Nuclear Instruments and Methods in Physics Research Section B: Beam Interactions with Materials and Atoms, v. 264, n. 2, p. 277-281, 2007.

CHEN, F. et al. Sensitivity comparison of two L-alanine doped blends to different photon energies. Health Physics, v. 98, n. 2, p. 383-387, 2010. 
CHU, S. et al. ESR/alanine dosimetry of high-energy electrons in radiotherapy. Applied Radiation and Isotopes, v. 40, n. 10-12, p. 993-996, 1989.

CIESIELSKI, B. et al. In vivo alanine/EPR dosimetry in daily clinical practice: a feasibility study. International Journal of Radiation Oncology Biology Physics, v. 56, n. 3, p. 899905, 2003.

CIESIELSKI, B. et al. EPR study of light illumination effects on radicals in gamma-irradiated L-alanine. Spectrochimica Acta Part A: Molecular and Biomolecular Spectroscopy, v. 60, n. 6, p. 1327-1333, 2004.

CLAIRAND, I. et al. EX vivo ESR measurements associated with Monte Carlo calculations for accident dosimetry: application to the 2001 Georgian accident. Radiation Protection Dosimetry, v. 119, n. 1-4, p. 500-505, 2006.

COEYTAUX, K. et al. Reported radiation overexposure accidents worldwide, 1980-2013: a systematic review. PLoS One, v. 10, n. 3, e0118709, 2015.

COFFEY, C. W. et al. A tissue equivalent phantom for stereotactic radiosurgery localization and dose verification. Stereotactic and Functional Neurosurgery, v. 61, n. 1, p. 130-141, 1993.

DANILCZUK, M. et al. Ammonium dithionate - a new material for highly sensitive EPR dosimetry. Spectrochimica Acta Part A, v. 69, n. 1, p. 18-21, 2008.

DAS, I. J.; DING, G. X.; AHNESJÖ, A. Small field: nonequilibrium radiation dosimetry. Medical Physics, v. 35, n. 1, p. 206- 215, 2007.

DAVIDSON, M. T. M.; JORDAN, K. J. Dosimetric evaluation of sucrose and granulated cane sugar in the therapeutic dose range. Medical Physics, v. 36, n. 4, p. 1340-1350, 2009.

DE ANGELIS, C. et al. Alanine/EPR dosimetry in brachytherapy. Physics in Medicine and Biology, v. 44, n. 5, p. 1181-1191, 1999.

DE ANGELIS, C. et al. Electron arc therapy treatment planning verification with alanine/EPR dosimetry. Applied Radiation and Isotopes, v. 52, n. 5, p. 1203-1207, 2000.

DESROSIERS, M. F.; PUHL, J. M.; MCLAUGHLIN, W. L. A new EPR dosimeter based on polyvinylalcohol. Applied Radiation and Isotopes, v. 44, n. 1-2, p. 325-326, 1993.

DIMITRIADIS, A. et al. Adaptation and validation of a commercial head phantom for cranial radiosurgery dosimetry end-to-end audit. The British Journal of Radiology, v. 90, n. 1074, p. 20170053, 2017.

DISTEFANO, G. et al. A national dosimetry audit for stereotactic ablative radiotherapy in lung. Radiotherapy and Oncology, v. 122, n. 3, p. 406-410, 2017.

DRZYMAL, R. E. et al. Assurance of high quality linac-based stereotactic radiosurgery. International Journal of Radiation Oncology Biology Physics, v. 30, n. 2, p. 459-472, 1994. 
DUGGAN, D. M.; COFFEY II, C. W. Small photon field dosimetry for stereotactic radiosurgery. Medical Dosimetry, v. 23, n. 3, p. 153-159, 1998.

EATON, G. R. et al. Quantitative EPR. Springer, 2010.

FATTIBENE, P. et al. The $4^{\text {th }}$ international comparison on EPR dosimetry with tooth enamel part 1: report on the results. Radiation Measurements, v. 46, n. 9, p. 765-771, 2011.

FEHER, G. Sensitivity considerations in microwave paramagnetic resonance absorption techniques. The Bell System Technical Journal, v.36, n. 2, p. 449-484, 1957.

GALL, K. et al. Alanine EPR dosimeter response in proton therapy beams. Applied Radiation and Isotopes, v. 47, n. 11-12, p. 1197-1199, 1996.

GANCHEVA, V.; SAGSTUEN, E.; YORDANOV, N. D. Study on the EPR/dosimetric properties of some substituted alanines. Radiation Physics and Chemistry, v. 75, n. 2, p. 329-335, 2006.

GARCIA, T. et al. Dose verification and calibration of the Cyberknife ${ }^{\circledR}$ by EPR/alanine dosimetry. Radiation Measurements, v. 46, n. 9, p. 952-957, 2011.

GUILARTE, V.; TROMPIER, F.; DUVAL, M. Evaluating the potential of Q-band ESR spectroscopy for dose reconstruction of fossil tooth enamel. PLoS ONE, v. 11, n. 3, p. 1-14, 2016.

GUSTAFSSON, H. et al. Ammonium formate, a compound for sensitive EPR dosimetry. Radiation Research, v. 161, n. 4, p. 464-470, 2004.

GUSTAFSSON, H.; LUND, E.; OLSSON, S. Lithium formate EPR dosimetry for verifications of planned dose distribution prior to intensity-modulated radiation therapy. Physics in Medicine and Biology, v. 53, n. 17, p. 4667- 4682, 2008.

GUSTAFSSON, H.; LUND, A.; LUND, E. Potassium dithionate EPR dosimetry for determination of absorbed dose and LET distributions in different radiation qualities. Radiation Measurements, v. 46, n. 9, p. 936-940, 2011.

GUSTAFSSON, H. et al. $\mathrm{SO}_{3}{ }^{-}$radicals for EPR dosimetry: X- and Q band EPR study and LET dependency of crystalline potassium dithionate. Radiation Measurements, v. 59, p. 123-128, 2013.

HASKELL, E. H.; HAYES, R. B., KENNER, G. H. A high sensitivity EPR technique for alanine dosimetry. Radiation Protection Dosimetry, v. 77, n. 1-2, p. 43-49, 1998.

HASSAN, G. M.; IKEYA, M.; TOYODA, S. Lithium lactate as an ESR dosimeter. Applied Radiation and Isotopes, v. 49, n. 7, p. 823-828, 1998.

HASSAN, G. M.; SHARAF, M. A. ESR dosimetric properties of some biomineral materials. Applied Radiation and Isotopes, v. 62, n. 2, p. 375-381, 2005. 
HASSAN, G. M.; ULUSOY, U.; IKEYA, M. Radical formation in lithium and magnesium oxalate. Japanese Journal of Applied Physics, v. 39, n. 11, p. 6236-6242, 2000.

HERRERA, E.; UREÑA-NÚÑEZ, F.; LOYA, A. D.; Lithium carbonate $\left(\mathrm{Li}_{2} \mathrm{CO}_{3}\right)$ as a material for thermal neutron fluence measurements. Applied Radiation and Isotopes, v. 63, n. 2, p. 241-246, 2005.

HUET, C. et al. Characterization and optimization of EBT2 radiochromic films dosimetry system for precise measurements of output factors in small fields used in radiotherapy. Radiation Measurements, v. 47, n. 1, p. 40-49, 2012.

IKEYA, M.; MIYAJIMA, J.; OKAJIMA, S. ESR dosimetry for atomic bomb survivors using Shell buttons and tooth enamel. Japanese Journal of Applied Physics, v. 23, n. 2, p. L697L699, 1984.

IKEYA, M.; ISHII, H. Atomic bomb and accident dosimetry with ESR: natural rocks and human tooth in-vivo spectrometer. Applied Radiation and Isotopes, v. 40, n.10-12, p. 10211027, 1989.

IKEYA, M. New applications of electron spin resonance: dating, dosimetry and microscopy. World Scientific, 1993.

IKEYA, M. ESR (EPR) dating based on natural radiation effects. The International Journal of Radiation Applications and Instrumentation. Part E. Nuclear Geophysics, v. 8, n. 3, p. 201-224, 1994.

INTERNATIONAL ATOMIC ENERGY AGENCY. Absorbed dose determination in external beam radiotherapy: an international code of practice for dosimetry based on standards of absorbed dose to water. Vienna, Austria: 2001.

IRSN; CEA. Tristan Garcia; François Trompier. Radiation dosimeter and dose measurement method by EPR spectroscopy. WO/2015/004176, 15 Jan. 2015.

ISRAELSSON, A.; GUSTAFSSON, H.; LUND, E. Dose response of xylitol and sorbitol for EPR retrospective dosimetry with applications to chewing gum. Radiation Protection Dosimetry, v. 154, n. 2, p. 133-141, 2013.

JOHNS, H. E.; CUNNINGHAM, J. R. The physics of radiology: fourth edition. Toronto: Charles C. Thomas, 1983.

JONAS, M. Concepts and methods for ESR dating. Radiation Measurements, v. 27, n. 5/6, p. 943-973, 1997.

KAI, A.; IKEYA, M.; MIKI, T. ESR accident dosimetry using medicine tablets coated with sugar. Radiation Protection Dosimetry, v. 34, n. 1-4, p. 307-310, 1990.

KHAN, F. M. The Physics of radiation therapy. Minneapolis: Lippincott Williams \& Wilkins, 2003. 
KINOSHITA, A.; JOSÉ, F. A.; BAFFA, O. An attempt to use sweeteners as a material for accident dosimetry. Health Physics, v. 98, n. 2, p. 406-411, 2010.

KOJIMA, T. et al. Alanine dosimeters using polymers as binders. Applied Radiation and Isotopes, v. 37, n. 6, p. 517-520, 1985.

KUNTZ, F. et al. Alanine-ESR in vivo dosimetry: a feasibility study and possible applications. Applied Radiation and Isotopes, v. 47, n. 11-12, p. 1183-1188, 1996.

LAU, S. K. M. et al. Frameless single-isocenter intensity modulated stereotactic radiosurgery for simultaneous treatment of multiple intracranial metastases. Translational Cancer Research, v. 3, n. 4, p. 383-390, 2014.

LELIE, S. et al. The investigation of lithium formate hydrate, sodium dithionate and Nmethyl taurine as a clinical EPR dosimeters. Radiation Measurements, v. 59, p. 218-224, 2013.

LELIEVELD, J.; KUNKEL, D.; LAWRENCE, M. G. Global risk of radioactive fallout after major nuclear accidents. Atmospheric Chemistry and Physics, v. 12, n. 9, p. 4245-4258, 2012.

LUND, A. et al. New materials for ESR dosimetry. Spectrochimica Acta A, v. 58, n. 6, p. 1301-1311, 2002.

LUND, E. et al. Formates and dithionates: sensitive EPR-dosimeter materials for radiation therapy. Applied Radiation Isotopes, v.62, n. 2, p. 317-324, 2005.

MA, Y. R. et al. Morphosynthesis of alanine mesocrystals by $\mathrm{pH}$ control. Journal of Physical Chemistry B, v. 110, n. 22, p. 10822-10828, 2006.

MALINEN, E. et al. Alanine radicals, part 4: relative amounts of radical species in alanine dosimeters after exposure to 6-19 MeV electrons and $10 \mathrm{kV}-10 \mathrm{MV}$ photons. Radiation Research, v. 159, n. 2, p. 149-153, 2003.

MALINEN, E. et al. The energy dependence of lithium formate EPR dosimeters for clinical electron beams. Physics in Medicine and Biology, v. 52, n. 14, p. 4361-4369, 2007.

MARRALE, M. et al. Power Saturation of ESR Signal in Ammonium Tartrate Exposed to ${ }^{60} \mathrm{Co} \gamma$-Ray Photons, Electrons and Protons. Radiation Research, v. 166, p. 802-809, 2006.

MEHTA, K.; GIRZIKOWSKY, R. Alanine-ESR dosimetry for radiotherapy IAEA experience. Applied Radiation and Isotopes, v. 47, n. 11, p. 1189-1191, 1996.

MERVE, D. et al. Accuracy requirements and uncertainties in radiotherapy: a report of the International Atomic Energy Agency. Acta Oncologica, v. 56, n. 1, p. 1-6, 2017.

MIYAGUSKU, L. et al. Irradiation dose control of chicken meat processing with alanine/ESR dosimetric system. Radiation Measurements, v. 42, n. 6-7, p. 1222-1226, 2007. 
MURALI, S. et al. ESR dosimetry using inorganic materials: a case study of $\mathrm{Li}_{2} \mathrm{CO}_{3}$ and $\mathrm{CaSO}_{4}$ :Dy as a prospective dosimeters. Applied Radiation and Isotopes, v. 55, n. 2, p. 253$258,2001$.

MURTHY, G. S.; EAGER, R. L.; MCCALLUM, K. J. Radiation chemistry of dithionates. Canadian Journal of Chemistry, v. 49, n. 22, p. 3733-3738, 1971.

MURTY, R. C. Effective atomic numbers of heterogeneous materials. Nature, v. 207, p. 398399, 1965.

NAGY, V. et al. Advancements in accuracy of the alanine EPR dosimetry system Part III: Usefulness of an adjacent reference sample. Radiation Physics and Chemistry, v. 59, n. 4, p. 429-441, 2000.

NAKAJIMA, T. Sugar as an emergency populace dosimeter for radiation accidents. Health Physics, v. 55, n. 6, p. 951-955, 1988.

NAKAJIMA, T. Possibility of retrospective dosimetry for persons accidentally exposed to ionizing radiation using electron spin resonance of sugar and mother-of-pearl. The British Journal of Radiology, v. 62, n. 734, p. 148-153, 1989.

NAKAJIMA, T.; OTSUKI, T. Dosimetry for radiation emergencies: radiation-induced free radicals in sugar of various countries and the effect of pulverizing on the ESR signal. Applied Radiation and Isotopes, v. 41, n. 4, p. 359-365, 1990.

NEGRON-MENDOZA, A. et al. Calcium carbonate as a possible dosimeter for high irradiation doses. Applied Radiation and Isotopes, v. 100, p. 55-59, 2015.

NICHIPOROV, D. et al. Investigation of applicability of alanine and radiochromic detectors to dosimetry of proton clinical beams. Applied Radiation and Isotopes, v. 46, n. 12, p. 1355$1362,1995$.

NIEDERBERGER, M.; COLFEN, H. Oriented attachment and mesocrystals: non-classical crystallization mechanisms based on nanoparticle assembly. Physical Chemistry Chemical Physics, v. 8, p. 3271-3287, 2006.

NOR, N. M. et al. EPR dosimeter material properties of potassium tartrate hemihydrate. Radiation Measurements, v. 87, p. 8-12, 2016.

OLSSON, S. K. et al. Ammonium tartrate as an ESR dosimeter material. Applied Radiation and Isotopes, v. 50, n. 5, p. 955-965, 1999.

OLSSON, S.K.; LUND, E.; LUND, A. Development of ammonium tartrate as an ESR dosimeter material for clinical purposes. Applied Radiation and Isotopes, v. 52, n. 5, p. 1235-1241, 2000.

OVENALL, D. W.; WHIFFEN, D. H. Electron spin resonance and structure of the $\mathrm{CO}_{2}{ }^{-}$ radical ion. Molecular Physics, v. 4, n. 2, p. 135-144, 1961. 
PANTA, P. P.; STRZELCZAK-BURLINSKA, G.; TOMASINSKI, Z. ESR/L-alanine system as a proposed standard dosimeter for electron-beam irradiations. Applied Radiation and Isotopes, v. 40, n. 10-12, p. 971-975.

PAVONI, J. F. et al. Evaluation of a composite gel-alanine phantom on an end-to-end test to treat multiple brain metastases by a single isocenter VMAT technique. Medical Physics, 2017.

POPOCA, R.; UREÑA-NÚÑEZ, F. Dosimetric evaluation of lithium carbonate $\left(\mathrm{Li}_{2} \mathrm{CO}_{3}\right)$ as a dosemeter for gamma-radiation dose measurements. Radiation Protection Dosimetry, v. 134, n. 2, p. 102-106, 2009.

RECH, A. B. et al. In vivo dose evaluation during gynaecological radiotherapy using Lalanine/ESR dosimetry. Radiation Protection Dosimetry, v. 159, n. 1-4, p. 194-198, 2014.

REGULLA, D. From dating to biophysics - 20 years of progress in applied ESR spectroscopy. Applied Radiation and Isotopes, v. 52, n. 5, p. 1023-1030, 2000.

REGULLA, D. F.; DEFFNER, U. Dosimetry of ESR spectroscopy of alanine. International Journal of Applied Radiation and Isotopes, v. 33, p. 1101-1114, 1982.

ROMANYUKHA, A. et al. South Ural nuclear workers: Comparison of individual doses from retrospective EPR dosimetry and operational personal monitoring. Applied Radiation and Isotopes, v. 45, n. 12, p. 1195-1199, 1994.

ROMANYUKHA, A. et al. Verification of occupational doses at the first nuclear plant in the former Soviet Union. Applied Radiation and Isotopes, v. 47, n. 11/12, p. 1277-1280, 1996.

ROMANYUKHA, A. et al. EPR measurements of fingernails in Q-band. Radiation Measurements, v. 46, n. 9, p. 888-892, 2011.

ROSSI, A. M. et al. Electron spin resonance dosimetry of teeth of Goiânia radiation accident victims. Applied Radiation and Isotopes, v. 52, n. 5, p. 1297-1303, 2000.

ROSSI, B. T.; CHEN, F.; BAFFA, O. A new 2 methylalanine-PVC ESR dosimeter. Applied Radiation and Isotopes, v. 62, n. 2, p. 287-291, 2005.

RUSHDI, M. A. H. et al. Strontium sulfate as an EPR dosimeter for radiation technology application. Radiation Physics and Chemistry, v. 106, p. 130-135, 2015.

SCHAEKEN, B. et al. Alanine/EPR dosimetry applied to the verification of a total body irradiation protocol and treatment planning dose calculation using a humanoid phantom. Medical Physics, v. 37, n. 12, p. 6292-6299, 2010.

SCHAUER, D. A. et al. Radiation dosimetry of an accidental overexposure using EPR spectrometry and imaging of human bone. Applied Radiation and Isotopes, v. 47, n. 11-12, p. 1345-1350, 2001.

SCHAUER, D. A. et al. Electron paramagnetic resonance (EPR) in medical dosimetry. Radiation Measurements, v. 41, n. 1, p. S117-S123, 2006. 
SCHULTKA, K. et al. EPR/alanine dosimetry in LDR brachytherapy - a feasibility study. Radiation Protection Dosimetry, v. 120, n. 1-4, p. 171-175, 2006.

SCHWAHN, D. et al. Mesocrystal to single crystal transformation of D,L-alanine evidence by small angle neutron scattering. Journal of Physical Chemistry C, v. 111, p. 3224-3227, 2007.

SEREZHENKO, V. A. et al. Radiation dosimetry for residents of the Chernobyl region: a comparison of cytogenetic and electron spin resonance methods. Radiation Protection Dosimetry, v. 42, n. 1, p. 33-36, 1992.

SHARAF, M. A.; HASSAN, G. M. Radiation induced radical in barium sulphate for ESR dosimetry: a preliminary study. Nuclear Instruments and Methods in Physics Research B, v. 225, n. 4, p. 521-527, 2004.

SHIVARAMU; RAMPRASATH, V. Effective atomic numbers for photon absorption and energy dependence of some thermoluminescent dosimetric compounds. Nuclear Instruments and Methods in Physics Research B, v. 168, n. 3, pp. 294-304, 2000.

SHOLOM, S.; MCKEEVER, S. W. S. Emergency EPR and OSL dosimetry with table vitamins and minerals. Radiation Protection Dosimetry, v. 172, n. 1-3, p. 139-144, 2016.

SHUKLA, A. K. (Ed.). Electron spin resonance in food science. $1^{\text {st }}$ ed. Academic Press, 2016. $156 \mathrm{p}$.

SOLIMAN, Y. S.; ABDEL-FATTAH, A. A. Magnesium lactate mixed EVA polymer/paraffin as an EPR dosimeter for radiation processing application. Radiation Physics and Chemistry, v. 81, n. 12, p. 1910-1916, 2012.

SWARTZ, H. M. et al. Clinical applications of EPR: overview and perspectives. NMR in Biomedicine, v. 15, n. 5, p. 335-351, 2004.

TANDERUP, K. et al. In vivo dosimetry in brachytherapy. Medical Physics, v. 40, n. 7, p. 070902-1-070902-15, 2013.

TEOH, M. et al. Volumetric modulated arc therapy: a review of current literature and clinical use in practice. The British Journal of Radiology, v. 84, n. 1007, p. 967-996, 2011.

TRIVEDI, A.; GREENSTOCK, C. L. Use of sugars and hair for ESR emergency dosimetry. Applied Radiation and Isotopes, v. 44, n. 1-2, p. 85-90, 1993.

TROMPIER, F. et al. Electron paramagnetic resonance radiation dosimetry in fingernails. Radiation Measurements, v. 44, n. 1, p. 6-10, 2009.

TROMPIER, F.; BASSINET, C.; CLAIRAND, I. Radiation accident dosimetry on plastics by EPR spectrometry. Health Physics, v. 98, n. 2, p. 388-394, 2010. 
TUNER, H.; KORKMAZ, M. Effects of gamma radiation on solid trisodium citrate dehydrate: radical kinetics, radiosensitivity and dosimetry. Radiation and Environmental Biophysics, v. 49, n. 4, p. 723-729, 2010.

UREÑA-NÚÑEZ, F.; BALLESTEROS, M. R. D. Dosimetric evaluation of sodium carbonate $\left(\mathrm{Na}_{2} \mathrm{CO}_{3}\right)$ by electronic paramagnetic resonance. Radiation Effects and Defects in Solids, v. 164, n. 4, p. 240-243, 2009.

VAN ESCH, A. et al. Implementing stereotactic rapidarc treatments into clinical routine from algorithm configuration to treatment validation. Medical Physics International, v. 5, n. 1, p. 95-118, 2017.

VEGA-RAMIREZ, J. L. et al. Dosimetry of small radiation field in inhomogeneous medium using alanine/EPR minidosimeters and PENELOPE Monte Carlo simulation. Radiation Measurements, v. 46, n. 9, p. 941-944, 2011.

VESTAD, T. A. et al. EPR dosimetric properties of formates. Applied Radiation and Isotopes, v. 59, n. 2-3, p. 181-188, 2003.

VESTAD, T. A. et al. Electron paramagnetic resonance (EPR) dosimetry using lithium formate in radiotherapy: comparison with thermoluminescence (TL) dosimetry using lithium fluoride rods. Physics in Medicine and Biology, v. 49, n. 20, p. 4701-4715, 2004a.

VESTAD, T. A. et al. Radiation-induced radicals in lithium formate monohydrate $\left(\mathrm{LiHCO}_{2} \cdot \mathrm{H}_{2} \mathrm{O}\right)$. EPR and ENDOR studies of X-irradiated crystal and polycrystalline samples. Physical Chemistry Chemical Physics, v. 6, n. 11, p. 3017-3022, 2004b.

WAGNER, D. et al. In vivo alanine/electron spin resonance (ESR) dosimetry in radiotherapy of prostate cancer: a feasibility study. Radiotherapy and Oncology, v. 88, n. 1, p. 140-147, 2008.

WAGNER, D.; ANTON, M.; VORWERK, H. Dose uncertainty in radiotherapy of patients with head and neck measured by in vivo ESR/alanine dosimetry using a mouthpiece. Physics in Medicine and Biology, v. 56, n. 5, p. 1373-1383, 2011.

WAGNER, D.; HERMANN, M; HILLE, A. In vivo dosimetry with alanine/electron spin resonance dosimetry to evaluate the urethra dose during high-dose-rate brachytherapy. Brachytherapy, 2017.

WAGNER, D. M. et al. Feasibility study of entrance and exit dose measurements at the contra lateral breast with alanine/electron spin resonance dosimetry in volumetric modulated radiotherapy of breast cancer. Physics in Medicine and Biology, v. 62, n. 13, p. 5642-5472, 2017.

WALDELAND, E. et al. Dosimetry of stereotactic radiosurgery using lithium formate EPR dosimeters. Physics in Medicine and Biology, v. 55, n. 8, p. 2307-2316, 2010a.

WALDELAND, E. et al. The energy dependence of lithium formate and alanine EPR dosimeters for medium energy x rays. The American Association of Physics in Medicine, v. 37, n. 7, p. 3569-3575, 2010 b. 
WALDELAND, E.; HELT-HANSE, J.; MALINEN, E. Characterization of lithium formate EPR dosimeters for high dose application - Comparison with alanine. Radiation Measurements, v. 46, n. 2, p. 213-218, 2011.

WEIL, J. A.; BOLTON, J. R.; WERTZ, J. E. Electron paramagnetic resonance: elementary theory and practical applications. New York: John Wiley \& Sons, 1994.

WERTZ, J. E.; BOLTON, J. R. Electron spin resonance: elementary theory and practical applications. New York: McGrawHill Company, 1972.

World Health Organization. WHO Model List of Essential Medicine $19^{\text {th }}$ List. Geneva, 2015 [quoted in 9 mar. 2017]. Available in: http://www.who.int/medicines/publications/essentialmedicines/en/.

WIESER, A. et al. The influence of non-radiation induced ESR background signal from paraffin-alanine probes for dosimetry in the radiotherapy dose range. Applied Radiation and Isotopes, v. 44, n. 1-2, p. 59-65, 1993.

WIESER, A. et al. Assessment of performance parameters for EPR dosimetry with tooth enamel. Radiation Measurements, v. 43, n. 2-6, p. 731-736, 2008.

WUERFEL, J. U. Dose measurements in small fields. Medical Physics International Journal, v. 1, n. 1, p. 81-90, 2013.

YUHAI, D.; CHANGQING, Z.; XIAOSHENG, W. Influence of lithium sulfate addition on the properties of Portland cement paste. Construction and Building Materials, v. 50, p. 457$462,2014$.

YURUS, S.; OZBEY, T.; KORKMAZ, M. ESR investigation of gamma irradiated sulbactam sodium. Journal of Pharmaceutical and Biomedical Analysis, v. 35, n. 5, p. 971-978, 2004. 